\title{
Sample Tasks from the PISA 2000 Assessment
}

READING, MATHEMATICAL AND SCIENTIFIC LITERACY
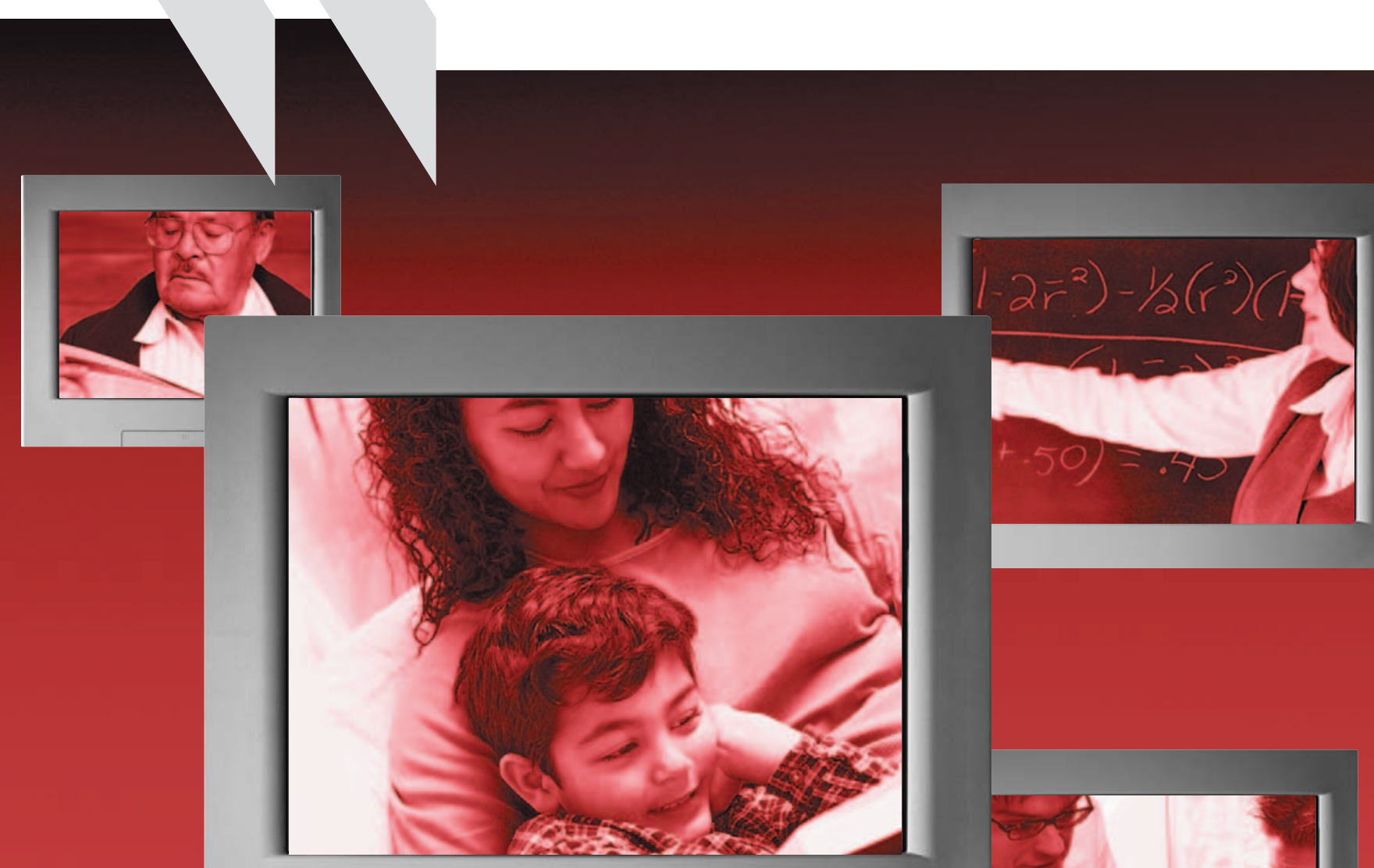

\section{OECD}

Programme for International Student Assessment 


\section{PROGRAMME FOR INTERNATIONAL STUDENT ASSESSMENT}

Sample tasks from the PISA 2000 assessment of reading, mathematical and scientific literacy 


\section{ORGANISATION FOR ECONOMIC CO-OPERATION AND DEVELOPMENT}

Pursuant to Article 1 of the Convention signed in Paris on $14^{\text {th }}$ December 1960, and which came into force on $30^{\text {th }}$ September 1961, the Organisation for Economic Co-operation and Development (OECD) shall promote policies designed:

- to achieve the highest sustainable economic growth and employment and a rising standard of living in Member countries, while maintaining financial stability, and thus to contribute to the development of the world economy;

- to contribute to sound economic expansion in Member as well as non-member countries in the process of economic development; and

- to contribute to the expansion of world trade on a multilateral, non-discriminatory basis in accordance with international obligations.

The original Member countries of the OECD are Austria, Belgium, Canada, Denmark, France, Germany, Greece, Iceland, Ireland, Italy, Luxembourg, the Netherlands, Norway, Portugal, Spain, Sweden, Switzerland, Turkey, the United Kingdom and the United States. The following countries became Members subsequently through accession at the dates indicated hereafter: Japan (28 ${ }^{\text {th }}$ April 1964), Finland (28 $\left.{ }^{\text {th }} J a n u a r y ~ 1969\right)$, Australia ( $7^{\text {th }}$ June 1971), New Zealand $\left(29^{\text {th }}\right.$ May 1973), Mexico (18 ${ }^{\text {th }}$ May 1994), the Czech Republic (21 $1^{\text {st }}$ December 1995), Hungary $7^{\text {th }}$ May 1996), Poland $\left(22^{\text {nd }}\right.$ November 1996), Korea ( $12^{\text {th }}$ December 1996) and the Slovak Republic (14 ${ }^{\text {th }}$ December 2000). The Commission of the European Communities takes part in the work of the OECD (Article 13 of the OECD Convention).

(C) OECD 2002

The Organisation for Economic Co-operation and Development (OECD) wishes to enhance public access to information about its activities and encourages and appreciates the dissemination of its works. Permission to reproduce or translate all or parts of material from Programme for International Student Assessment: Sample tasks from the PISA 2000 assessment of reading, mathematical and scientific literacy is granted free of charge provided the source is duly mentioned as follows: "(C) OECD (2002). Reproduced by permission of the OECD." 


\section{FOREWORD}

Are students well prepared to meet the challenges of the future? Are they able to analyse, reason and communicate their ideas effectively? Do they have the capacity to continue learning throughout life? Parents, students, the public and those who run education systems need to know the answers to these questions.

Many education systems monitor student learning in order to provide some answers to these questions. Comparative international analyses can extend and enrich the national picture by providing a larger context within which to interpret national results. They can show countries their areas of relative strength and weakness and help them to monitor progress and raise aspirations. They can also provide directions for national policy, for schools' curriculum and instructional efforts and for students' learning. Coupled with appropriate incentives, they can motivate students to learn better, teachers to teach better, and schools to be more effective.

In response to the need for internationally comparable evidence on student performance, the OECD launched the Programme for International Student Assessment (PISA). PISA represents a new commitment by the governments of OECD countries to monitor the outcomes of education systems in terms of student achievement on a regular basis and within a common framework that is internationally agreed upon. PISA aims at providing a new basis for policy dialogue and for collaboration in defining and operationalising educational goals - in innovative ways that reflect judgements about the skills that are relevant to adult life. It provides inputs for standard-setting and evaluation; insights into the factors that contribute to the development of competencies and into how these factors operate in different countries, and it should lead to a better understanding of the causes and consequences of observed skill shortages. By supporting a shift in policy focus from educational inputs to learning outcomes, PISA can assist countries in seeking to bring about improvements in schooling and better preparation for young people as they enter an adult life of rapid change and deepening global interdependence.

PISA is a collaborative effort, bringing together scientific expertise from the participating countries, steered jointly by their governments on the basis of shared, policy-driven interests. Participating countries take responsibility for the project at the policy level through a Board of Participating Countries. Experts from participating countries serve on working groups that are charged with linking the PISA policy objectives with the best available substantive and technical expertise in the field of international comparative assessment of educational outcomes. Through participating in these expert groups, countries ensure that the PISA assessment instruments are internationally valid and take into account the cultural and curricular contexts of OECD Member countries, that they provide a realistic basis for measurement, and that they place an emphasis on authenticity and educational validity. The frameworks and assessment instruments for PISA 2000 are the product of a multi-year development process and were adopted by OECD Member countries in December 1999.

First results from the PISA 2000 assessment were published in Knowledge and Skills for Life - First Results from PISA 2000. This publication presents evidence on the performance in reading, mathematical and scientific literacy of students, schools and countries, provides insights into the factors that influence the development of these skills at home and at school, and examines how these factors interact and what the implications are for policy development. 
The publication Sample Tasks from the PISA 2000 Assessment of Reading, Mathematical and Scientific Literacy describes the instruments underlying the PISA assessment. It introduces the PISA approach to assessing reading, mathematical and scientific literacy with its three dimensions of processes, content and context. Further, it presents tasks from the PISA 2000 assessment together with how these tasks were scored and how they relate to the conceptual framework underlying PISA.

This report is a product of a collaborative effort between the countries participating in PISA, the experts and the institutions working within the framework of the PISA Consortium, and the OECD. This report was prepared by the OECD Directorate for Education, Employment, Labour and Social Affairs, principally by Claudia Tamassia and Andreas Schleicher in co-operation with Irwin Kirsch as the chair of the Reading Expert Group, and Steven Bakker, Joy McQueen, Jan Lokan, Juliette Mendelovits, Ross Turner and Margaret $\mathrm{Wu}$ as members of the test development team.

The report is published on the responsibility of the Secretary-General of the OECD. 


\section{TABLE OF CONTENTS}

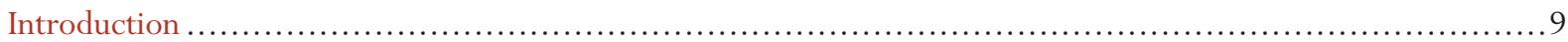

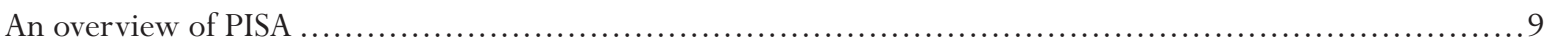

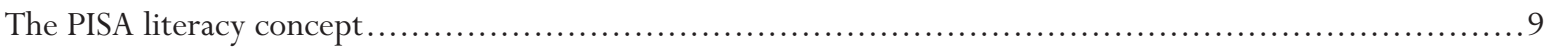

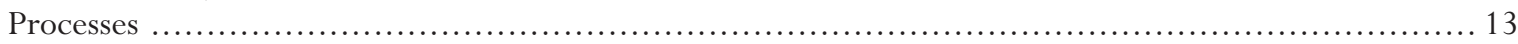

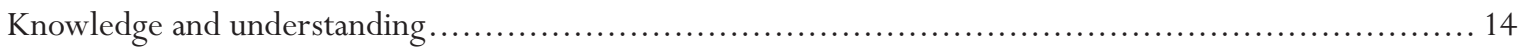

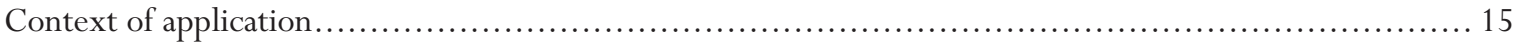

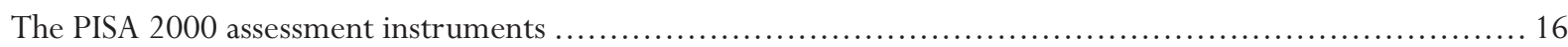

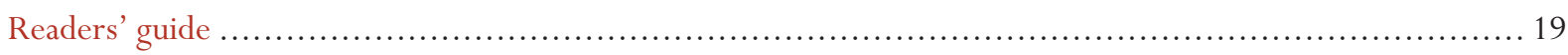

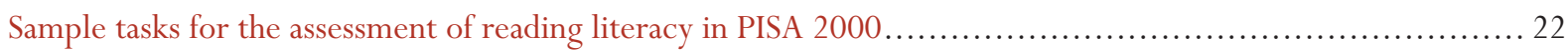

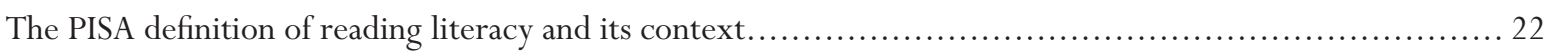

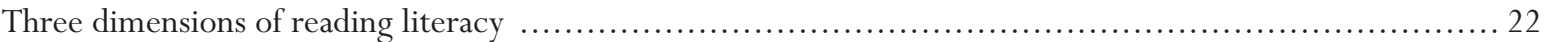

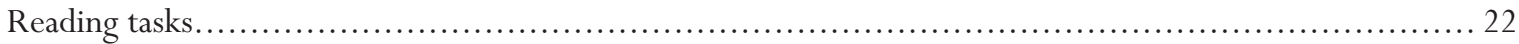

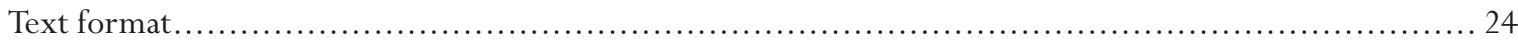

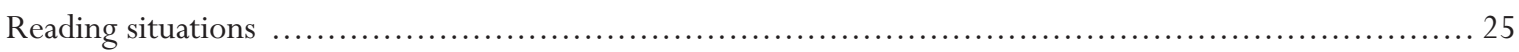

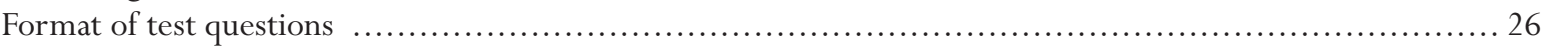

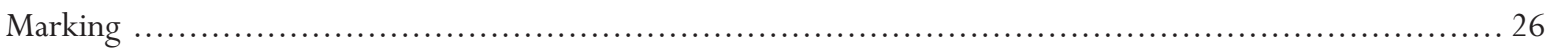

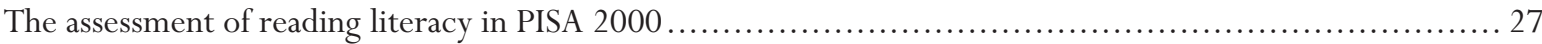

Reading units

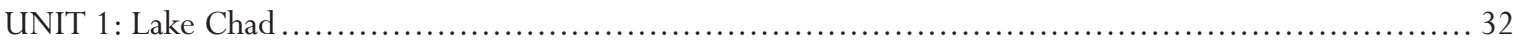

Question 1: LAKE CHAD (R040Q02) …......................................................... 33

Question 2: LAKE CHAD (R040Q03A) ........................................................... 33

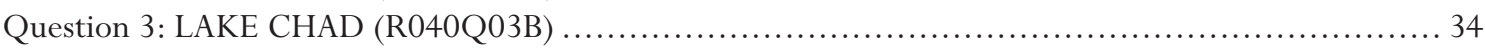

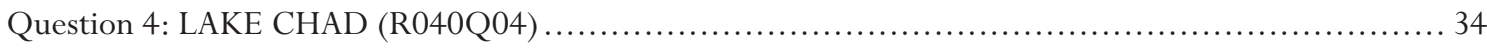

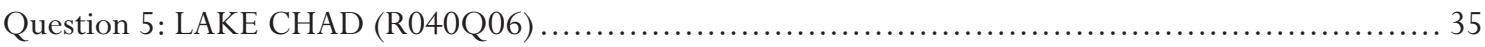

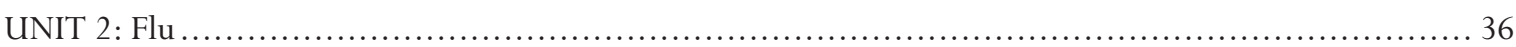

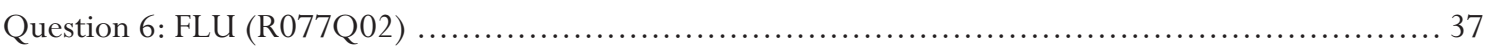

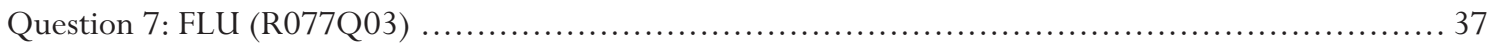

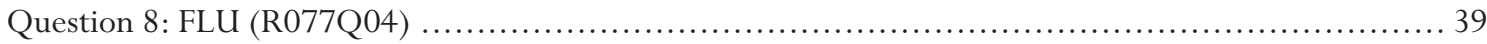

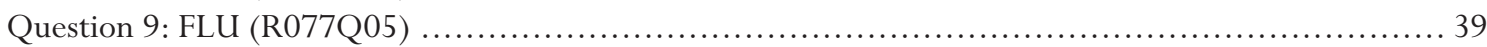

Question 10: FLU (R077Q06) ........................................................... 41

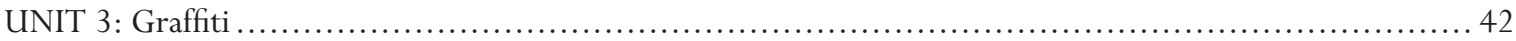

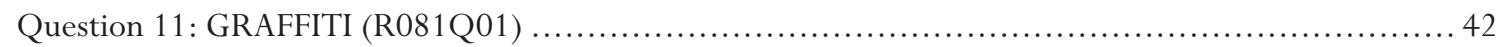

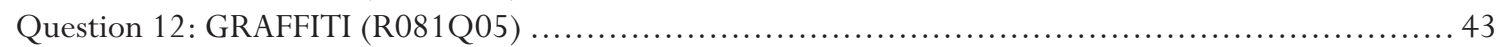

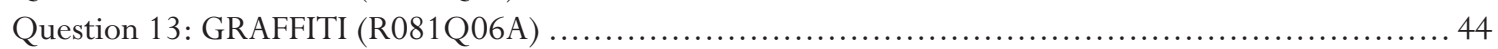

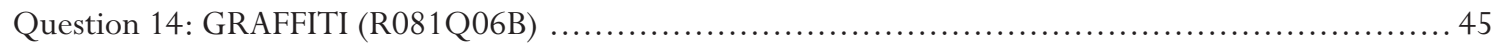

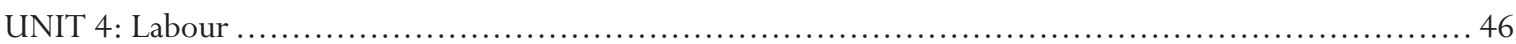

Question 15: LABOUR (R088Q01) .......................................................... 47

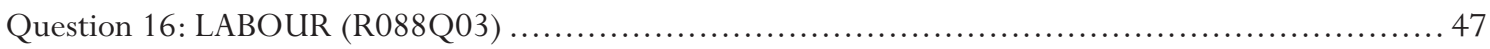

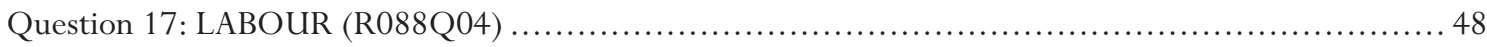

Question 18: LABOUR (R088Q05) ............................................................... 49

Question 19: LABOUR (R088Q07) .............................................................. 49 


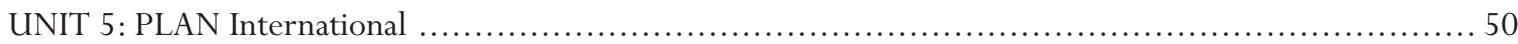

Question 20: PLAN INTERNATIONAL (R099Q04A) .......................................... 51

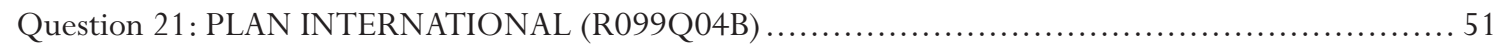

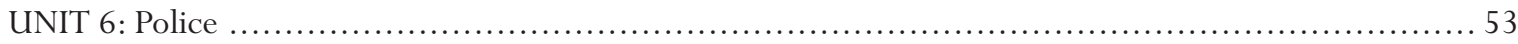

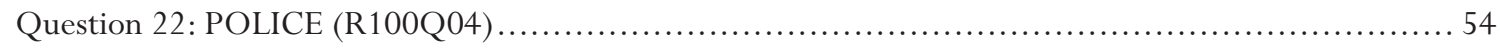

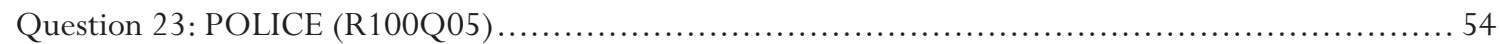

Question 24: POLICE (R100Q06) ............................................................. 54

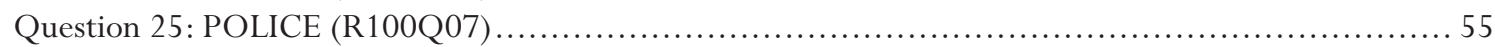

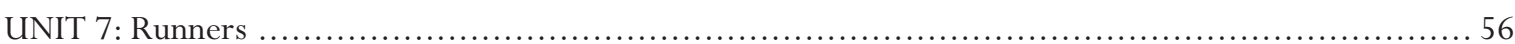

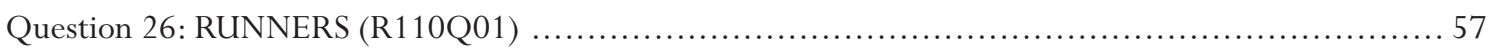

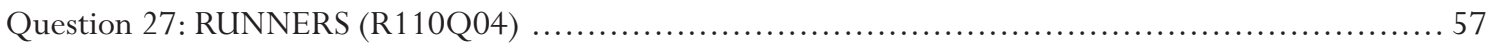

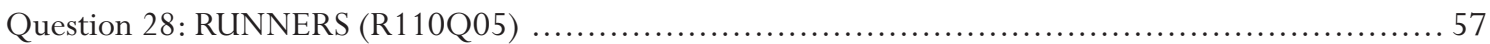

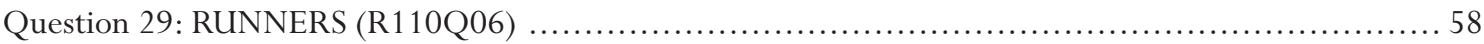

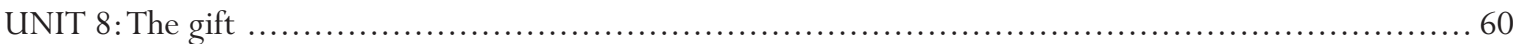

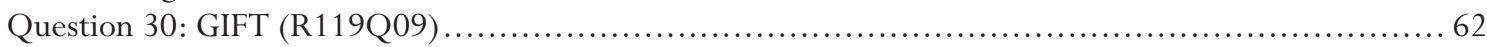

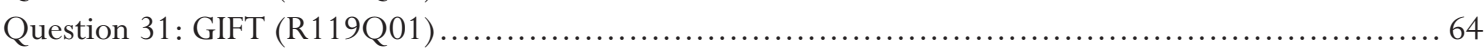

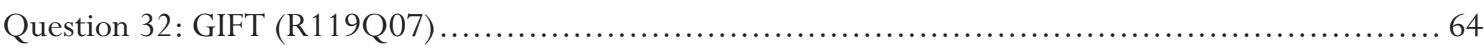

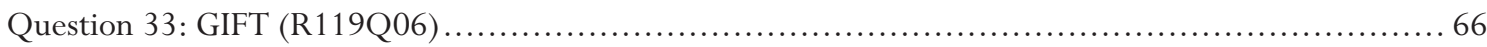

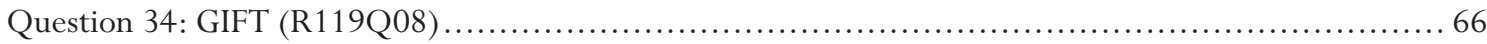

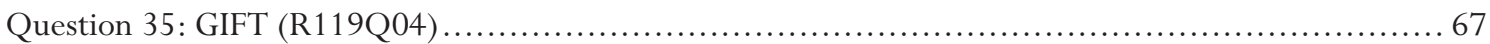

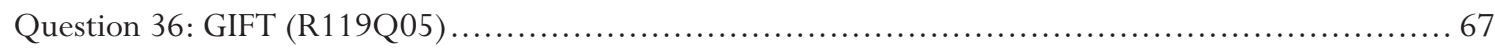

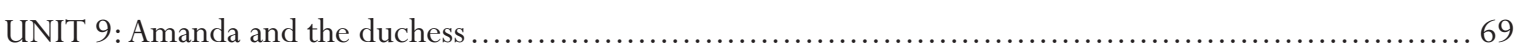

Question 37: AMANDA AND THE DUCHESS (R216Q01) ..................................... 71

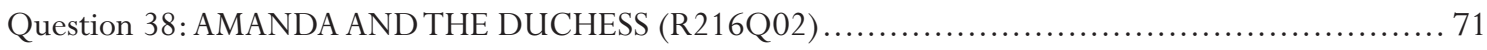

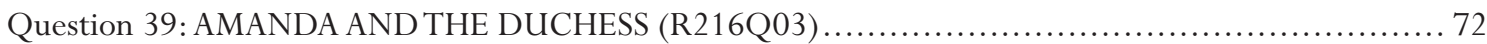

Question 40: AMANDA AND THE DUCHESS (R216Q04) ....................................... 73

Question 41: AMANDA AND THE DUCHESS (R216Q06) ......................................... 74

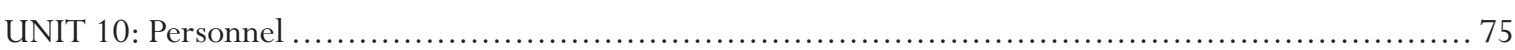

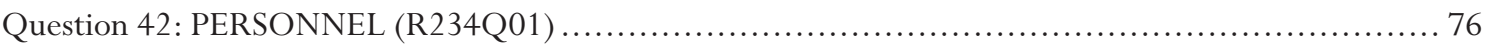

Question 43: PERSONNEL (R234Q02) ......................................................... 76

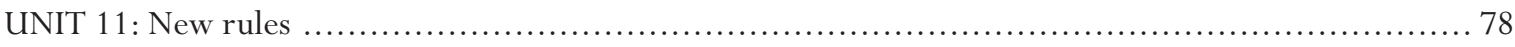

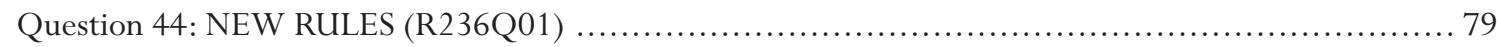

Question 45: NEW RULES (R236Q02) .......................................................... 79

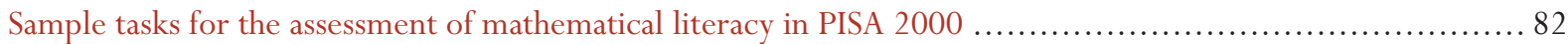

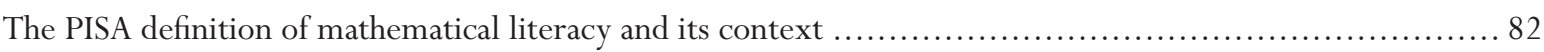

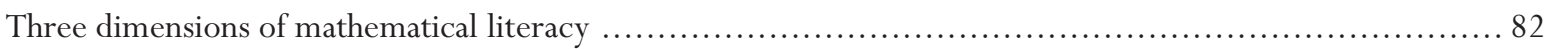

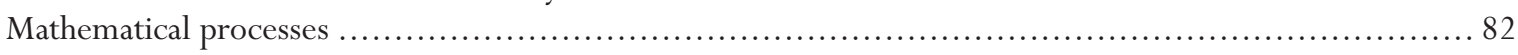

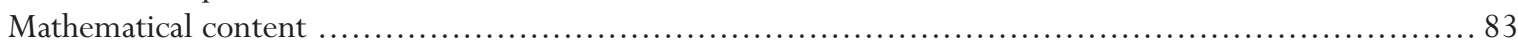

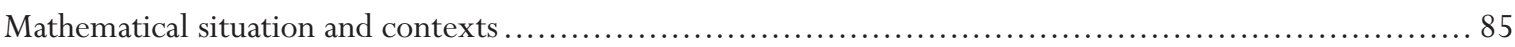

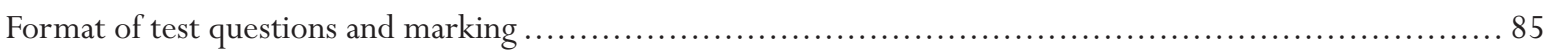

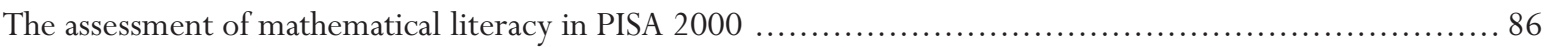


Mathematics units

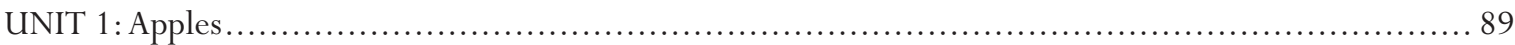

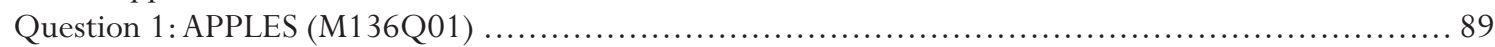

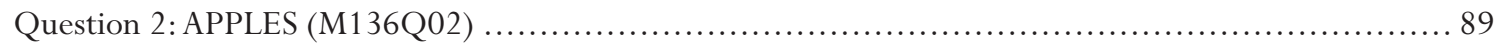

Question 3: APPLES (M136Q03) ....................................................... 90

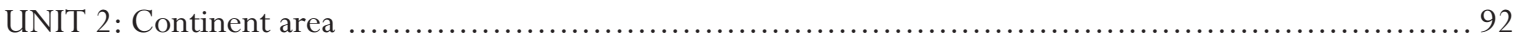

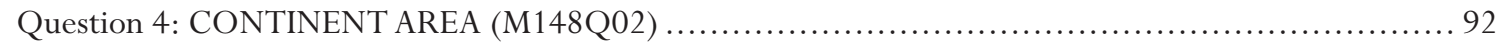

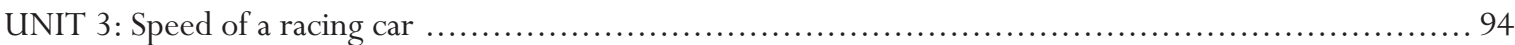

Question 5: SPEED OF RACING CAR (M159Q01) ............................................ 94

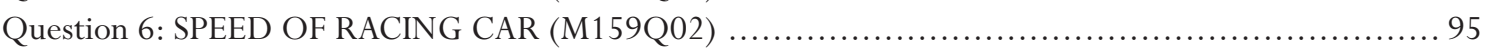

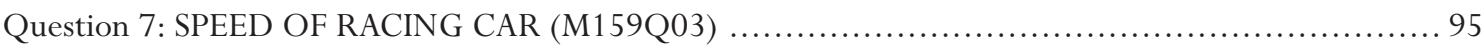

Question 8: SPEED OF RACING CAR (M159Q05) ........................................... 95

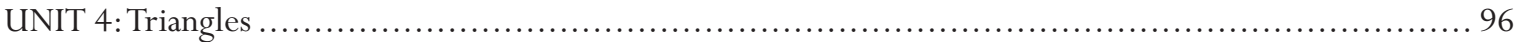

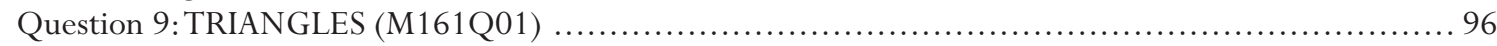

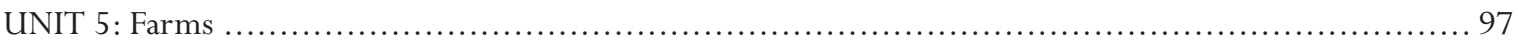

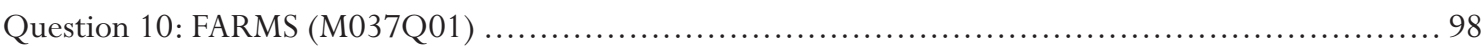

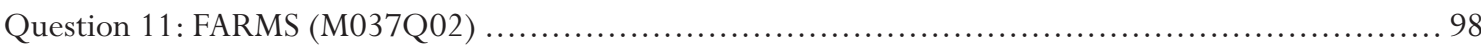

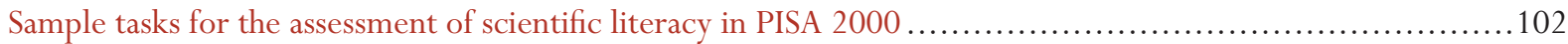

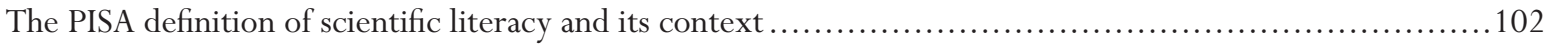

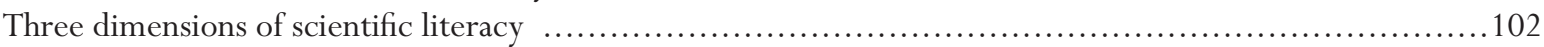

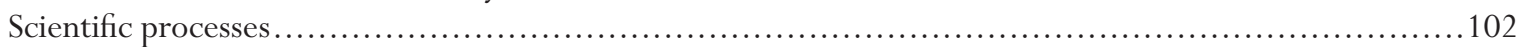

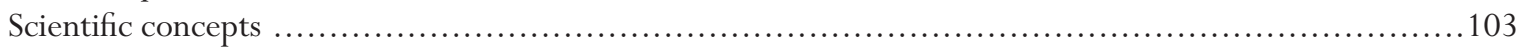

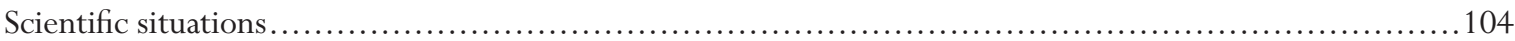

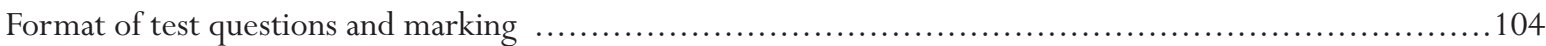

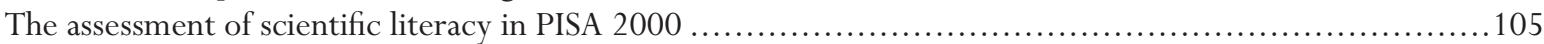

Science units

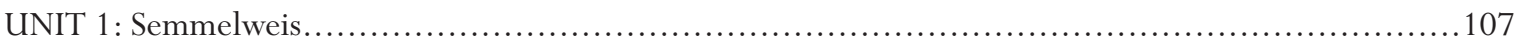

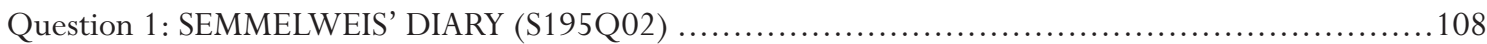

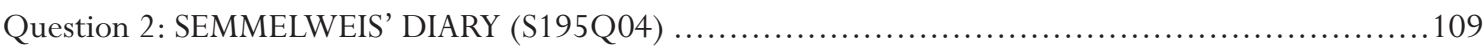

Question 3: SEMMELWEIS' DIARY (S195Q05) ............................................ 110

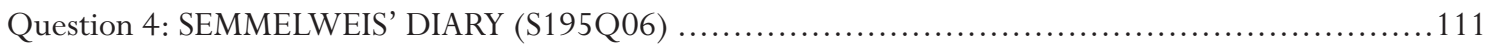

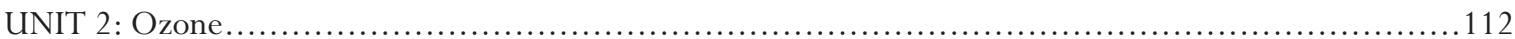

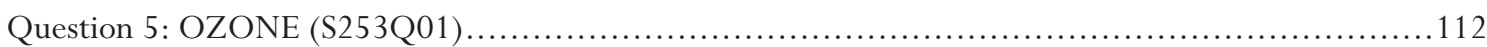

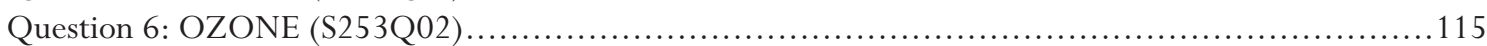

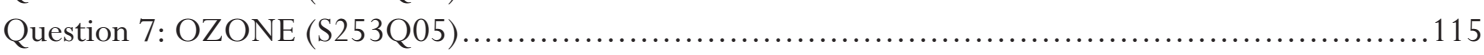

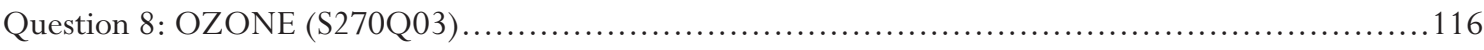

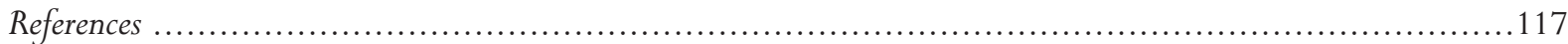





\section{An overview of PISA}

The OECD's Programme for International Student Assessment (PISA) is a collaborative effort on the part of the Member countries of the OECD to measure how well young adults, at age 15 and therefore approaching the end of compulsory schooling, are prepared to meet the challenges of today's knowledge societies. The assessment is forward-looking, focusing on young people's ability to use their knowledge and skills to meet real-life challenges, rather than on the extent to which they have mastered a specific school curriculum. This orientation reflects a change in the goals and objectives of curricula themselves, which are increasingly concerned with what students can do with what they learn at school, and not merely with whether they have learned it.

PISA is the most comprehensive and rigorous international effort to date to assess student performance and to collect data on the student, family and institutional factors that can help to explain differences in performance. Decisions about the scope and nature of the assessments and the background information to be collected were made by leading experts in participating countries, and steered jointly by their governments on the basis of shared, policy-driven interests. Substantial efforts and resources were devoted to achieving cultural and linguistic breadth in the assessment materials. Stringent quality assurance mechanisms were applied in translation, sampling and data collection. As a consequence, the results of PISA have a high degree of validity and reliability, and can significantly improve our understanding of the outcomes of education in the world's most developed countries.

The first PISA survey was conducted in 2000 in 32 countries (including 28 OECD Member countries), using written tasks answered by students in schools under independently supervised test conditions. Another 13 countries will complete the same assessment in 2002. PISA 2000 surveyed reading literacy, mathematical literacy and scientific literacy, with a primary focus on reading. Measures of attitudes to learning, and information on how students manage their own learning, were also obtained in 25 countries as part of an international option.

This publication explains the conceptual framework on which the PISA 2000 assessment is based in terms of the content that students need to acquire, the processes that need to be performed, and the contexts in which knowledge and skills are applied. It then illustrates how the assessment is to be performed by reproducing tasks from the PISA 2000 assessment and explaining what each is measuring. Further information on the conceptual framework underlying PISA can be found in Measuring Student Knowledge and Skills - A New Framework for Assessment (OECD, 1999). The publication Knowledge and Skills for Life - First Results from PISA 2000 (OECD, 2001) summarises the performance of students in PISA 2000 and uses PISA to analyse which factors promote success in education. In addition, it uses background information on students, their schools and their education systems to examine a range of factors associated with different levels of performance.

\section{The PISA literacy concept}

It has long been accepted that an important objective of schooling is the development of a "literate" adult population. Historically, this objective has been synonymous with ensuring that all adults in a society are able to read and write. Literacy defined as the ability to read and write - has been seen as essential to personal fulfilment, to full adult participation in social, cultural and political life, to personal empowerment, and to success in securing and maintaining employment.

The notion that schools have a responsibility to create a future society in which all adults are also 


\section{Box 1 PISA 2000 - an internationally standardised assessment of 15-year-olds}

Sample size

- More than a quarter of a million students, representing almost 17 million 15 -year-olds enrolled in the schools of the 32 participating countries, were assessed in 2000. Another 13 countries will administer the same assessment in 2002.

\section{Content}

- PISA 2000 covered three domains: reading literacy, mathematical literacy and scientific literacy.

- PISA 2000 looked at young people's ability to use their knowledge and skills in order to meet real-life challenges rather than how well they had mastered a specific school curriculum.

- The emphasis was placed on the mastery of processes, the understanding of concepts, and the ability to function in various situations within each domain.

- As part of an international option taken up in 25 countries, PISA 2000 collected information on students' attitudes to learning.

Methods

- PISA 2000 used pencil-and-paper assessments, lasting two hours for each student.

- PISA 2000 used both multiple-choice questions and questions requiring students to construct their own answers. Questions were typically organised in units based on a passage describing a real-life situation.

- A total of seven hours of assessment tasks was included, with different students taking different combinations of the assessment tasks.

- Students answered a background questionnaire that took about 30 minutes to complete and, as part of an international option, completed questionnaires on learning and study practices as well as familiarity with computers.

- School principals completed a questionnaire about their school.

Outcomes

- A profile of knowledge and skills among 15-year-olds.

- Contextual indicators relating results to student and school characteristics.

- A knowledge base for policy analysis and research.

- Trend indicators showing how results change over time, once data become available from subsequent cycles of PISA.

Future assessments

- PISA will continue in three-year cycles. In 2003, the focus will be on mathematics and in 2006 on science. The assessment of cross-curricular competencies is being progressively integrated into PISA, beginning with an assessment of problem-solving skills in 2003. 
mathematically "literate", scientifically "literate", and technologically "literate" is a relatively recent idea. For much of the past century, the content of school mathematics and science curricula was dominated by the need to provide foundations for the professional training of mathematicians, scientists and engineers.

But with the increasing role of science, mathematics and technology in modern life, the objectives of personal fulfilment, employment, and full participation in society increasingly require an adult population which is not only able to read and write, but also one which is mathematically, scientifically and technologically literate.

A key feature of the broadened definition of "literacy" in PISA is a more explicit focus on the knowledge, understanding and skills required for effective functioning in everyday life.

Literacy for effective participation in modern society requires mastery of a body of basic knowledge and skills. For example, reading literacy depends on the ability to decode text, to interpret meanings of words and grammatical structures, and to construct meaning at least at a superficial level. But reading literacy for effective participation in modern society requires much more than this: it also depends on the ability to read between the lines and to reflect on the purposes and intended audiences of texts, to recognise devices used by writers to convey messages and influence readers, and to interpret meaning from the structures and features of texts. Reading literacy depends on an ability to understand and interpret a wide variety of text types, and to make sense of texts by relating them to the contexts in which they appear.

Mathematical literacy similarly depends on familiarity with a body of mathematical knowledge and skills which includes basic number facts and operations, working with money, fundamental ideas about space and shape, including working with measurements, and notions of uncertainty, growth and change. But mathematical literacy for effective functioning in modern society requires much more than this: it also depends on the ability to think and work mathematically, including modelling and problem solving. These competencies include knowing the extent and limits of mathematical concepts, following and evaluating mathematical arguments, posing mathematical problems, choosing ways of representing mathematical situations, and expressing oneself on matters with a mathematical content. Mathematical literacy depends on an ability to apply this knowledge, this understanding and these skills in a wide variety of personal, social and work contexts.

Scientific literacy also depends on familiarity with a body of scientific knowledge and skills. This body of knowledge includes an understanding of fundamental scientific concepts such as food chains, sustainability, energy conservation, photosynthesis, rates of reaction, adaptation, states of matter, and inheritance. But scientific literacy for effective functioning in modern society requires much more than this: it also depends on the ability to use processes of scientific enquiry such as recognising the nature and limits of such enquiry, identifying evidence required to answer scientific questions, and drawing, evaluating and communicating conclusions. Scientific literacy depends on an ability to apply this knowledge, this understanding and these skills in a wide variety of personal, social, and work contexts.

PISA adopts definitions of reading literacy, mathematical literacy and scientific literacy that go beyond mastery of essential knowledge and skills (Box 2). Furthermore, literacy is regarded as knowledge and skills for adult life. Its acquisition is a lifelong process - taking place not just at school or through formal learning, but also through interaction with peers, colleagues and wider communities. Fifteen-year-olds cannot be expected to have learned in school everything that they will need to know as adults. They need a solid foundation of knowledge in areas such as reading, mathematics and science. However, in order to go on learning in these domains and to apply their learning to 
the real world, they need to understand some basic processes and principles, and have the flexibility to use them in different situations. The three PISA domains of literacy - reading, mathematical and scientific literacy - therefore emphasise the ability to undertake a number of fundamental processes in a range of situations, backed by a broad understanding of key concepts, rather than the possession of specific knowledge. In all three domains, PISA places the emphasis not primarily on the mastery of specific curriculum content, but on the ability to reflect on and use reading, mathematical and scientific knowledge, understanding and skills to achieve personal goals and to participate effectively in society (OECD, 1999).

In each domain, the assessment is organised in three dimensions, corresponding to process skills, knowledge and understanding, and the context of application. The remainder of this section gives an overview of each dimension. The next three sections explain more precisely the criteria for assessment in each dimension within individual domains and illustrate these with sample tasks.

It should be borne in mind that PISA 2000 gives more emphasis to reading literacy than to the other two domains. PISA will take place every three years. In each cycle, two-thirds of testing time will be devoted to assessing one domain in detail. Mathematical literacy will become the major domain in 2003, and scientific literacy in 2006.

\section{Processes}

Reading literacy, mathematical literacy and scientific literacy require an understanding of and facility with the methods and processes pertinent to each of these domains.

Beyond the ability to retrieve surface meaning from text, reading literacy requires an understanding and appreciation of the writer's craft, and an ability to reason about text. Readers require an understanding of text structure, genre, and

\section{Box 2 PISA definitions of literacy}

\section{Reading literacy}

The capacity to understand, use and reflect on written texts, in order to achieve one's goals, to develop one's knowledge and potential, and to participate in society.

\section{Mathematical literacy}

The capacity to identify, to understand, and to engage in mathematics and make well-founded judgements about the role that mathematics plays, as needed for an individual's current and future private life, occupational life, social life with peers and relatives, and life as a constructive, concerned, and reflective citizen.

\section{Scientific literacy}

The capacity to use scientific knowledge, to identify questions and to draw evidence-based conclusions in order to understand and help make decisions about the natural world and the changes made to it through human activity. 
register. They must be able to follow chains of reasoning; to compare and contrast information in a text; draw inferences; identify supporting evidence; identify and understand irony, metaphor and humour; detect nuances and subtleties of language; recognise ways in which texts are constructed to persuade and influence; and relate what they read to their own background experience and knowledge.

Mathematical literacy similarly involves a range of process skills. The focus here is on students' abilities to analyse, reason and communicate ideas effectively by posing, formulating and solving mathematical problems. Mathematical literacy skills include thinking skills (e.g., distinguishing between different kinds of mathematical statements); argumentation skills (e.g., following and evaluating chains of mathematical arguments); modelling skills (e.g., translating "reality" into mathematical structures); problem posing and solving skills; representation skills (e.g., distinguishing between different forms of representation of mathematical situations); symbolic skills; technical skills (e.g., solving equations); communication skills; and skills in using mathematical tools and aids.

Scientific literacy depends on the ability to relate evidence and data to claims or conclusions. In particular, scientific literacy involves the processes of recognising scientifically investigable questions (e.g., identifying the question or idea being tested, distinguishing questions that can be answered by scientific investigation from those which cannot); identifying evidence needed in a scientific investigation (e.g., identifying and recognising what things should be compared, what variables should be changed or controlled, and what additional information is required); drawing or evaluating conclusions (e.g., producing a conclusion from a given set of evidence or data, and identifying assumptions made in reaching a conclusion); and communicating valid conclusions (e.g., producing an argument based on a situation or on data given, expressed in a manner that is appropriate and clear to the intended audience). Scientific literacy also includes an understanding of the methods by which science derives evidence to support claims for scientific knowledge, and of the strengths and limitations of science in the real world.

Another important element of literacy (reading, mathematical and scientific) is the ability to stand apart from arguments, evidence or text, to reflect on these, and to evaluate and criticise claims made. These skills go beyond analysis, problem solving and communication to evaluation and critical reflection.

In the domain of reading literacy,

(...) reflecting on the content of a text requires that the reader connects information found in a text to knowledge from other sources. Readers must also assess the claims made in the text against their own knowledge of the world (...). Readers must be able to develop an understanding of what is said and intended in a text, and must test that mental representation against what they know and believe on the basis of either prior information, or information found in other texts. Readers must call on supporting evidence from within the text and contrast that with other sources of information, using both general and specific knowledge, and the ability to reason abstractly (OECD, 1999, p. 32).

In the domain of scientific literacy, An important life skill (...) is the capacity to draw appropriate and guarded conclusions from evidence and information (...), to criticise claims made by others on the basis of the evidence put forward, and to distinguish opinion from evidence-based statements. Science has a particular part to play here since it is concerned with rationality in testing ideas and theories against evidence from the world around (OECD, 1999, p. 59). 
A brief summary of some of the processes included in the PISA definitions of reading literacy, mathematical literacy and scientific literacy is shown in Box 3.

\section{Knowledge and understanding}

Literacy requires the development of a body of knowledge and understanding. Reading literacy requires a knowledge of words, the ability to decode written text, and a knowledge of grammatical structures. Mathematical literacy requires knowledge of mathematical facts, terms and concepts, and an understanding of mathematical principles. Scientific literacy requires knowledge of scientific facts, terms and concepts, and an understanding of scientific principles and laws.

As individuals' levels of reading literacy, mathematical literacy and scientific literacy develop, they are able to draw on an increasingly rich store of knowledge and an increasingly deep understanding of principles within each domain. The development of knowledge and understanding specific to each domain is an important component of the development of literacy.

But literacy involves much more than the mastery of bodies of knowledge. It also involves an understanding of the methods, processes and limitations of a domain, and the ability to use knowledge, understanding and skills in everyday contexts.

PISA differs from some other assessment programmes in that it is not primarily an assessment of the extent to which students have mastered bodies of knowledge and skills identified in school curricula. It is not an assessment of achievement in school reading, mathematics and science only. PISA recognises the necessity of curriculum-based knowledge and understanding for reading literacy, mathematical literacy and scientific literacy (see Box 4), but tests for these mainly in terms of the acquisition of broad concepts and skills that allow that knowledge to be applied.

\section{Box 3 PISA literacy processes}

Reading literacy

"Performing different kinds of reading tasks, such as forming a broad general understanding, retrieving specific information, developing an interpretation or reflecting on the content or form of the text."

\section{Mathematical literacy}

"Mathematical competencies, e.g., modelling, problem solving, divided into three classes: i) reproductions, definitions and computations; ii) making connections and integrating problem solving; and iii) mathematisation, mathematical thinking and generalisation.”

\section{Scientific literacy}

"Process skills, e.g., recognising scientifically investigable questions, identifying evidence, drawing, evaluating and communicating conclusions, and demonstrating understanding of scientific concepts. These do not depend on a pre-set body of scientific knowledge, but cannot be applied in the absence of scientific content." 


\section{Box 4 PISA concept of knowledge and understanding}

Reading literacy

Reading different kinds of text: continuous text classified by type (e.g., description, narration, exposition, argumentation and instruction) and non-continous texts classified by structure (e.g., forms, calls and advertisement, charts and graphs or tables).

\section{Mathematical literacy}

Mathematical content: primarily "overarching concepts". In the first cycle, these are change and relationships, and space and shape. In future cycles, uncertainty and quantity will also be assessed.

\section{Scientific literacy}

Scientific concepts: e.g., structure and properties of matter, chemical and physical changes, energy transformations, forces and movement, form and function, human biology, biodiversity or genetic control, chosen from the major fields of physics, biology, chemistry, etc., and applied in matters related to science in life and health, science in Earth and environment, and science in technology.

\section{Context of application}

Finally, literacy incorporates an awareness and appreciation of the contexts in which texts are constructed, mathematics is used, and science operates, and an ability to apply the knowledge, understanding and skills specific to the appropriate domain to a wide range of contexts in the world outside the classroom. This definition of literacy goes beyond the narrower conceptions of literacy of the 1970s (sometimes called "functional" or "survival" literacy). The focus of these earlier approaches was on minimal skills required to function in adult society.

Reading literacy as it is defined today includes an understanding of the contexts in which written texts are created, and the ability to use this contextual understanding to interpret and think about texts. Modern definitions also recognise that reading literacy plays a crucial role in facilitating participation in a wide variety of social contexts. In the PISA definition: "participate" includes social, cultural and political engagement. Participation may include a critical stance, a step towards personal liberation, emancipation and empowerment. The term "society" includes economic and political as well as social and cultural life (OECD, 1999, p. 21).

Modern definitions of mathematical and scientific literacy similarly emphasise the importance of recognising and understanding the contexts in which mathematics and science operate and the forces that shape these fields of human activity.

In PISA, reading literacy, mathematical literacy and scientific literacy are assumed to include the ability to apply processes and to use knowledge across a range of contexts:

- Reading literacy includes the ability to read a range of classroom materials and reading materials outside classrooms, including reading for personal use (personal letters, fiction, 
biography, etc.), for public use (official documents, public information, etc.), for employment, and for education (textbooks, etc.).

- Mathematical literacy includes the ability to apply mathematical knowledge, skills and understandings in "authentic" contexts. A context is considered authentic if it forms the actual experience and practices of part of participants in a real-world setting. An important part of the definition of mathematical literacy is doing and using mathematics in a variety of situations. These situations include personal life, school life, work and sports (or leisure in general), the local community and society as encountered in daily life, and scientific contexts.

- Scientific literacy includes the ability to solve problems in real-world situations, which may affect us as individuals (e.g., food and energy use), as members of a local community (e.g., treatment of the water supply or siting of a power station) or as world citizens (e.g., global warming, diminution of biodiversity). Contexts to which scientific literacy could be applied include self and family (personal), community (public), life throughout the world (global), and the evolution of scientific knowledge and its influence on social decisions (historical relevance).

Box 5 summarises some of these contexts.

\section{The PISA 2000 assessment instruments}

PISA 2000 was carefully designed by an international network of leading institutions and experts to serve the purposes described above. Each student participated, in his/her own school, in a written assessment session of two hours, and spent about half an hour responding to a questionnaire about himself or herself. School principals were asked to give further information on school characteristics in another 30-minute questionnaire. PISA was implemented in the following ways (for details, see the PISA 2000 Technical Report):

- A wide range of assessment questions. PISA 2000 assessments were in printed form, with questions taking a range of formats. Students were required to consider written passages and diagrams, and to answer a series of questions on each. Much of the material was designed to determine whether students could reflect and think actively about the domain. Examples of items are given in the next sections.

\section{Box 5 PISA context of application}

\section{Reading literacy}

"Reading texts written for different situations, e.g., for personal interest or to meet work requirements."

\section{Mathematical literacy}

"Using mathematics in different situations, e.g., problems that affect individuals, communities or the whole world."

Scientific literacy

"Using science in different situations, e.g., problems that affect individuals, communities or the whole world." 
- Broad coverage of the domain. Each student was assessed for two hours, but not all students were given the same assessment tasks. A range of tasks, equivalent to seven hours of assessment time, was drawn up in order to cover all the areas. Different combinations of tasks were grouped in nine different assessment booklets. Each task appeared in several booklets, which ensured that each was answered by a representative sample of students. Each student received one booklet. The number of tasks in each of the nine booklets varied from 55 to 67, depending on the reading load. In total, the PISA 2000 assessment was based on 141 tasks of reading literacy, 32 tasks of mathematical literacy, and 35 tasks of scientific literacy.

- Co-operation between all participating countries in the development of internationally valid assessments. On the basis of the internationally agreed assessment frameworks and test specifications, countries developed assessment questions that were reviewed by subject-matter specialists and assessment experts. Additional questions were developed to ensure that all areas of the frameworks were covered adequately. Questions were pilot tested, the results were reviewed, and the revised set of questions was then validated in a field trial. Finally, in order to ensure that the questions were valid across countries, languages and cultures, they were rated by participating countries for cultural appropriateness, curricular and non-curricular relevance, and appropriate level of difficulty.

- Standardised procedures for the preparation and implementation of the assessment. PISA represents an unprecedented effort to achieve comparability of results across countries, cultures and languages. In addition to comprehensive coverage of 15-year-old students in each country, these efforts have included co-operation with a wide range of experts in all participating countries, the development of standardised procedures for the preparation and implementation of the assessment, and rigorous attention to quality control throughout. The assessment instruments were prepared in both English and French, and then translated into the languages of participating countries using procedures that ensured the linguistic integrity and equivalence of the instruments. For non-English and non-French speaking countries, two independent translations of the assessment instruments were prepared and then consolidated, drawing, in most cases, on both source versions. 

The remaining sections of this publication present a selection of sample tasks that were used in the PISA 2000 assessment of reading, mathematical and scientific literacy. Each of these sections has three parts:

a) The first part introduces the definition of the respective assessment domain and describes how this definition was operationalised for the purpose of the PISA 2000 assessment.

b) The second part illustrates the PISA 2000 performance scales for the domain on the basis of the characteristics of the underlying tasks.

c) The third part presents the actual sample tasks.

The presentation of the sample tasks is organised by unit, where the name of the respective unit is presented first (e.g., Lake Chad), followed by the stem of the unit or the unit stimulus, and the questions that were presented to the students as part of that unit.

The presentation of each question includes the following elements:

- The presentation begins with the name of the respective unit followed by a unique question code in brackets, e.g. (R040Q02). This identification code is needed for users who wish to retrieve student responses to the question from the PISA 2000 online database (http://www.pisa.oecd.org/pisa/outcome.htm).

- The classification of the question by the three organising dimensions of the PISA 2000 assessment framework (reading task, text format and situation in the case of reading literacy; process, content and situation in the case of mathematical literacy, and process, concept and situation in the case of scientific literacy).

- The presentation of the respective question.

- The criteria used for marking.

a) For multiple-choice questions or other questions that have either a correct or an incorrect answer, the correct answer has been circled and repeated in the scoring section, e.g., Question 1: Lake Chad.

b) For open-ended questions that can be answered as fully correct, partially correct or incorrect, the criteria for scoring student responses are shown. Keywords representing important aspects which should be mentioned in the students' responses are underlined (e.g., Answers which refer to the reappearance of the lake in score 1, Question 3: Lake Chad). In cases where it may not be obvious to the reader why a response is either incorrect or only partially correct, a short explanation follows the response in [italic brackets] (e.g., [Expresses an opinion rather 
than suggesting an explanation], score 0, Question 21: PLAN International). For some questions, responses from students must contain multiple elements in order to be assigned a certain score. In such cases, these elements are identified by numbers in (parentheses) and referred to in each of the potential student responses (e.g., [Describes a specific aspect of layout (1).], score 2, Question 7: Flu).

c) In the case of mathematics and science open-ended questions, two sets of scores are assigned to each student response. The first digit presents the actual score. The second digit, shown in (parentheses), is used to categorise the different kinds of responses on the basis of the strategies used by the student to answer the item. The meaning of the codes used for the second digit varies for each item and are specified within the marking criteria. For example, Question 4: Continent Area requires students to estimate the area of Antarctica. Students will receive full credit, score 2, if they use the correct method AND give the correct result. Within this category, responses are further classified by the strategy they used to solve the problem, such as: i) responses will receive a score of 2 and be classified into strategy 1 [2(1)] if the area is estimated by drawing a square or rectangle; ii) responses will receive a score of 2 and be classified into strategy 2 [2(2)] if the area is estimated by drawing a circle; iii) responses will receive a score of 2 and be classified into strategy 3 [2(3)] if the area is estimated by adding areas of several regular geometric figures, and so on. 

- Content - types of text: the form in which written material is encountered and needs to be understood (many and varied forms such as narrative prose, or graphic presentation), a wide selection of which is represented in the PISA assessment tasks.

Reading literacy is defined in PISA as:

understanding, using, and reflecting on written texts, in order to achieve one's goals, to develop one's knowledge and potential, and to participate in society.

Definitions of reading and of reading literacy have changed over time in parallel with social, economic and cultural changes. Literacy is no longer considered simply the ability to read and write. It is viewed as an advancing set of knowledge, skills, and strategies, which individuals build on throughout life.

The PISA definition therefore goes beyond the notion that reading literacy means decoding written material and literal comprehension. Reading incorporates understanding and reflecting on texts. Literacy involves the ability of individuals to use written information to fulfil their goals, and of complex modern societies to use written information to function effectively. The PISA 2000 reading literacy tasks aim to represent the kinds of literacy that 15 -year-olds will face in their future lives.

\section{Three dimensions of reading literacy}

Readers respond to a given text in a variety of ways as they seek to understand and use what they are reading. This dynamic process has many dimensions, three of which are used to construct the PISA assessment:

- Processes: the various reading tasks required of readers (such as retrieval of information or interpretation of text) used in PISA to simulate the types of task that students will encounter in real life.

- Context: the situation in which reading takes place (e.g. for private or occupational use), defined in PISA according to how the author intended the text to be used. PISA tasks are designed to relate to a variety of such contexts.

\section{Reading tasks}

PISA assesses students' ability to perform a variety of reading tasks. It aims to simulate the kinds of task encountered in "authentic" reading situations - i.e. in real life. To this end, the assessment measures five aspects of understanding a text. It is expected that all readers, irrespective of their overall proficiency, will be able to demonstrate some level of competency in each aspect. While there is an interrelationship between the five aspects, since each may require many of the same underlying skills, successfully accomplishing one may not be dependent upon successfully completing another. The five aspects of reading assessed in PISA are:

\section{Forming a broad general understanding}

This requires the reader to consider the text as a whole or in a broad perspective. Students may be asked, for example, to demonstrate initial understanding by identifying the main topic of the text, to explain the purpose of a map or graph, to match a piece of text to a question about the broad purpose of the text, or to focus on more than one specific reference in the text and to deduce the theme from the repetition of a particular category of information. Selecting the main idea implies establishing a hierarchy among ideas and choosing the most general and overarching ones. Such a task indicates whether the student can distinguish between key ideas and minor details, or can recognise the summary of the main theme in a sentence or title. 


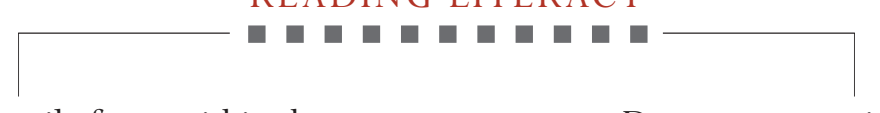

Use information primarily from within the text

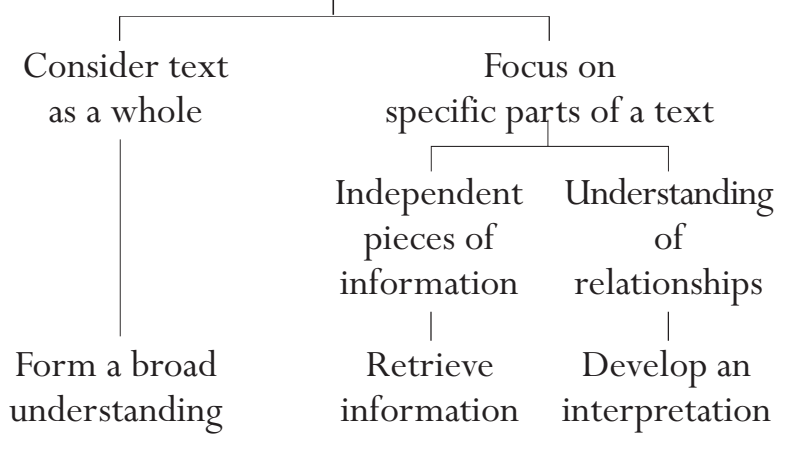

Draw upon outside knowledge

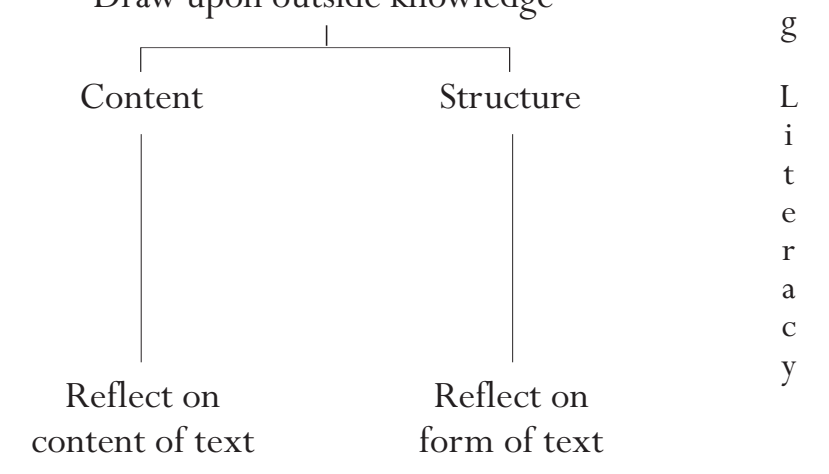

\section{Retrieving information}

In the course of daily life, readers often need a particular piece of information. They may need to look up a telephone number. They may want to check the departure time for a bus or train. They may want to find a particular fact to support or refute a claim someone has made. To retrieve effectively, readers must scan, search, locate, and select relevant information. In assessment tasks that call for retrieving information, students have to identify the essential elements of a message: characters, time, setting, etc. They must match information given in the question with either literal or synonymous information in the text and use this to find the new information asked for. This may require discriminating between two similar pieces of information. By systematically varying the elements that contribute to difficulty, measurement of various levels of proficient performance associated with this aspect of comprehension can be achieved.

\section{Developing an interpretation}

This requires readers to extend their initial impressions, processing information in a logical manner so that they develop a more specific or complete understanding of what they have read. Tasks that might be used to assess this aspect include comparing and contrasting information - by integrating two or more pieces of information from

the text, drawing inferences about the relationship between different sources of information, and identifying and listing supporting evidence in order to infer the author's intent.

\section{Reflecting on the content of a text}

This requires the reader to relate information found in a text to knowledge from other sources. Readers must assess the claims made in the text against their own knowledge of the world or against information found in other texts in the assessment or explicitly provided in the question. In many situations, readers must know how to justify their own point of view. Typical assessment tasks include providing evidence or arguments from outside the text, assessing the relevance of particular pieces of information or evidence, drawing comparisons with moral or aesthetic rules (standards), identifying information that might strengthen the author's argument, and evaluating the sufficiency of the evidence or information provided in the text.

\section{Reflecting on the form of a text}

Tasks in this category require readers to stand apart from the text, consider it objectively, and evaluate its quality and appropriateness. Knowledge of such things as text structure, genre, and register play an important role in these tasks. Students are required to detect nuances in language - for example, 
understanding when the choice of an adjective might affect interpretation. Assessment tasks include determining the usefulness of a particular text for a specified purpose, evaluating an author's use of certain textual features in accomplishing a particular goal, and identifying or commenting on the author's use of style and the author's purpose and attitude.

Table 1 shows the distribution of reading literacy tasks in the PISA 2000 assessment by each of the five aspects defined above. The first three aspects, which account for 70 per cent of the reading literacy assessment, look at how well a student can understand and use information within a text. The remaining tasks require wider reflection.

Table 1 Distribution of reading tasks by aspects of reading literacy

\begin{tabular}{l|c} 
Aspect & $\begin{array}{c}\% \text { of PISA reading } \\
\text { literacy assessment }\end{array}$ \\
\hline Retrieving information & 20 \\
Broad understanding & 20 \\
Developing an interpretation & 30 \\
Reflecting on content & 15 \\
Reflecting on form & 15 \\
Total & 100 \\
\hline
\end{tabular}

\section{Text format}

At the heart of the organisation of the PISA reading assessment is a distinction between continuous and non-continuous texts. Continuous texts are typically composed of sentences that are, in turn, organised into paragraphs. These may be fitted into even larger structures such as sections, chapters, and books. Non-continuous texts, or documents as they are known in some approaches, present information in a variety of different ways, such as forms, graphs and maps.

\section{Continuous text types}

Continuous text types are all in a standard "prose" form. They are classified according to the author's purpose, with the following five types used in PISA:

1. Description refers to properties of objects in space, and typically provides an answer to "what" questions.

2. Narration refers to properties of objects in time and typically provides answers to "when", or "in what sequence" questions.

3. Exposition presents information as composite concepts or mental constructs, or those elements into which concepts or mental constructs can be analysed. The text provides an explanation of how the component elements interrelate in a meaningful whole and often answers "how" questions.

4. Argumentation presents propositions as to the relationships between concepts, or other propositions. Argumentation texts often answer "why" questions.

5. Instruction (sometimes called injunction) provides directions on what to do and includes procedures, rules, regulations and statutes specifying certain behaviours.

\section{Non-continuous text types}

Unlike continuous texts, non-continuous texts vary in form, and are thus classified according to their structure rather than the author's purpose. The following six types are used in PISA:

1. Forms are structured and formatted texts which request the reader to respond to specific questions in specified ways. Typical examples are tax forms, immigration forms, visa forms, application forms, statistical questionnaires, etc.

2. Calls and advertisements are documents designed to invite the reader to do something, e.g., to buy goods or services, attend gatherings or meetings, elect a person to a public office, etc. The purpose of these documents is to persuade the reader. They offer something and request attention and action at the same time. Advertisements, invitations, summonses, warnings and notices are examples of this document format. 
3. Charts and graphs are iconic representations of data. They are used for the purposes of scientific argumentation, and also in journals and newspapers to display numerical and tabular public information in a visual format.

4. Diagrams often accompany technical descriptions (e.g., demonstrating parts of a household appliance), expository texts, and instructive texts (e.g., illustrating how to assemble a household appliance). It is often useful to distinguish procedural (how to) from process (how something works) diagrams.

5. Tables and matrices. Tables are row and column matrices. Typically, all the entries in each column and each row share properties, and thus the column and row labels are part of the information structure of the text. Common tables include timetables, spreadsheets, order forms, and indexes.

6. Maps are non-continuous texts that indicate the geographical relationships between places. There is a variety of types of maps. Road maps mark the distances and routes between identified places. Thematic maps indicate the relationships between locations and social or physical features.

The distribution and variety of texts that students are asked to read for PISA, shown in Table 2, is an important characteristic of the assessment. Continuous texts represent about two-thirds of the texts contained in the assessment, of which the largest single category is expository materials. Twothirds of non-continuous texts are tables or charts and graphs. The remaining non-continuous texts are maps, advertisements, and forms of the type that 15 -year-olds are expected to be able to read and use.

\section{Reading situations}

PISA distinguishes four types of reading situations: reading for private use, reading for public use, reading for work, and reading for education.

While it is the intent of the PISA reading literacy assessment to measure the kinds of reading that
Table 2 Distribution of reading tasks by text format

\begin{tabular}{lc} 
Text format & $\begin{array}{c}\% \text { of PISA reading } \\
\text { literacy assessment }\end{array}$ \\
\hline Narrative & 13 \\
Expository & 22 \\
Descriptive & 13 \\
Argumentative/Persuasive & 13 \\
Injunctive & 5 \\
Total continuous texts & 66
\end{tabular}

\begin{tabular}{l|c} 
Text format & $\begin{array}{c}\% \text { of PISA reading } \\
\text { literacy assessment }\end{array}$ \\
\hline Charts and Graphs & 11 \\
Tables & 11 \\
Diagrams & 3 \\
Maps & 3 \\
Forms & 3 \\
Advertisements & 2 \\
\hline Total non-continuous texts & 33 \\
\hline
\end{tabular}

occur both within and outside classrooms, the manner in which reading situations are defined cannot be based simply on where reading takes place. For example, textbooks are read both in schools and at home, and the processes and purposes of reading these texts differ little from one setting to another.

In PISA, the reading situations can therefore be understood as a general categorisation of texts based on their intended use, on implicit or explicit relations to others, and on the general contents. Close attention has therefore been paid to the origin and content of texts. The goal is to reach a balance between reflecting the broad definition of reading literacy used in PISA and representing the linguistic and cultural diversity of participating countries. This diversity will help to ensure that no one group is either advantaged or disadvantaged by the assessment content. 
1. Reading for private use (personal) is carried out to satisfy an individual's own interests, both practical and intellectual. It also includes reading to maintain, or develop, personal connections to other people. Contents typically include personal letters, fiction, biography, and informational texts read for curiosity, as a part of leisure or recreational activities.

2. Reading for public use is carried out to participate in the activities of the wider society. It includes the use of official documents as well as information about public events. In general, these tasks are associated with more or less anonymous contact with others.

3. Reading for work (occupational) may not yet be required by most 15 -year-olds, but there are two important reasons to include such situations in PISA. First, reading in such situations is usually closely associated with the accomplishment of some immediate task. Secondly, some reading abilities will help to equip students for the world of work into which the PISA target population will shortly move.

4. Reading for education, or reading to learn, is normally involved with acquiring information as part of a larger learning task. The materials are often not chosen by the reader, but assigned by a teacher. The content is usually designed specifically for educational purposes.

Table 3 shows the distribution of reading literacy tasks in the assessment across all four situations.

Table 3 Distribution of reading literacy tasks by situations

\begin{tabular}{lc} 
Situations & $\begin{array}{c}\text { \% of PISA reading } \\
\text { literacy assessment }\end{array}$ \\
\hline Personal & 28 \\
Educational & 28 \\
Occupational & 16 \\
Public & 28 \\
Total & 100 \\
\hline
\end{tabular}

The occupational situation is given less weight because of the likelihood that 15-year-olds are relatively unfamiliar with this category of text. It is also important to reduce the potential dependence on specific occupational knowledge that can result when occupational texts are selected.

\section{Format of test questions}

Reading literacy was assessed using a series of texts, students being set a number of tasks on each text. Forty-five per cent of the tasks required students to construct their own responses, either by providing a brief answer from a wide range of possible answers or by constructing a longer response, allowing for the possibility of divergent, individual responses and opposing viewpoints. The latter tasks usually asked students to relate information or ideas in the stimulus text to their own experience or opinions, the acceptability of their answer depending less on the position taken by the student than on the ability to use what they had read when justifying or explaining that position. Partial credit was provided for partially correct or less sophisticated answers, and all of these tasks were marked by hand. A further 45 per cent of the tasks were asked in multiplechoice format, in which students either made one choice from among four or five given alternatives or a series of choices by circling a word or short phrase (for example "yes" or "no") for each point. The remaining 10 per cent of the tasks required students to construct their response from among a limited range of acceptable answers.

\section{Marking}

While multiple-choice questions have either a correct or an incorrect answer, partial credit models allow for more complex marking of other questions. Psychometric models for such marking are well established and in some ways are preferable to the "right or wrong" approach as they make use of more of the information that appears in the answers. Partial credit marking was used for some of the more complex questions in which students constructed their own answers. It is important to note that markers were advised to ignore spelling and grammatical 
errors, unless they completely obscured the meaning, as this assessment was not seen as a test of written expression.

\section{The assessment of reading literacy in PISA 2000}

As explained before, the concept of reading literacy in PISA has three dimensions, which have guided the development of the assessment: the type of reading task (processes), the form and structure of the reading material (content), and the use for which the text was constructed (context). Personal competence is best understood in terms of the first of these. The other two are properties of the task materials that were helpful in ensuring that a range of diverse tasks were included in the tests.

The "type of reading task" dimension is measured on three scales. A "retrieving information" scale reports on students' ability to locate information in a text. An "interpreting texts" scale reports on students' ability to construct meaning and draw inferences from written information. A "reflection and evaluation" scale reports on students' ability to relate texts to their knowledge, ideas and experiences. In addition, a combined reading literacy scale summarises the results from all three reading literacy scales.

To facilitate the interpretation of the scores assigned to students, the combined reading literacy scale is designed to have an average score of 500 points, with about two-thirds of students across OECD countries scoring between 400 and 600 points. These reference points provide an "anchor" for the measurement of student performance. The mean scores for the three scales that contribute to the combined reading scale differ slightly from 500 .

The scores on each scale represent degrees of proficiency in a particular aspect of reading literacy. For example, a low score on the interpreting scale indicates that a student has limited skills in understanding relationships, constructing meaning or drawing inferences from one or more parts of a text. By contrast, a high score on the interpreting scale indicates that a student has advanced skills in this area. There are easier and harder tasks for each of the three reading literacy scales, and there is no hierarchical relationship between the three scales. Each of the three reading literacy scales is divided into five levels of knowledge and skills. Level 5 corresponds to a score of more than 625, Level 4 to scores in the range 553 to 625 , Level 3 to scores from 481 to 552, Level 2 to scores from 408 to 480 , and Level 1 to scores from 335 to 407. Students at a particular level not only demonstrate the knowledge and skills associated with that level but also the proficiencies required at lower levels. Thus all students proficient at Level 3 are also proficient at Levels 1 and 2. All students at a given level are expected to answer at least half of the questions at that level correctly. Students scoring below 335 points, i.e., those who do not reach Level 1, are not able routinely to show the most basic skills that PISA seeks to measure. While such performance should not be interpreted to mean that those students have no literacy skills at all, performance below Level 1 does signal serious deficiencies in students' ability to use reading literacy as a tool for the acquisition of knowledge and skills in other areas.

The division of the scales into levels of difficulty and of performance makes it possible not only to rank students' performance but also to describe what they can do (see Figure 1). Each successive reading level is associated with tasks of ascending difficulty. The tasks at each level of reading literacy were judged by panels of experts to share many features and requirements and to differ consistently from tasks at either higher or lower levels. The assumed difficulty of tasks was then validated empirically on the basis of student performance in participating countries.

The reading literacy tasks used in PISA 2000 vary widely in terms of text format, situation and task requirements. The following examples show some of the tasks that were used in PISA 2000, 
together with the associated reading literacy skills demonstrated by students at the various levels of the three reading literacy scales. The descriptions reflect the skills assessed by each task. These descriptions provide some insight into the range of processes required of students and the proficiencies which they need to demonstrate at various points along the reading literacy scales.

\section{Box 6 How to read Figure 1.1}

In the same way that students are allocated a performance score on each PISA scale, the level of difficulty of the tasks can also be expressed in terms of these scales. While students receive scale scores according to their performance in the assessment tasks, the difficulty of a task is derived from the average performance in that task of students in all countries. The score corresponding to the difficulty of the task is indicated along the vertical line in Figure 1.1. For example, Question 1 is the first question shown in the sequence of reading questions in this publication and shown in the first column of page 30 as a retrieving information question. It has a notional level of difficulty of 478 points. A student with a score of 478 is expected to be capable of dealing with tasks up to this level of difficulty. That does not mean that every student receiving a score of 478 or above will have answered this task correctly or that all students receiving scores below 478 will have answered it incorrectly. Nor does it mean that students with a score of 478 will answer correctly all tasks with a notional level of difficulty below this point and will answer incorrectly all tasks with a level of difficulty above it. The difficulty of a task is established in such a way that students with a score equal to that of a given task will have a known probability of answering it correctly. Students with scores above/below 478 points will have a greater/lesser likelihood of answering the task taken as an example here (and others like it) correctly.

Figure 1.1 also provides a summary description of what each task intends to measure. For example, Question 1 requires students to locate and combine pieces of information in a graph and its introduction.

Finally, Figure 1.1 provides two identification codes for each question. One is the order in which the question appears in this publication and the second, shown in parenthesis at the end of the description, indicates the identification code for the question in the PISA 2000 database. The prefix $\mathrm{R}$ is used to identify reading questions, the prefix $\mathrm{M}$ identifies mathematics questions and the prefix $\mathrm{S}$ science questions.

Students' answers to some of the open-ended questions may be partially correct, in which case they receive partial credit for their answers, corresponding to a lower score on the proficiency scale than that of a fully correct answer. In such cases, each response category is represented as a separate entry in Figure 1.1. Where applicable, an indication of the score level for the corresponding response categories follows the second identification of the question, within the parenthesis. 
What is being assessed on each of the reading literacy scales:

Retrieving information is defined as locating one or more pieces of information in a text.
Interpreting texts is defined as constructing meaning and drawing inferences from one or more parts of a text.
Reflection and evaluation is defined as relating a text to one's experience, knowledge and ideas.

Characteristics of the tasks associated with increasing difficulty on each of the reading literacy scales:
Task difficulty depends on the type of reflection required, with the easiest tasks requiring simple connections or explanations relating the text to external experience, and the more difficult requiring a hypothesis or evaluation. Difficulty also depends on the familiarity of the knowledge that must be drawn on from outside the text; on the complexity of the text; on the level of textual understanding demanded; and on how explicitly the reader is directed to relevant factors in both the task and the text.

\section{Level}

Task difficulty depends on the type of

retation required, with the easiest requiring identifying the main idea in a text, mor difficult tasks requiring understanding relationship quiring either an understanding of the Difficulty also depends on how explicitly the text provides the ideas or information the reader need in order to complete the task; on how prominen the required information is; and on how much competing information is present. Finally, the length and complexity of the text and the familiarity of its content affect difficulty.
5 Locate and possibly sequence or combine multiple pieces of deeply embedded information, some of which may be outside the main body of the text. Infer which information in the text is relevant to the task. Deal with highly plausible and/or extensive competing information.

Locate and possibly sequence or combine multiple pieces of embedded information, each of which may need to meet multiple criteria, in a text with unfamiliar context or form. Infer which information in the text is relevant to the task.
Either construe the meaning of nuanced language or demonstrate a full and detailed understanding of a text.
Critically evaluate or hypothesise, drawing on specialised knowledge. Deal with concepts that are contrary to expectations and draw on a deep understanding of long or complex texts.
Locate, and in some cases recognise, the relationship between pieces of information, each of which may need to meet multiple criteria. Deal with prominent competing information.

Locate one or more pieces of information, each of which may be required to meet multiple criteria. Deal with competing information.
Use a high level of text-based inference to understand and apply categories in an unfamiliar context, and to construe the meaning of a section of text by taking into account the text as a whole. Deal with ambiguities, ideas that are contrary to expectation and ideas that are negatively worded.
Integrate several parts of a text in order to identify a main idea, understand a relationship or construe the meaning of a word or phrase. Compare, contrast or categorise taking many criteria into account. Deal with competing information.

Identify the main idea in a text, understand relationships, form or apply simple categories, or construe meaning within a limited part of the text when the information is not prominent and low-level inferences are required.
Make connections or comparisons, give explanations, or evaluate a feature of text. Demonstrate a detailed understanding of the text in relation to familiar, everyday knowledge, or draw on less common knowledge.

Make a comparison or connections between the text and outside knowledge, or explain a feature of the text by drawing on personal experience and attitudes.
1 Take account of a single criterion to locate one or more independent pieces of explicitly stated information.
Recognise the main theme or author's purpose in a text about a familiar topic, when the required information in the text is prominent.
Make a simple connection between information in the text and common, everyday knowledge.

Source: OECD PISA, 2001. 


\section{Retrieving information \\ Locating one or more pieces \\ of information in a text}

\section{Interpreting texts \\ Constructing meaning by drawing \\ inferences from one or more parts of a text}

\section{Reflection and evaluation \\ Relating a text to one's ideas, \\ knowledge and experience}

LEVEL

LEVEL

655 (Question 43) This task requires students to locate two independent pieces of embedded information based on multiple conditions amidst highly plausible competing information in a notice about job services. (R234QO2)

631 (Question 16) This task requires students to locate correct numerical information in a tree diagram and combine it with conditional information given in........-> a footnote. (R088Q03, score 2)

608 (Question 40) This task requires students to identify two pieces of directorial information embedded in a play script and apply it correctly to an accompanying diagram. (R216004)

540 (Question 2) This task requires students to identify the starting date of a graph when strong competing information appears in the graph. (R040Q03A)

515 (Question 22) This task requires students to locate information in a scientific magazine article for young people by making a synonymous match among competing information. (R100Q04)

485 (Question 16) This task requires students to locate correct numerical information in a tree diagram. At this level, conditional information is not used. (R088Q03, score 1)

478 (Question 1) This task requires students to locate and combine pieces of information in a graph and its introduction. (R040Q02)

Source: OECD PISA, 2001
727 (Question 17) This task requires students to analyse and match several described cases to labour force status categories where some of the relevant information is in footnotes and therefore not prominent. (R088Q04, score 2)

669 (Question 45) This task requires students to demonstrate understanding by identifying two examples from a long and closely argued editorial on how modern technology creates the need for new responses. (R236Q02)

645 (Question 32) This task requires students to detect nuances of language in short quotations from a story and relate them to the main theme. Readers must deal with conflicting ideas in the immediate vicinity of the quotations. (R119007, score 2)

603 (Question 35) This task requires students to construe the meaning of a sentence in context by taking into account information across a large section of text. The sentence in isolation is ambiguous and there are apparently plausible alternative readings. (R119Q04)

567 (Question 39) This task requires students to apply categories given in a list of definitions in order to find relevant examples in a play script. Readers need to make several category matches. (R216Q03)

562 (Question 10) This task requires students to analyse and categorise several described cases by taking into account and integrating multiple conditions dispersed throughout a notice about immunisation. (R077Q06)

558 (Question 44) This task requires students to follow the thread of a discussion across paragraphs in a dense text containing strong competing information. (R236Q01)

542 (Question 12) This task requires students to infer an analogical relationship between two phenomena in the text. (R081005)

539 (Question 32) This task requires students to construe the meaning of short quotations from a story in relation to the immediate situation being described or to the atmosphere of the story as a whole. (R119Q07, score 1)

529 (Question 34) This task requires students to explain a character's motivation by linking a chain of events scattered throughout a long narrative text. (R119008)

521 (Question 8) This task requires students to construe the meaning of several words or phrases in order to compare the status of recommendations in a notice about immunisation. Readers need to integrate information across paragraphs amid distracting information. (R077Q04)
822 (Question 21) This task requires students to hypothesise about an unexpected phenomenon (that an aid agency gives relatively low levels of support to a very poor country) by taking account of outside knowledge along with all relevant information in a complex text on a relatively unfamiliar topic. (R099Q04B, score 2)

705 (Question 21) This task requires students to hypothesise about an unexpected phenomenon (that an aid agency gives relatively low levels of support to a very poo country) by taking account of outside knowledge along with some relevant information in a complex text on a relativel unfamiliar topic. (R099Q04B, score 1)

652 (Question 36) This task requires students to evaluate the appropriateness of the ending of a narrative by commenting on its connection with the general theme or mood: of the text. Readers need to draw inferences, making use of ideas activated during reading but not explicity stated in the text, which is a complete and relatively subtle short story. (R119Q05, score 2)

637 (Question 9) This task requires students to evaluate the appropriateness of an apparently contradictory section of a notice about an immunisation program in the workplace, taking into account the persuasive intent of the text and/or its logical coherence. (R077Q05)

600 (Question 3) This task requires students to hypothesise about the reason for an author's decision by drawing on evidence in a graph and relating it to the inferred main theme of a complex set of texts. (R040Q03B)

583 (Question 7) This task requires students to evaluate the appropriateness of formal text features in relation to the intended tone of a notice about immunisation. Readers need to draw on their understanding of what constitutes appropriate style for a particular purpose and audience. (RO77Q03, score 2)

581 (Question 14) This task requires students to evaluate the writer's craft by comparing two short letters on the topic of graffiti. Readers need to draw on their understanding of what constitutes good style in writing. (R081 QO66)
EVEI 
Short description of selected reading literacy tasks and their associated scores

\section{Retrieving information \\ Locating one or more pieces \\ of information in a text}

LEVEL

\author{
Interpreting texts \\ Constructing meaning by drawing \\ inferences from one or more parts of a text
}

Reflection and evaluation $n$ Relating a text to one's ideas, $\quad g$ knowledge and experience

LEVEL
443 (Question 6) This task requires students to locate explicitly stated information in a notice about an immunisation program in the workplace where competing or distracting information is present. (R077Q02)

405 (Question 28) This task requires students to locate several pieces of explicitly stated information in a sports article. (R110Q05)

392 (Question 27) This task requires students to locate a single explicitly stated piece of information in a sports article with little competing information. (R110Q04)

367 (Question 33) This task requires students to locate a single explicitly stated piece of information in a lengthy narrative when the relevant piece of text is indicated and there is little competing information. (R119006)

363 (Question 42) This task requires students to locate a single explicitly stated piece of information in a notice about job services. (R234Q01)
518 (Question 23) This task requires students to recognise an appropriate summary of a clearly identified paragraph in a scientific magazine article for young people by integrating information from several sentences. Some competing information is present. (R100Q05)

508 (Question 5) This task requires students to integrate information from two graphic displays where different conventions are used and where readers need to have interpreted the structure of both displays in order to translate the relevant information from one form to the other. (R040Q06)

477 (Question 15) This task requires students to understand the relationship of information presented in a tree diagram. (R088001)

473 (Question 17) This task requires students to analyse and match some described cases to labour force status categories where some of the relevant information is in footnotes and therefore not prominent. (R088Q04, score 1)

455 (Question 41) This task requires students to construe the meaning of a short sentence by relating it to the storyline developed in the rest of the text. (R216006)

447 (Question 31) This task requires students to understand the setting of a story from information given in a single paragraph. (R119001)

423 (Question 37) This task requires students to recognise the main theme of an extract from a play script when it can be inferred from information in a brief introduction to the text. (R2160O1)

421 (Question 11) This task requires students to identify the purpose that two short texts have in common by comparing the main ideas in each of them. (R081Q01)

406 (Question 24) This task requires students to identify the writer's general purpose in a scientific magazine article written for young people. (R100Q06)

402 (Question 25) This task requires students to integrate information from different paragraphs in order to identify the main idea of a scientific magazine article written for young people. (R100Q07)

397 (Question 4) This task requires students to recognise the main idea of a chart by relating it to its title. (R040Q04)

356 (Question 26) This task requires students to recognise the main theme of a sports article when it is implied in the subheading and repeated several times in the body of the article. (R110Q01)
LEVEL

567 (Question 36) This task requires students to evaluate the appropriateness of the ending of a narrative by commenting on the consistency of the ending with the plot as a whole. The text is a complete and relatively subtle short story. (R119005, score 1)

561 (Question 38) This task requires students to connect examples in a given script with their own knowledge about what constitutes a stage direction in a play, and to describe the convention used to represent them. (R216Q02)

542 (Question 7) This task requires students to evaluate the appropriateness of content in relation to the intended tone of $a$ notice about immunisation. Readers need to draw on their understanding of what constitutes appropriate content for a particular purpose and audience. (R077Q03, score 1)

537 (Question 30) This task require students to connect their own concepts of compassion and cruelty with the behaviour of a character in a narrative, and to use evidence identified in the text to justify opposing points of view. (R119Q09, score 2)

486 (Question 19) This task requires students to evaluate the formal features of a tree diagram in order to recognise the appropriateness of its structure for showing categories within groups. (R088Q07)

480 (Question 30) This task requires students to connect their own concepts of compassion and cruelty with the behaviour of a character in a narrative, and to use evidence identified in text to justify a point of view. (R119009, score 1)

471 (Question 13) This task requires students to compare claims made in two short texts with their own views and attitudes. Readers are also required to demonstrate broad understanding of at least one of the two letters. (R081006a)

445 (Question 18) This task requires students to draw on knowledge of the form and content of a tree diagram about the labour force to distinguish between variables and structural features. (R088005)

402 (Question 29) This task requires students to make a connection by articulating the relationship between two parts of a single, specified sentence in a magazine article about sports shoes. (R110Q06) 


\section{READING UNIT 1}

\section{Lake Chad}

Figure A shows changing levels of Lake Chad, in Saharan North Africa. Lake Chad disappeared completely in about 20000 BC, during the last Ice Age. In about 11000 BC it reappeared. Today, its level is about the same as it was in AD 1000.

Figure A

Lake Chad: changing levels

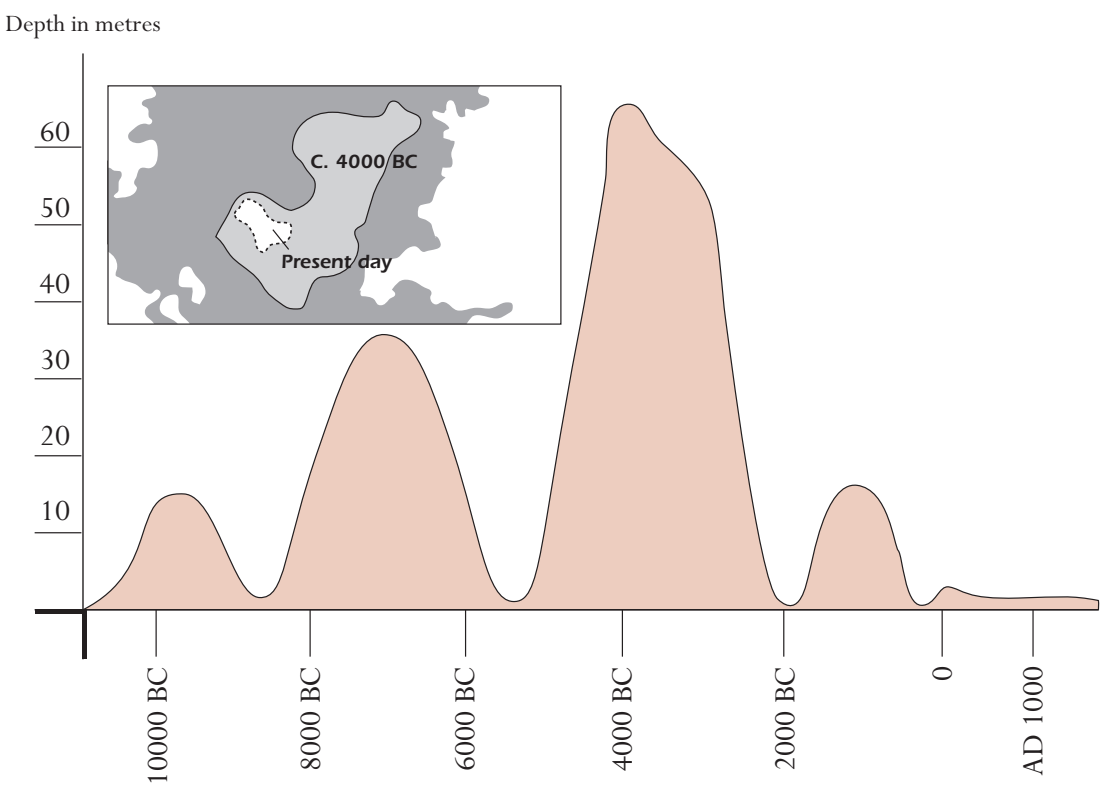

Figure B shows Saharan rock art (ancient drawings or paintings found on the walls of caves) and changing patterns of wildlife.

Figure B

Saharan rock art and changing patterns of wildlife

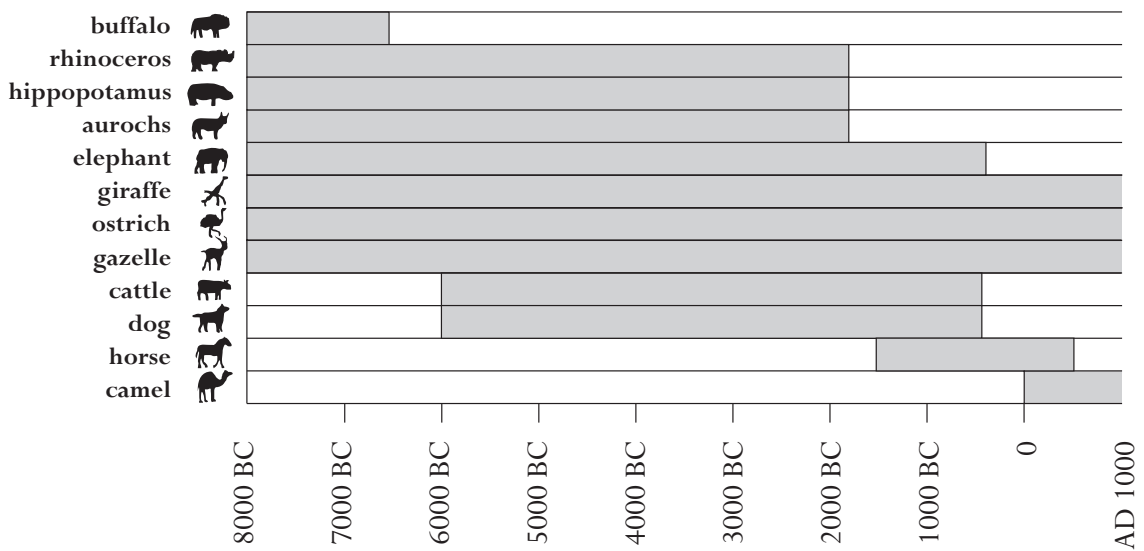

Source: Copyright Bartholomew Ltd 1988. Extracted from TheTimes Atlas of Archaeology and reproduced by permission of Harper Collins Publishers. 
Use the information about Lake Chad on the opposite page to answer the questions below.

Question 1: LAKE CHAD (RO40QO2)

Reading task: Retrieving information

Text format: Non-continuous

Situation: Public

What is the depth of Lake Chad today?

(A) About two metres.

B About fifteen metres.

C About fifty metres.

D It has disappeared completely.

E The information is not provided.

\section{Scoring - Question 1}

Score 1: Answer A - about two metres.

Score 0: Other answers.

\section{Question 2: LAKE CHAD (R040QO3A)}

Reading task: Retrieving information

Text format: Non-continuous

Situation: Public

In about which year does the graph in Figure A start?

\section{Scoring - Question 2}

Score 1: Answers which state 11000 BC (or an approximation between 10500 and 12000), indicating that the student has extrapolated from the scale). For example:

- 11000 .

- 11000 BC.

- $10500 \mathrm{BC}$.

- Just before 10000 BC.

- About 12000.

- About 11000 BC.

Score 0: Other answers, including arrow pointing to the starting point of the graph. For example:

- $10000 \mathrm{BC}$. [Has failed to extrapolate from the scale.]

- 20000 BC.

- 8000 BC. [Has looked at wrong figure.]

- $11000 \mathrm{BC} 4000 \mathrm{BC}$. [Ignore crossed-out answer.]

- 0 . 
Question 3: LAKE CHAD (R040QO3B)

Reading task: Reflection and evaluation

Text format: Non-continuous

Situation: Public

Why has the author chosen to start the graph at this point?

\section{Scoring - Question 3}

Score 1: Answers which refer to the reappearance of the lake. Note: an answer may receive score 1 even if the previous answer is incorrect. For example:

- Lake Chad reappeared in 11000 BC after disappearing completely around 20000 BC.

- The lake disappeared during the Ice Age and then came back at about this time.

- It reappeared then.

- About 11000 BC it came back.

- Then the lake reappeared after being gone for 9000 years.

Score 0: Other answers. For example:

- This is when animals started to appear.

- $11000 \mathrm{BC}$ is when humans began to do rock art.

- 11000 BC was when the lake (first) appeared.

- Because at that time Lake Chad was completely dried up.

- Because that was the first movement on the graph.

\section{Question 4: LAKE CHAD (R040Q04)}

Reading task: Interpreting texts

Text format: Non-continuous

Situation: Public

Figure $B$ is based on the assumption that

A the animals in the rock art were present in the area at the time they were drawn.

$B$ the artists who drew the animals were highly skilled.

C the artists who drew the animals were able to travel widely.

D there was no attempt to domesticate the animals which were depicted in the rock art.

\section{Scoring - Question 4}

Score 1: Answer A - the animals in the rock art were present in the area at the time they were drawn.

Score 0: Other answers. 
Question 5: LAKE CHAD (R040Q06)

Reading task: Interpreting texts

Text format: Non-continuous

Situation: Public

For this question you need to draw together information from Figure $A$ and Figure B.

The disappearance of the rhinoceros, hippopotamus and aurochs from Saharan rock art happened

A at the beginning of the most recent Ice Age.

$B$ in the middle of the period when Lake Chad was at its highest level.

(C) after the level of Lake Chad had been falling for over a thousand years.

$D$ at the beginning of an uninterrupted dry period.

\section{Scoring - Question 5}

Score 1: Answer C - after the level of Lake Chad had been falling for over a thousand years.

Score 0: Other answers. 


\section{READING UNIT 2}

Flu

\section{ACOL VOLUNTARY FLU IMMUNISATION PROGRAM}

As you are no doubt aware, the flu can strike rapidly and extensively during winter. It can leave its victims ill for weeks.

The best way to fight the virus is to have a fit and healthy body. Daily exercise and a diet including plenty of fruit and vegetables are highly recommended to assist the immune system to fight this invading virus.

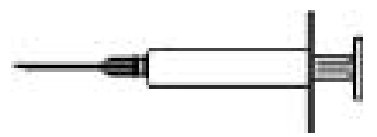

ACOL has decided to offer staff the opportunity to be immunised against the flu as an additional way to prevent this insidious virus from spreading amongst us. ACOL has arranged for a nurse to administer the immunisations at ACOL, during a half-day session in work hours in the week of May 17. This program is free and available to all members of staff.

Participation is voluntary. Staff taking up the option will be asked to sign a consent form indicating that they do not have any allergies, and that they understand they may experience minor side effects.

Medical advice indicates that the immunisation does not produce influenza. However, it may cause some side effects such as fatigue, mild fever and tenderness of the arm.

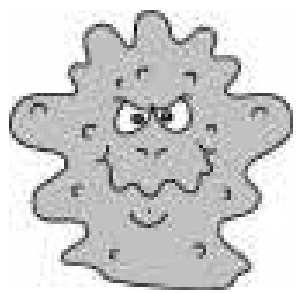

\section{WHO SHOULD BE IMMUNISED?}

Anyone interested in being protected against the virus.

This immunisation is especially recommended for people over the age of 65 . But regardless of age, ANYONE who has a chronic debilitating disease, especially cardiac, pulmonary, bronchial or diabetic conditions.

In an office environment ALL staff are at risk of catching the flu.

\section{WHO SHOULD NOT BE IMMUNISED?}

Individuals hypersensitive to eggs, people suffering from an acute feverish illness and pregnant women.

Check with your doctor if you are taking any medication or have had a previous reaction to a flu injection. 
you would like to be immunised in the week of May 17 please advise the personnel officer, Fiona McSweeney, by Friday May 7. The date and time will be set according to the availability of the nurse, the number of participants and the time convenient for most staff. If you would like to be immunised for this winter but cannot attend at the arranged time please let Fiona know. An alternative session may be arranged if there are sufficient numbers.

For further information please contact Fiona on ext. 5577.

$$
\text { Goof }{ }^{j 0 y} \text { Health }
$$

Fiona McSweeney, the personnel officer at a company called ACOL, prepared the information sheet above for ACOL staff. Refer to the information sheet to answer the questions which follow.

\section{Question 6: FLU (R077QO2)}

Reading task: Retrieving information

Text format: Continuous

Situation: Occupational

Which one of the following describes a feature of the ACOL flu immunisation program?

A Daily exercise classes will be run during the winter.

(B) Immunisations will be given during working hours.

C A small bonus will be offered to participants.

D A doctor will give the injections.

\section{Scoring - Question 6}

Score 1: Answer B - immunisations will be given during working hours.

Score 0: Other answers.

Question 7: FLU (R077Q03)

Reading task: Reflection and evaluation

Text format: Continuous

Situation: Occupational

We can talk about the content of a piece of writing (what it says).

We can talk about its style (the way it is presented).

Fiona wanted the style of this information sheet to be friendly and encouraging.

Do you think she succeeded?

Explain your answer by referring in detail to the layout, style of writing, pictures or other graphics. 


\section{Scoring - Question 7}

Score 2: Answers which refer accurately to the text AND relate style to purpose, and in a way that in consistent with the writer's intention of being "friendly and encouraging". The answer must do AT LEAST ONE of the following:

(1) refer to one of the features in detail (layout, style of writing, pictures or other graphics or other similar detail) - that is, to a specific part or quality of a feature; AND/OR

(2) use evaluative terms other than "friendly" and "encouraging". (Note that such terms as "interesting", "easy to read" and "clear" are not sufficiently specific on their own.)

Opinion about whether Fiona succeeded may be stated or implied. For example:

- No, it was a bad idea to put a picture of a syringe near the beginning. That looks scary. [Refers to one specific part of the design: a particular picture (1). Uses own evaluative term:"scary" (2).]

- Yes, the pictures break up the writing and make it easy to read. [Describes a specific aspect of layout (1).]

- The cartoon-like picture of the virus is friendly. [Refers to a specific aspect ("cartoon-like") of one illustration (1).]

- No, the pictures are childish and irrelevant. [Uses own terms ("childish", "irrelevant") to evaluate one of the features mentioned in the stem (2).]

- Yes, the written style is relaxed and informal. [Uses own terms ("relaxed", "informal") to evaluate one of the features mentioned in the stem (2).]

- Yes, the style was warm and inviting. [Uses own terms to evaluate style (2).]

- There is too much writing. People wouldn't bother reading it. [Refers to a relevant feature of the presentation: amount of text (1). Uses own evaluative terms (2).]

- She doesn't put pressure on people to get the injection, and that would encourage people. [Implicit reference to manner or register: an aspect of style (2).]

- No, the writing style is very formal. [Debatable but plausible application of own evaluative term: "formal"(2).]

Score 1: Answers which refer accurately to the text AND relate purpose to information and content (rather than style), and acknowledge the writer's intention of being "friendly and encouraging". Opinion about whether Fiona succeeded may be stated or implied. For example:

- No, there is no way that a message about having an injection could be friendly and encouraging.

- Yes, she succeeded. She gives many opportunities and can arrange times for flu immunisation. She also gives suggestions about health.

Score 0: Answers which are insufficient or vague. For example:

- Yes, it makes it sound as if it would be a good idea.

- Yes, it is friendly and encouraging. [Terms not applied to specific features.]

- No, it doesn't work.

- No, because some of the information is not correct. [Refers to content without making any connection to the idea of a "friendly and encouraging" style.]

- Yes, the illustrations are encouraging and the style of the announcement is also acceptable. ["Illustrations are encouraging" does not go beyond the terms of the question. "The style of the announcement is also acceptable" is too vague.]

- She succeeded, easy to read, and clear. [The terms used are not specific enough.] 
- I think that she has succeeded well. She has selected pictures and written interesting text. [Pictures are not evaluated in any way, and "interesting text" is too vague.]

OR: Answers which show inaccurate comprehension of the material or are implausible or irrelevant. For example:

- Yes, everyone should have the injection. [Irrelevant and inaccurate.]

- No, the pictures have nothing to do with the message. [Inaccurate]

- Yes, because she wants people to be worried about getting the flu. [Conflicts with the idea of a "friendly and encouraging" style.]

- It's good but it's only one opinion. [Irrelevant]

- Yes, it gave brief information on what they will do to stop flu. [Irrelevant - refers to content in a non-specific way.]

- Yes, she just tells the facts. [Irrelevant]

- Yes, because more people should be immunised. [Gives a general opinion on the subject of immunisation, does not refer to the style or to details of content.]

- Yes, I do because no one wants to be sick. Everyone wants good health. [Irrelevant]

\section{Question 8: FLU (R077Q04)}

Reading task: Interpreting texts

Text format: Continuous

Situation: Occupational

This information sheet suggests that if you want to protect yourself against the flu virus, a flu injection is

A more effective than exercise and a healthy diet, but more risky.

(B) a good idea, but not a substitute for exercise and a healthy diet.

$C$ as effective as exercise and a healthy diet, and less troublesome.

D not worth considering if you have plenty of exercise and a healthy diet.

\section{Scoring - Question 8}

Score 1: Answer B - a good idea, but not a substitute for exercise and a healthy diet.

Score 0: Other answers.

\section{Question 9: FLU (R077Q05)}

Reading task: Reflection and evaluation

Text format: Continuous

Situation: Occupational

Part of the information sheet says:

\section{Who should be immunised?}

Anyone interested in being protected against the virus. 
After Fiona had circulated the information sheet, a colleague told her that she should have left out the words "Anyone interested in being protected against the virus" because they were misleading.

Do you agree that these words are misleading and should have been left out?

Explain your answer.

\section{Scoring - Question 9}

Score 1: Answers which evaluate the section of text in relation to the term "misleading" by indicating that there is a potential contradiction. "Who should be immunised? Anyone..." vs "Who should not be immunised?"). May or may not explain what the contradiction is. Agreement or disagreement may be stated or implied. For example:

- Yes, because it would be dangerous for some people to have the immunisation (e.g. pregnant women). [Describes contradiction.]

- No, because you only have to read another couple of lines to realise that some people shouldn't have the injection, and on the whole she wants people to have it.

- Yes, because she says "anyone" can and later she states the people who should not be immunised. [Contradiction identified.]

- This line suggests that all people should get the vaccine, which is untrue. [Contradiction briefly indicated.]

- Yes, to some extent. Maybe: "Anyone interested in being protected against the virus, but who doesn't suffer from any of the following symptoms or diseases.” [Suggested rewording implies recognition of the contradiction.]

OR: Answers which evaluate the section of text in relation to the term "misleading" by indicating that the statement may be an exaggeration. (i.e. Not everyone needs the immunisation, or the immunisation does not offer complete protection.) May or may not explain what the exaggeration is. Agreement or disagreement may be stated or implied. For example:

- Leave out because having the immunisation is not a guarantee that you won't get the flu.

- I don't agree, even though it makes it sound as if you will definitely get the flu if you don't have the injection.

- Having the injection is not a complete protection.

- Leave out because not everyone gets the flu, especially if you are fit and well.

- Yes I agree because it makes the shot sound better than it is. [Implies an exaggeration, though unspecified.]

Score 0: Answers which evaluate the section of text, but not in relation to the term "misleading". For example:

(1) Indicates that the statement is strong, effective and/or encouraging without mentioning potential contradiction or misleading element; OR

(2) Indicates that the statement "Anyone interested in being protected against the virus" is redundant because it is stating the obvious.

- It was good to put it in, because it would encourage people. (1)

- It should be there because it makes the message stand out. (1)

- I think that these words should have been left out because it goes without saying that everyone wants to be protected against the virus, even if this is not accomplished through immunisation. (2) 
OR: Answers which are insufficient or vague, or restate "misleading" without explanation. For example:

- Leave it in, it's good. [No explanation.]

- They should have put another picture there instead of the heading. [No explanation.]

- Yes, this sentence is misleading and it could cause problems. [No explanation]

OR: Answers which show inaccurate comprehension of the material or are implausible or irrelevant. For example:

- It should have been left out because everyone has the right to decide for themselves. [Misunderstanding of register of the text: it is not an order.]

- I think the word FLU should have been put in between THE and VIRUS, because people just taking a glance at it might think that they are talking about another virus and not the flu. [Implausible explanation for "misleading”.]

- Yes, people may be interested but may have a fear of needles. [Irrelevant]

\section{Question 10: FLU (R077Q06)}

Reading task: Interpreting texts

Text format: Continuous

Situation: Occupational

\section{According to the information sheet, which one of these staff members should contact Fiona?}

A Steve from the store, who does not want to be immunised because he would rather rely on his natural immunity.

B Julie from sales, who wants to know if the immunisation program is compulsory.

C Alice from the mailroom who would like to be immunised this winter but is having a baby in two months.

(D) Michael from accounts who would like to be immunised but will be on leave in the week of May 17.

\section{Scoring - Question 10}

Score 1: Answer D - Michael from accounts who would like to be immunised but will be on leave in the week of May 17.

Score 0: Other answers. 


\section{READING UNIT 3 \\ Graffiti}

The two letters below come from the internet and are about graffiti. Graffiti is illegal painting and writing on walls and elsewhere. Refer to the letters to answer the questions below.

I'm simmering with anger as the school wall is cleaned and repainted for the fourth time to get rid of graffiti. Creativity is admirable but people should find ways to express themselves that do not inflict extra costs upon society.

Why do you spoil the reputation of young people by painting graffiti where it's forbidden? Professional artists do not hang their paintings in the streets, do they? Instead they seek funding and gain fame through legal exhibitions.

In my opinion buildings, fences and park benches are works of art in themselves. It's really pathetic to spoil this architecture with graffiti and what's more, the method destroys the ozone layer. Really, I can't understand why these criminal artists bother as their "artistic works" are just removed from sight over and over again.

\section{Helga}

Source: Mari Hankala.
There is no accounting for taste. Society is full of communication and advertising. Company logos, shop names. Large intrusive posters on the streets. Are they acceptable? Yes, mostly. Is graffiti acceptable? Some people say yes, some no.

Who pays the price for graffiti? Who is ultimately paying the price for advertisements? Correct. The consumer.

Have the people who put up billboards asked your permission? No. Should graffiti painters do so then? Isn't it all just a question of communication - your own name, the names of gangs and large works of art in the street?

Think about the striped and chequered clothes that appeared in the stores a few years ago. And ski wear. The patterns and colours were stolen directly from the flowery concrete walls. It's quite amusing that these patterns and colours are accepted and admired but that graffiti in the same style is considered dreadful.

Times are hard for art.

Sophia

\section{Question 11: GRAFFITI (R081QO1)}

Reading task: Interpreting texts

Text format: Continuous

Situation: Public

The purpose of each of these letters is to

A explain what graffiti is.

(B) present an opinion about graffiti.

$C$ demonstrate the popularity of graffiti.

$D$ tell people how much is spent removing graffiti.

\section{Scoring - Question 11}

Score 1: Answer B - present an opinion about graffiti.

Score 0: Other answers. 


\section{Question 12: GRAFFITI (R081Q05)}

Reading task: Interpreting texts

Text format: Continuous

Situation: Public

Why does Sophia refer to advertising?

\section{Scoring - Question 12}

Score 1: Answers which recognise that a comparison is being drawn between graffiti and advertising, and are consistent with the idea that advertising is a legal form of graffiti. For example:

- To show us that advertising can be as invasive as graffiti.

- Because some people think advertising is just as ugly as spray-painting.

- She's saying that advertising is just a legal form of graffiti.

- She thinks advertising is like graffiti.

- Because they don't ask your permission to put up billboards. [The comparison between advertising and graffiti is implicit.]

- Because advertisements are placed in society without our permission, as is graffiti.

- Because the billboards are like graffiti. [A minimal answer. Recognises a similarity without elaborating on what the similarity is.]

- Because it is another form of display.

- Because advertisers stick posters on the wall and she thinks they are graffiti as well.

- Because it is on the walls too.

- Because they are equally nice or ugly to look at.

- She refers to advertising because it is acceptable unlike graffiti. [Similarity of graffiti and advertising is implied by contrasting attitudes to the two.]

OR: Answers which recognise that referring to advertising is a strategy to defend graffiti. For example:

- So that we will see that graffiti are legitimate after all.

Score 0: Answers which are insufficient or vague. For example:

- It's a way of making her point.

- Because she wants to, she mentions it as an example.

- It's a strategy.

- Company logos and shop names.

OR: Answers which show inaccurate comprehension of the material or are implausible or irrelevant. For example:

- She's describing the graffiti.

- Because people put graffiti on them.

- Graffiti are a kind of advertising.

- Because graffiti is advertising for a certain person or gang. [Comparison goes in the wrong direction, i.e., graffiti is a form of advertising.] 


\section{Question 13: GRAFFITI (R081Q06A)}

Reading task: Reflection and evaluation

Text format: Continuous

Situation: Public

Which of the two letter writers do you agree with? Explain your answer by using your own words to refer to what is said in one or both of the letters.

\section{Scoring - Question 13}

Score 1: Answers which explain the student's point of view by referring to the content of one or both letters. They may refer to the writer's general position (i.e. for or against) or to a detail of her argument. The interpretation of the writer's argument must be plausible. The explanation may take the form of paraphrase of part of the text, but must not be wholly or largely copied without alteration or addition. For example:

- I agree with Helga. Graffiti is illegal and that makes it vandalism.

- Helga because I am against graffiti. [Minimum answer]

- Sophia. I think it's hypocritical to fine graffiti artists and then make millions by copying their designs.

- I sort of agree with both of them. It should be illegal to paint over walls in public places but these people should be given the opportunity to do their work somewhere else.

- Sophia's because she cares about art.

- I agree with both. Graffiti is bad but advertising is just as bad so I won't be hypocritical.

- Helga because I don't really like graffiti either but I understand Sophia's point of view and how she didn't want to condemn people for doing something they believe in.

- Helga's because it really is a pity to spoil the reputation of young people for nothing. [Borderline case: some direct quotation, but embedded in other text.]

- Sophia. It is true that patterns and colours stolen from graffiti appear in stores and are accepted by people who consider graffiti dreadful. [The explanation is a combination of phrases from the text, but the amount of manipulation indicates that it has been well understood.]

Score 0: Support for own point of view is confined to a direct quotation (with or without quotation marks). For example:

- Helga because I agree that people should find ways to express themselves that do not inflict extra costs upon society.

- Helga. Why spoil the reputation of young people?

OR: Answers which are insufficient or vague. For example:

- Sophia's because I think Helga's letter doesn't back her argument with reasons (Sophia compares her argument to advertising etc.) [Answers in terms of style or quality of argument.]

- Helga because she used more details. [Answers in terms of style or quality of argument.]

- I agree with Helga. [No support for opinion.]

- Helga's because I believe what she is saying. [No support for opinion.]

- Both, because I can understand where Helga is coming from. But Sophia is also right. [No support for opinion.] 
OR: Answers which show inaccurate comprehension of the material or are implausible or irrelevant. For example:

- I agree more with Helga. Sophia doesn't seem to be sure what she thinks.

- Helga's because she thinks some have talent. [Misinterpretation of Helga's argument.]

\section{Question 14: GRAFFITI (R081Q06B)}

Reading task: Reflection and evaluation

Text format: Continuous

Situation: Public

We can talk about what a letter says (its content).

We can talk about the way a letter is written (its style).

Regardless of which letter you agree with, in your opinion, which do you think is the better letter? Explain your answer by referring to the way one or both letters are written.

\section{Scoring - Question 14}

Score 1: Answers which explain opinion with reference to the style or form of one or both letters. They should refer to criteria such as style of writing, structure of argument, cogency of argument, tone, register used, or strategies for persuading readers. Terms like "better arguments" must be substantiated. For example:

- Helga's. She gave you lots of different points to consider and she mentioned the environmental damage that graffiti artists do, which I think is very important.

- Helga's letter was effective because of the way she addressed the graffiti artists directly.

- I think Helga's letter was the better one of the two. I thought Sophia's was a bit biased.

- I thought Sophia put forward a very strong argument but Helga's was structured better.

- Sophia, because she didn't really aim it at anyone. [Explains his/her choice in terms of quality of content. Explanation is intelligible when interpreted as "Doesn't attack anyone".]

- I like Helga's letter. She was quite dominant getting her opinion out.

Score 0: Answers which judge in terms of agreement or disagreement with the writer's position, or simply paraphrase content. For example:

- Helga. I agree with everything she said.

- Helga's was the better letter. Graffiti are costly and wasteful, just as she says.

OR: Answers which judge without sufficient explanation. For example:

- Sophia's letter was the best.

- Sophia's was easier to read.

- Helga had a better argument.

OR: Answers which show inaccurate comprehension of the material or are implausible or irrelevant. For example:

- Helga's is better written. She works step by step through the problem and then, on the basis of that, she comes to a logical conclusion.

- Sophia because she kept her position to herself until the end of her letter. 
The tree diagram below shows the structure of a country's labour force or "working-age population". The total population of the country in 1995 was about 3.4 million.

\section{READING UNIT 4}

\section{Labour}

\section{The labour force structure, year ended 31 March $1995(000 \mathrm{~s})^{1}$}

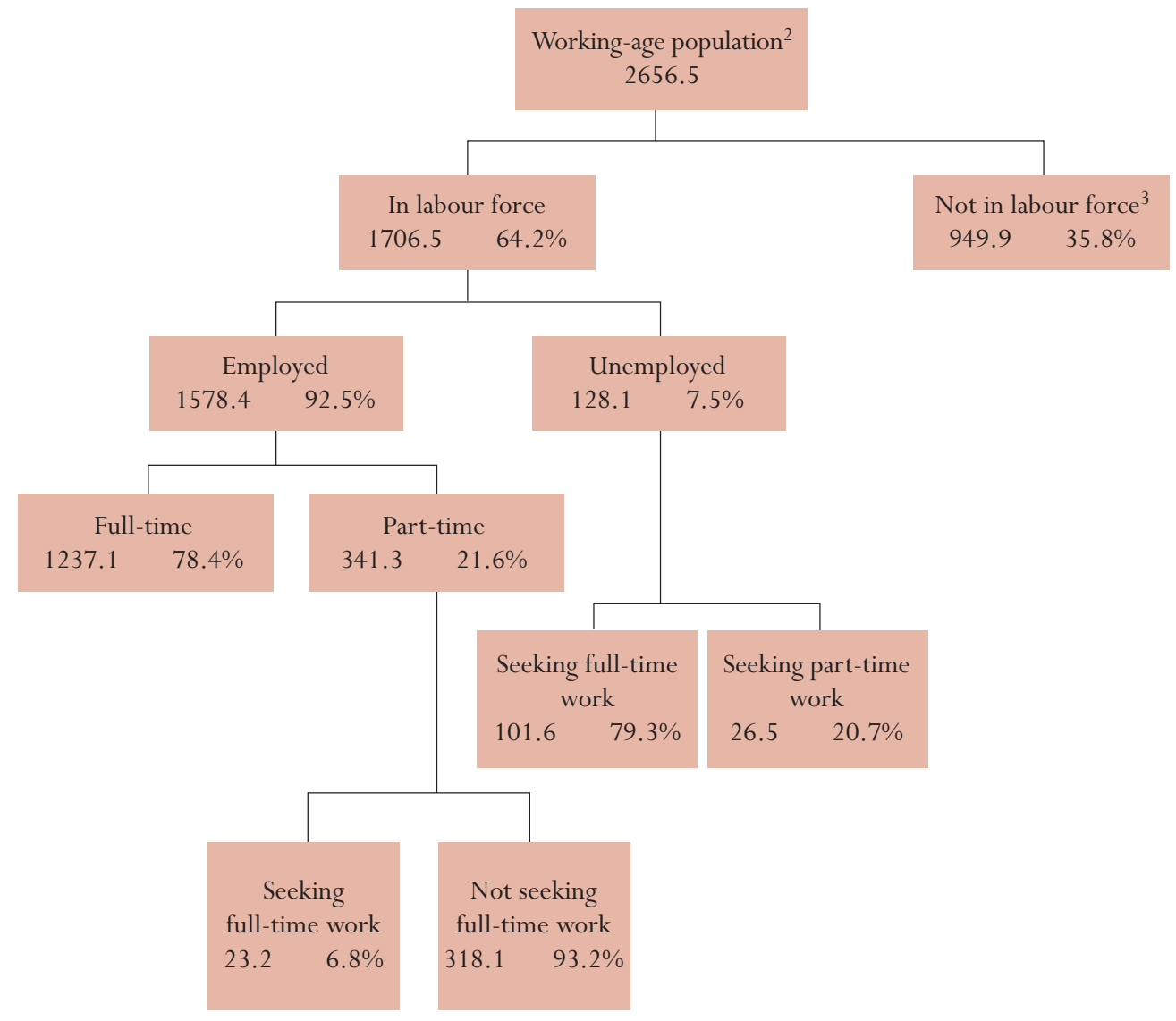

1. Numbers of people are given in thousands (000s).

2. The working-age population is defined as people between the ages of 15 and 65.

3. People "Not in labour force" are those not actively seeking work and/or not available for work.

Source: D. Miller, Form 6 Economics, ESA Publications, Box 9453, Newmarker, Auckland, NZ, p. 64.

Use the above information about a country's labour force to answer the following questions. 
Question 15: LABOUR (R088Q01)

Reading task: Interpreting texts

Text format: Non-continuous

Situation: Educational

What are the two main groups into which the working-age population is divided?

A Employed and unemployed.

B Of working age and not of working age.

C Full-time workers and part-time workers.

(D) In the labour force and not in the labour force.

\section{Scoring - Question 15}

Score 1: Answer D - in the labour force and not in the labour force.

Score 0: Other answers.

\section{Question 16: LABOUR (R088Q03)}

Reading task: Retrieving information

Text format: Non-continuous

Situation: Educational

How many people of working age were not in the labour force? (Write the number of people, not the percentage.)

\section{Scoring - Question 16}

Score 2: Answers which indicate that the number in the tree diagram AND the "000s" in the title/ footnote have been integrated: 949 900. Allow approximations between 949000 and 950000 in figures or words. Also accept 900000 or one million (in words or figures) with qualifier.

- 949900.

- Just under nine hundred and fifty thousand.

- 950000.

- 949.9 thousand.

- Almost a million.

- About 900 thousand.

- 949.9 X 1000.

- 949900.

- $949(000)$.

Score 1: Answers which indicate that the number in the tree diagram has been located, but that the "000s" in the title/footnote has not been correctly integrated. Answers stating 949.9 in words or figures. Allow approximations comparable to those for Score 2. 


\section{Question 17: LABOUR (R088Q04)}

Reading task: Interpreting texts

Text format: Non-continuous

Situation: Educational

In which part of the tree diagram, if any, would each of the people listed in the table below be included? Show your answer by placing a cross in the correct box in the table.

The first one has been done for you.

\begin{tabular}{|c|c|c|c|c|}
\hline & $\begin{array}{l}\text { "In labour force: } \\
\text { employed" }\end{array}$ & $\begin{array}{l}\text { "In labour force: } \\
\text { unemployed" }\end{array}$ & $\begin{array}{l}\text { "Not in } \\
\text { labour force" }\end{array}$ & $\begin{array}{l}\text { Not included } \\
\text { in any category }\end{array}$ \\
\hline A part-time waiter, aged 35 & 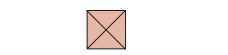 & $\square$ & $\square$ & $\square$ \\
\hline $\begin{array}{l}\text { A business woman, aged } 43 \text {, who works } \\
\text { a sixty-hour week }\end{array}$ & $\otimes$ & $\square$ & 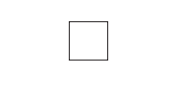 & \begin{tabular}{|l|} 
\\
\end{tabular} \\
\hline A full-time student, aged 21 & $\square$ & $\square$ & $\bigotimes$ & \begin{tabular}{|l|l|} 
\\
\end{tabular} \\
\hline $\begin{array}{l}\text { A man, aged } 28 \text {, who recently sold his shop } \\
\text { and is looking for work }\end{array}$ & $\square$ & $\varnothing$ & $\square$ & $\square$ \\
\hline $\begin{array}{l}\text { A woman, aged } 55 \text {, who has never worked or } \\
\text { wanted to work outside the home }\end{array}$ & 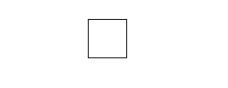 & $\square$ & $\bigotimes$ & $\square$ \\
\hline $\begin{array}{l}\text { A grandmother, aged } 80 \text {, who still works } \\
\text { a few hours a day at the family's market stall }\end{array}$ & $\square$ & $\square$ & $\square$ & 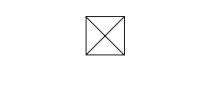 \\
\hline
\end{tabular}

\section{Scoring - Question 17}

Score 2: 5 answers correct.

Score 1: 3 or 4 answers correct.

Score 0: 2 or fewer answers correct. 
Question 18: LABOUR (R088Q05)

Reading task: Reflection and evaluation

Text format: Non-continuous

Situation: Educational

Suppose that information about the labour force was presented in a tree diagram like this every year.

Listed below are four features of the tree diagram. Show whether or not you would expect these features to change from year to year, by circling either "Change" or "No change". The first one has been done for you.

\begin{tabular}{l|c}
$\begin{array}{l}\text { Features of Tree Diagram } \\
\text { The labels in each box (e.g. "In labour force") }\end{array}$ & Answer \\
\hline The percentages (e.g. "64.2\%") & Change/No change \\
\hline The numbers (e.g. "2656.5") & Change/No change \\
\hline The footnotes under the tree diagram & Change/No change \\
\hline
\end{tabular}

\section{Scoring - Question 18}

Score 1: 3 answers correct.

Score 0: 2 or fewer answers correct.

\section{Question 19: LABOUR (R088Q07)}

Reading task: Reflection and evaluation

Text format: Non-continuous

Situation: Educational

The information about the labour force structure is presented as a tree diagram, but it could have been presented in a number of other ways, such as a written description, a pie chart, a graph or a table.

The tree diagram was probably chosen because it is especially useful for showing
A changes over time.
$B$ the size of the country's total population.
(C) categories within each group.
D the size of each group.

\section{Scoring - Question 19}

Score 1: Answer C - categories within each group.

Score 0: Other answers. 


\section{READING UNIT 5}

\section{PLAN International}

\section{PLAN International Program Results Financial Year 1996}

\section{Region of Eastern and Southern Africa}

RESA

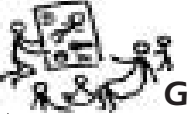

Growing up healthy

Health posts built with 4 rooms or less

Health workers trained for 1 day

Children given nutrition supplements $>1$ week
Children given financial help with health/

dental treatment

\begin{tabular}{|c|c|c|c|c|c|c|c|c|c|}
\hline$\underset{\vec{b}}{\stackrel{\vec{b}}{\vec{b}}}$ & 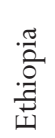 & 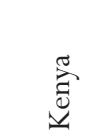 & $\frac{\vec{c}}{\sum^{3}}$ & 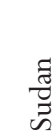 & $\begin{array}{l}\stackrel{\Xi}{\Xi} \\
\text { స్ } \\
\text { స్ }\end{array}$ & 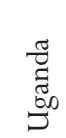 & 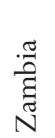 & $\begin{array}{l}\frac{0}{3} \\
\frac{0}{\Xi} \\
\text { है }\end{array}$ & $\frac{n}{0}$ \\
\hline 1 & 0 & 6 & 0 & 7 & 1 & 2 & 0 & 9 & 26 \\
\hline 1053 & 0 & 719 & 0 & 425 & 1003 & 20 & 80 & 1085 & 4385 \\
\hline 10195 & 0 & 2240 & 2400 & 0 & 0 & 0 & 02 & 51402 & 266237 \\
\hline 984 & 0 & 396 & 0 & 305 & 0 & 581 & 0 & 17 & 2283 \\
\hline
\end{tabular}

\section{2.}

Teachers trained for 1 week

School exercise books bought/donated

School textbooks bought/donated

Uniforms bought/made/donated

Children helped with school fees/a scholarship

School desks built/bought/donated

Permanent classrooms built

Classrooms repaired

Adults receiving training in literacy this

financial year

$\begin{array}{rrrrrrrrrr}0 & 0 & 367 & 0 & 970 & 115 & 565 & 0 & 303 & \mathbf{2 3 2 0} \\ 667 & 0 & 0 & 41200 & 0 & 69106 & 0 & 150 & 0 & \mathbf{1 1 1} \mathbf{1 2 3} \\ 0 & 0 & 45650 & 9600 & 1182 & 8769 & 7285 & 150 & 58387 & \mathbf{1 3 1 0 2 3} \\ 8897 & 0 & 5761 & 0 & 2000 & 6040 & 0 & 0 & 434 & \mathbf{2 3 1 3 2} \\ 12321 & 0 & 1598 & 0 & 154 & 0 & 0 & 0 & 2014 & \mathbf{1 6 0 8 7} \\ 3200 & 0 & 3689 & 250 & 1564 & 1725 & 1794 & 0 & 4109 & \mathbf{1 6 3 3 1} \\ 44 & 0 & 50 & 8 & 93 & 31 & 45 & 0 & 82 & 353 \\ 0 & 0 & 34 & 0 & 0 & 14 & 0 & 0 & 33 & \mathbf{8 1} \\ 1160 & 0 & 3000 & 568 & 3617 & 0 & 0 & 0 & 350 & \mathbf{8 6 9 5}\end{array}$

\section{คลก}

Latrines or toilets dug/built

Houses connected to a new sewage system

Wells dug/improved (or springs capped)

New positive boreholes drilled

Gravity feed drinking water systems built

Drinking water systems repaired/improved

Houses improved with PLAN project

New houses built for beneficiaries

Community halls built or improved

Community leaders trained for 1 day or more

Kilometres of roadway improved

Bridges built

Families benefited directly from erosion control

Houses newly served by electrification project

$\begin{array}{rrr}50 & 0 & 2403 \\ 143 & 0 & 0 \\ 0 & 0 & 15 \\ 0 & 0 & 8 \\ 0 & 0 & 28 \\ 0 & 0 & 392 \\ 265 & 0 & 520 \\ 225 & 0 & 596 \\ 2 & 0 & 2 \\ 2214 & 95 & 3522 \\ 1.2 & 0 & 26 \\ 0 & 0 & 4 \\ 0 & 0 & 1092 \\ 448 & 0 & 2\end{array}$

$\begin{array}{rr}0 & 57 \\ 0 & 0 \\ 0 & 7 \\ 93 & 14 \\ 0 & 1 \\ 0 & 2 \\ 0 & 0 \\ 0 & 0 \\ 0 & 3 \\ 232 & 200 \\ 0 & 0 \\ 2 & 11 \\ 0 & 1500 \\ 0 & 0\end{array}$

162
0
13
0
0
0
0
2
0
375
0
0
0
0

$\begin{array}{rrr}23 & 96 & 4311 \\ 0 & 0 & 0 \\ 0 & 0 & 159 \\ 27 & 0 & 220 \\ 0 & 0 & 0 \\ 0 & 0 & 31 \\ 1 & 0 & 2 \\ 6 & 0 & 313 \\ 3 & 0 & 2 \\ 814 & 20 & 2693 \\ 0 & 0 & 5.34 \\ 0 & 0 & 1 \\ 0 & 0 & 18405 \\ 0 & 0 & 44\end{array}$

7102

143

194

362

29

425

788

1142

12

13365

80.6

18

20997

494

Source: Adapted from PLAN International Program Output Chart financial year 1996, appendix to Quarterly Report to the International Board first quarter 1997.

The table above is part of a report published by PLAN International, an international aid organisation. It gives some information about PLAN's work in one of its regions of operation (Eastern and Southern Africa). Refer to the table to answer the following questions. 


\section{Question 20: PLAN INTERNATIONAL (R099Q04A)}

What does the table indicate about the level of PLAN International's activity in Ethiopia in 1996, compared with other countries in the region?

A The level of activity was comparatively high in Ethiopia.

(B) The level of activity was comparatively low in Ethiopia.

C It was about the same as in other countries in the region.

D It was comparatively high in the Habitat category, and low in the other categories.

Answer B - the level of activity was comparatively low in Ethiopia.

Note: This question is for information only and will not contribute independently to the student's score. The answer is taken into account in assessing the answer to Question 21.

\section{Question 21: PLAN INTERNATIONAL (R099QO4B)}

Reading task: Reflection and evaluation

Text format: Non-continuous

Situation: Public

In 1996 Ethiopia was one of the poorest countries in the world.

Taking this fact and the information in the table into account, what do you think might explain the level of PLAN International's activities in Ethiopia compared with its activities in other countries?

\section{Scoring - Question 21}

Score 2: Student has answered Question 20 correctly (Answer B). Answers which explain the level of PLAN's activity by drawing on ALL the information supplied, with explicit or implicit reference to the type of activity conducted in Ethiopia by PLAN. Answer must also be consistent with (though does not need to refer to) BOTH of the following:

(1) PLAN's low level of activity in Ethiopia (information supplied in the table); AND

(2) Ethiopia's poverty (information given in the stem). For example:

- Aid organisations often start their work in a country by training local people so I would say PLAN had just started working in Ethiopia in 1996.

- Training community workers might be the only kind of aid they can give there. There might not be the hospitals or schools in which they could base the other kinds of aid work.

- Other foreign aid groups might be helping with medicine etc. and PLAN sees they need to know how to run the country. [Implicitly refers to training community leaders.]

Score 1: Student has answered Question 20 correctly (Answer B). Answers which explain the level of PLAN's work by drawing on MOST of the information supplied. Answer must be consistent with (though does not need to refer to) BOTH of the following: 
(1) PLAN's low level of activity in Ethiopia (information supplied in the table); AND

(2) Ethiopia's poverty (information given in the stem). For example:

- It might be hard to distribute aid there because things are in such a mess.

- There may be a war on so it would be hard to give aid.

- They don't know how to help there.

- If other organisations are helping in Ethiopia, there is less for PLAN to do.

- I could imagine that the other countries received help first and that Ethiopia will be helped in the near future.

- The people of Ethiopia may have a certain culture which makes it difficult to interact with foreigners.

- I think they are giving a bit too much help in other countries and Ethiopia is missing out. PLAN International might not have enough funding and money for all the countries in need.

Score 0: Student has answered Question 20 incorrectly (not Answer B).

OR: $\quad$ Student has answered Question 20 correctly (Answer B) but the answer does not take into account the information supplied about Ethiopia's relative poverty. For example:

- Ethiopia does not need PLAN's help as much as the other countries. [Draws on information in the table but does not take into account the information about Ethiopia's relative poverty supplied in the stem.]

- Ethiopia is not as poor as the other countries so it doesn't need PLAN's help as much. [Draws on information in the table but is inconsistent with information about Ethiopia's relative poverty supplied in the stem.]

- Ethiopia might only need more help with their community leaders than other countries. [Draws in detail on information in the table but does not take into account the information about Ethiopia's relative poverty supplied in the stem.]

OR: $\quad$ Student has answered Question 20 correctly (Answer B) but gives an insufficient or vague or inaccurate answer. For example:

- They don't do as much work in Ethiopia. [Restates information in Answer B in question 20 without attempting to explain it.]

- PLAN hardly does anything in Ethiopia.

- PLAN gives the same amount to every country. [Contradicts information in Answer B in question 20.]

OR: $\quad$ Student has answered Question 20 correctly (Answer B) but gives an implausible or irrelevant answer. For example:

- They should be giving more to Ethiopia. [Expresses an opinion rather than suggesting an explanation.]

- They are only training community workers. They don't seem to be doing anything for the health or learning of the people there. [Does not explain the level of activity.] 


\section{\begin{tabular}{|l|}
\hline \\
A murder has been \\
committed but the \\
suspect denies \\
everything. He claims \\
not to know the \\
victim. He says he \\
never knew him, \\
never went near him, \\
never touched him... \\
The police and the \\
judge are convinced \\
that he is not telling \\
the truth. But how \\
to prove it?
\end{tabular}}

At the crime scene, investigators have gathered every possible shred of evidence imaginable: fibres from fabrics, hairs, finger marks, cigarette ends... The few hairs found on the victim's jacket are red. And they look strangely like the suspect's. If it could be proved that these hairs are indeed his, this would be evidence that he had in fact met the victim.

\section{Every individual is unique} Specialists set to work. They examine some cells at the root

\section{Scientific Police Weapons}

of these hairs and some of the suspect's blood cells. In the nucleus of each cell in our bodies there is DNA. What is it? DNA is like a necklace made of two twisted strings of pearls. Imagine that these pearls come in four different colours and that thousands of coloured pearls (which make up a gene) are strung in a very specific order. In each individual this order is exactly the same in all the cells in the body: those of the hair roots as well as those of the big toe, those of the liver and those of the stomach or blood. But the order of the pearls varies from one person to another. Given the number of pearls strung in this way, there is very little chance of two people having the same DNA, with the exception of identical twins. Unique to each individual, DNA is thus a sort of genetic identity card.

Geneticists are therefore able to compare the suspect's genetic identity card (determined from his blood) with that of the person with the red hair. If the genetic card is the same, they will know that the suspect did in fact go near the victim he said he'd never met.

Just one piece of evidence

More and more often in cases of sexual assault, murder, theft or other crimes, the police are having genetic analyses done. Why? To try to find evidence of contact between two people, two objects or a person and an object. Proving such contact is often very useful to the investigation. But it does not necessarily provide proof of a crime. It is just one piece of evidence amongst many others.

Anne Versailles

\section{We are made up of billions of cells}

Every living thing is made up of lots of cells. A cell is very small indeed. It can also be said to be microscopic because it can only be seen using a microscope which magnifies it many times. Each cell has an outer membrane and a nucleus in which the DNA is found.

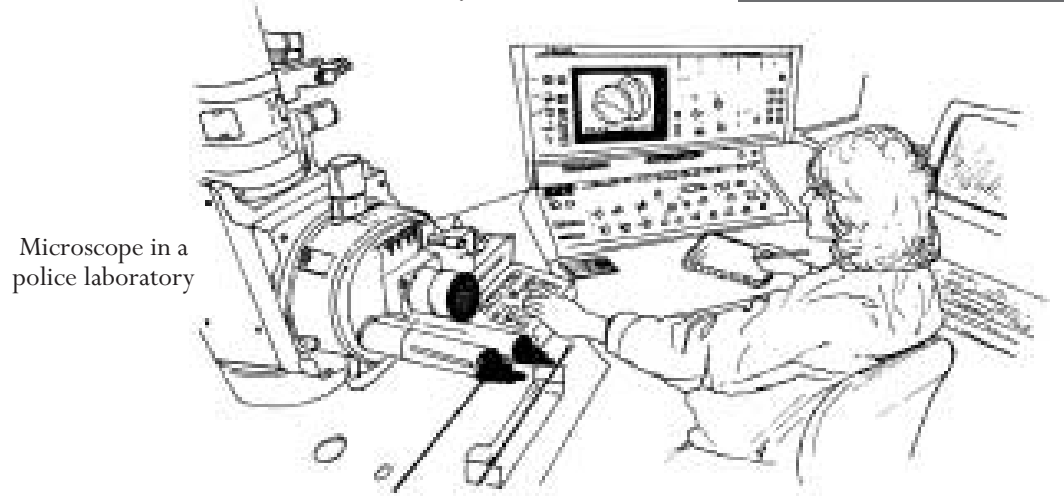

\section{Genetic what?}

DNA is made up of a number of genes, each consisting of thousands of "pearls". Together these genes form the genetic identity card of a person.

\section{How is the genetic identity card revealed?}

The geneticist takes the few cells from the base of the hairs found on the victim, or from the saliva left on a cigarette end. He puts them into a product which destroys everything around the DNA of the cells. He then does the same thing with some cells from the suspect's blood. The DNA is then specially prepared for analysis. After this, it is placed in a special gel and an electric current is passed through the gel. After a few hours, this produces stripes similar to a bar code (like the ones on things we buy) which are visible under a special lamp. The bar code of the suspect's DNA is then compared with that of the hairs found on the victim.

Source: Le Ligueur, 27 may 1998.

Refer to the magazine article above to answer the following questions. 


\section{Question 22: POLICE (R100Q04)}

Reading task: Retrieving information Text format: Continuous Situation: Educational

To explain the structure of DNA, the author talks about a pearl necklace. How do these pearl necklaces vary from one individual to another?

A They vary in length.

(B) The order of the pearls is different.

C The number of necklaces is different.

D The colour of the pearls is different.

\section{Scoring - Question 22}

Score 1: Answer B - the order of the pearls is different.

Score 0: Other answers.

\section{Question 23: POLICE (R100Q05)}

Reading task: Interpreting texts

Text format: Continuous

Situation: Educational

What is the purpose of the box headed "How is the genetic identity card revealed"?

To explain

A what DNA is.

B what a bar code is.

(C) how cells are analysed to find the pattern of DNA.

D how it can be proved that a crime has been committed.

\section{Scoring - Question 23}

Score 1: Answer C - how cells are analysed to find the pattern of DNA.

Score 0: Other answers.

\section{Question 24: POLICE (R100Q06)}

Reading task: Interpreting texts Text format: Continuous

Situation: Educational

What is the author's main aim?
A To warn.
B To amuse.
(C) To inform.
D To convince. 


\section{Scoring - Question 24}

Score 1: Answer C - To inform.

Score 0: Other answers.

Question 25: POLICE (R100QO7)

Reading task: Interpreting texts

Text format: Continuous

Situation: Educational

The end of the introduction (the first shaded section) says: "But how to prove it?"

According to the passage, investigators try to find an answer to this question by

A interrogating witnesses.

(B) carrying out genetic analyses.

$C$ interrogating the suspect thoroughly.

D going over all the results of the investigation again.

\section{Scoring - Question 25}

Score 1: Answer B - carrying out genetic analyses.

Score 0: Other answers. 


\section{READING UNIT 7 \\ RUNNERS}

\section{Feel good in your runners}

For 14 years the Sports Medicine Centre of Lyon (France) has been studying the injuries of young sports players and sports professionals. The study has established that the best course is prevention ... and good shoes.

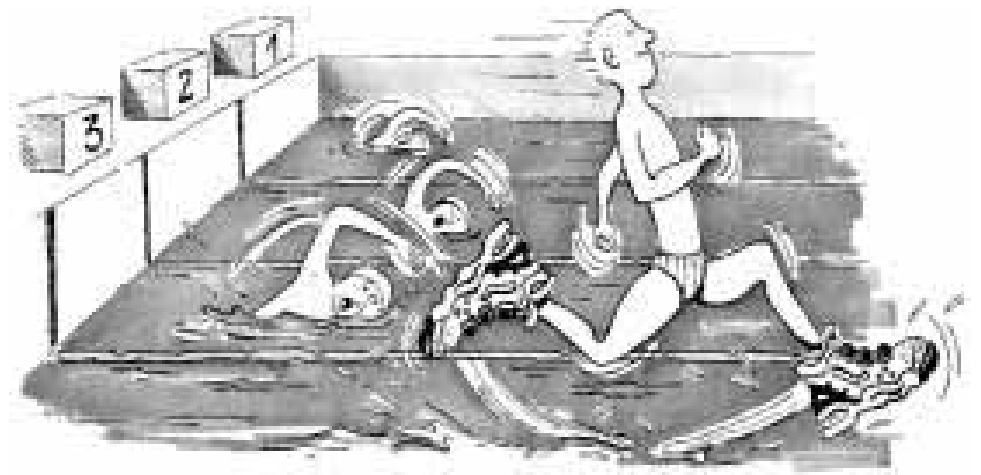

Knocks, falls, wear and tear...

Eighteen per cent of sports players aged 8 to 12 already have heel injuries. The cartilage of a footballer's ankle does not respond well to shocks, and 25\% of professionals have discovered for themselves that it is an especially weak point. The cartilage of the delicate knee joint can also be irreparably damaged and if care is not taken right from childhood (10-12 years of age), this can cause premature osteoarthritis. The hip does not escape damage either and, particularly when tired, players run the risk of fractures as a result of falls or collisions.

According to the study, footballers who have been playing for more than ten years have bony outgrowths either on the tibia or on the heel. This is what is known as "footballer's foot", a deformity caused by shoes with soles and ankle parts that are too flexible.

\section{Protect, support, stabilise, absorb}

If a shoe is too rigid, it restricts movement. If it is too flexible, it increases the risk of injuries and sprains. A good sports shoe should meet four criteria:

Firstly, it must provide exterior protection: resisting knocks from the ball or another player, coping with unevenness in the ground, and keeping the foot warm and dry even when it is freezing cold and raining.

It must support the foot, and in particular the ankle joint, to avoid sprains, swelling and other problems, which may even affect the knee.

It must also provide players with good stability so that they do not slip on a wet ground or skid on a surface that is too dry.

Finally, it must absorb shocks, especially those suffered by volleyball and basketball players who are constantly jumping.

\section{Dry feet}

To avoid minor but painful conditions such as blisters or even splits or athlete's foot (fungal infections), the shoe must allow evaporation of perspiration and must prevent outside dampness from getting in. The ideal material for this is leather, which can be water-proofed to prevent the shoe from getting soaked the first time it rains. 
Use the article on the opposite page to answer the questions below.

Question 26: RUNNERS (R110Q01)

Reading task: Interpreting texts

Text format: Continuous

Situation: Educational

What does the author intend to show in this text?

A That the quality of many sports shoes has greatly improved.

B That it is best not to play football if you are under 12 years of age.

C That young people are suffering more and more injuries due to their poor physical condition.

(D) That it is very important for young sports players to wear good sports shoes.

\section{Scoring - Question 26}

Score 1: Answer D - that it is very important for young sports players to wear good sports shoes.

Score 0: Other answers.

\section{Question 27: RUNNERS (R110Q04)}

Reading task: Retrieving information

Text format: Continuous

Situation: Educational

According to the article, why should sports shoes not be too rigid?

\section{Scoring - Question 27}

Score 1: Answers which refer to restriction of movement. For example:

- They restrict movement.

- They prevent you from running easily.

Score 0: Answers which show inaccurate comprehension of the material or are implausible or irrelevant. For example:

- To avoid injuries.

- They can't support the foot.

- Because you need to support the foot and ankle.

OR: Answers which are insufficient or vague. For example:

- Otherwise they are not suitable.

\section{Question 28: RUNNERS (R110Q05)}

Reading task: Retrieving information

Text format: Continuous

Situation: Educational

One part of the article says, "A good sports shoe should meet four criteria."

What are these criteria? 


\section{Scoring - Question 28}

Score 1: Answers which refer to the four criteria in italics in the text. Each reference may be a direct quotation, a paraphrase or an elaboration of the criterion. Criteria may be given in any order. The four criteria are:

(1) To provide exterior protection

(2) To support the foot

(3) To provide good stability

(4) To absorb shocks.

For example:

- Exterior protection. (1)

Support of the foot. (2)

Good stability. (3)

Shock absorption. (4)

- It must provide exterior protection, support the foot, provide the player with good stability and must absorb shocks.

- Protect, support, stabilise, absorb. [Quotes sub-heading of this section of text.]

Score 0: Other answers. For example:

- Protect against knocks from the ball or feet.

Cope with unevenness in the ground.

Keep the foot warm and dry.

Support the foot.

[First three points in this answer are all part of criterion (1) (provide exterior protection).]

\section{Question 29: RUNNERS (R110Q06)}

Reading task: Reflection and evaluation

Text format: Continuous

Situation: Educational

Look at this sentence from near the end of the article. It is presented here in two parts:

"To avoid minor but painful conditions such as blisters or even splits or athlete's foot (fungal infections),..." (first part)

"...the shoe must allow evaporation of perspiration and must prevent outside dampness from getting in." (second part)

What is the relationship between the first and second parts of the sentence? 
The second part

A contradicts the first part.

$B$ repeats the first part.

B ilustrates the problem described in the first part.

C illustrates the problem described in the first part.

(D) gives the solution to the problem described in the first part.

Scoring - Question 29

Score 1: Answer D - gives the solution to the problem described in the first part. Score 0: Other answers. 


\section{READING UNIT 8 \\ The gift}

How many days, she wondered, had she sat like this, watching the cold brown water inch up the dissolving bluff. She could just faintly remember the beginning of the rain, driving in across the swamp from the south and beating against the shell of her house. Then the river itself started rising, slowly at first until at last it paused to turn back. From hour to hour it slithered up creeks and ditches and poured

5 over low places. In the night, while she slept, it claimed the road and surrounded her so that she sat alone, her boat gone, the house like a piece of drift lodged on its bluff. Now even against the tarred planks of the supports the waters touched. And still they rose.

As far as she could see, to the treetops where the opposite banks had been, the swamp was an empty sea, awash with sheets of rain, the river lost somewhere in its vastness. Her house with its boat bottom had been built to ride just such a flood, if one ever came, but now it was old. Maybe the boards underneath were partly rotted away. Maybe the cable mooring the house to the great live oak would snap loose and let her go turning downstream, the way her boat had gone.

No one could come now. She could cry out but it would be no use, no one would hear. Down the length and breadth of the swamp others were fighting to save what little they could, maybe even their lives.

15 She had seen a whole house go floating by, so quiet she was reminded of sitting at a funeral. She thought when she saw it she knew whose house it was. It had been bad seeing it drift by, but the owners must have escaped to higher ground. Later, with the rain and darkness pressing in, she had heard a panther scream upriver.

Now the house seemed to shudder around her like something alive. She reached out to catch a lamp as

20 it tilted off the table by her bed and put it between her feet to hold it steady. Then creaking and groaning with effort the house struggled up from the clay, floated free, bobbing like a cork and swung out slowly with the pull of the river. She gripped the edge of the bed. Swaying from side to side, the house moved to the length of its mooring. There was a jolt and a complaining of old timbers and then a pause. Slowly the current released it and let it swing back, rasping across its resting place. She caught her breath and sat for a long time feeling the slow pendulous sweeps. The dark sifted down through the incessant rain, and, head on arm, she slept holding on to the bed.

Sometime in the night the cry awoke her, a sound so anguished she was on her feet before she was awake. In the dark she stumbled against the bed. It came from out there, from the river. She could hear something moving, something large that made a dredging, sweeping sound. It could be another house.

30 Then it hit, not head on but glancing and sliding down the length of her house. It was a tree. She listened as the branches and leaves cleared themselves and went on downstream, leaving only the rain and the lappings of the flood, sounds so constant now that they seemed a part of the silence. Huddled on the bed, she was almost asleep again when another cry sounded, this time so close it could have been in the room. Staring into the dark, she eased back on the bed until her hand caught the cold shape of the rifle. Then crouched on the pillow, she cradled the gun across her knees. "Who's there?" she called.

The answer was a repeated cry, but less shrill, tired sounding, then the empty silence closing in. She drew back against the bed. Whatever was there she could hear it moving about on the porch. Planks creaked and she could distinguish the sounds of objects being knocked over. There was a scratching on 
the wall as if it would tear its way in. She knew now what it was, a big cat, deposited by the uprooted

tree that had passed her. It had come with the flood, a gift.

Unconsciously she pressed her hand against her face and along her tightened throat. The rifle rocked across her knees. She had never seen a panther in her life. She had heard about them from others and heard their cries, like suffering, in the distance. The cat was scratching on the wall again, rattling the window by the door. As long as she guarded the window and kept the cat hemmed in by the wall and water, caged, she would be all right. Outside, the animal paused to rake his claws across the rusted outer screen. Now and then, it whined and growled.

When the light filtered down through the rain at last, coming like another kind of dark, she was still sitting on the bed, stiff and cold. Her arms, used to rowing on the river, ached from the stillness of holding the rifle. She had hardly allowed herself to move for fear any sound might give strength to the cat. Rigid, 50 she swayed with the movement of the house. The rain still fell as if it would never stop. Through the grey light, finally, she could see the rain-pitted flood and far away the cloudy shape of drowned treetops. The cat was not moving now. Maybe he had gone away. Laying the gun aside she slipped off the bed and moved without a sound to the window. It was still there, crouched at the edge of the porch, staring up at the live oak, the mooring of her house, as if gauging its chances of leaping to an overhanging branch. It did not seem so frightening now that she could see it, its coarse fur napped into twigs, its sides pinched and ribs showing. It would be easy to shoot it where it sat, its long tail whipping back and forth. She was moving back to get the gun when it turned around. With no warning, no crouch or tensing of muscles, it sprang at the window, shattering a pane of glass. She fell back, stifling a scream, and taking up the rifle, she fired through the window. She could not see the panther now, but she had missed. It began to pace again. She could glimpse its head and the arch of its back as it passed the window.

Shivering, she pulled back on the bed and lay down. The lulling constant sound of the river and the rain, the penetrating chill, drained away her purpose. She watched the window and kept the gun ready. After waiting a long while she moved again to look. The panther had fallen asleep, its head on its paws, like a housecat. For the first time since the rains began she wanted to cry, for herself, for all the people, for 65 everything in the flood. Sliding down on the bed, she pulled the quilt around her shoulders. She should have got out when she could, while the roads were still open or before her boat was washed away. As she rocked back and forth with the sway of the house a deep ache in her stomach reminded her she hadn't eaten. She couldn't remember for how long. Like the cat, she was starving. Easing into the kitchen, she made a fire with the few remaining sticks of wood. If the flood lasted she would have to burn the chair, 70 maybe even the table itself. Taking down the remains of a smoked ham from the ceiling, she cut thick slices of the brownish red meat and placed them in a skillet. The smell of the frying meat made her dizzy. There were stale biscuits from the last time she had cooked and she could make some coffee. There was plenty of water.

While she was cooking her food, she almost forgot about the cat until it whined. It was hungry too. "Let 75 me eat," she called to it, "and then I'll see to you." And she laughed under her breath. As she hung the rest of the ham back on its nail the cat growled a deep throaty rumble that made her hand shake.

After she had eaten, she went to the bed again and took up the rifle. The house had risen so high now it no longer scraped across the bluff when it swung back from the river. The food had warmed her. She could get rid of the cat while light still hung in the rain. She crept slowly to the window. It was still there, mewling, beginning to move about the porch. She stared at it a long time, unafraid. Then 
without thinking what she was doing, she laid the gun aside and started around the edge of the bed to the kitchen. Behind her the cat was moving, fretting. She took down what was left of the ham and making her way back across the swaying floor to the window she shoved it through the broken pane. On the other side there was a hungry snarl and something like a shock passed from the animal to her. Stunned 85 by what she had done, she drew back to the bed. She could hear the sounds of the panther tearing at the meat. The house rocked around her.

The next time she awoke she knew at once that everything had changed. The rain had stopped. She felt for the movement of the house but it no longer swayed on the flood. Drawing her door open, she saw through the torn screen a different world. The house was resting on the bluff where it always had. A few 90 feet down, the river still raced on in a torrent, but it no longer covered the few feet between the house and the live oak. And the cat was gone. Leading from the porch to the live oak and doubtless on into the swamp were tracks, indistinct and already disappearing into the soft mud. And there on the porch, gnawed to whiteness, was what was left of the ham.

Source: Louis Dollarhide, “The Gift” in MississippiWriters: Reflections of Childhood andYouth, Volume I, edited by Dorothy Abbott, University Press of Mississippi, 1985.

Use the story "The Gift" on the previous pages to answer the questions which follow. (Note that line numbers are given in the margin of the story to help you find parts which are referred to in the questions.)

\section{Question 30: GIFT (R119009)}

Reading task: Reflection and evaluation

Text format: Continuous

Situation: Personal

Here is part of a conversation between two people who read "The Gift":

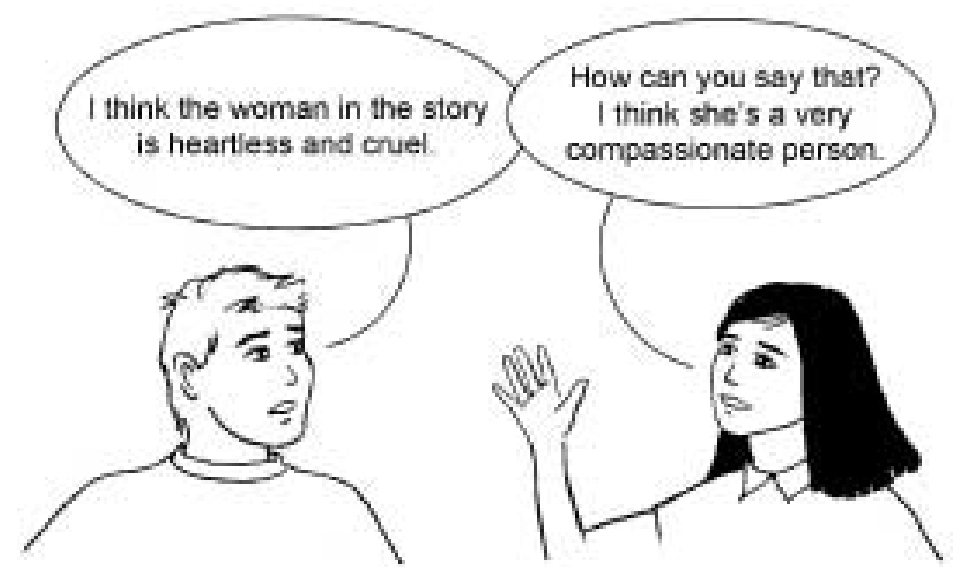

Give evidence from the story to show how each of these speakers could justify their points of view.

Speaker 1

Speaker 2 


\section{Scoring - Question 30}

Score 2: Answers which received score 1 for Speaker 1 AND score 1 for Speaker 2.

Speaker 1 - "heartless and cruel”

Score 1: Answers which provide evidence from the story to support the idea that the woman is heartless and cruel. They may refer to her intention to shoot the panther, or to the fact that she actually shoots at the panther. They may also use quotation or close paraphrase. For example:

- She tries to shoot the panther.

- She's cruel because her first thought is to kill the panther.

- She laughs when she thinks about killing the cat.

- When she was eating she laughed at the cat's whining.

- And taking up the rifle she fired it through the window. [Quotation]

Score 0: Answers which are insufficient or vague. For example:

- She's unkind to the panther.

OR: Answers which show inaccurate comprehension of the material or are implausible or irrelevant. For example:

- She's cruel because she keeps the cat locked outside. [Implausible that she should do otherwise, given the danger the cat represents in the story.]

- He thinks that the woman should show more compassion. [Irrelevant: explains what the boy in the dialogue is saying, rather than referring to the story.]

OR:

\section{Speaker 2 - "compassionate"}

Score 1: Answers which provide evidence from the story to support the idea that the woman is compassionate. They may refer to her action in feeding the panther, or to suggestions about her capacity for compassion towards the panther or more generally. They may also use quotation or close paraphrase. For example:

- She's generous because she shares her food with the cat.

- She gives it ham.

- She took down what was left of the ham and shoved it through the broken pane. [Quotation]

- When she first hears the panther she thinks it sounds sad, not scary. [Evidence of capacity for compassion towards the panther.]

- It says "she wanted to cry, for herself, for all the people, for everything in the flood". [Quoted evidence of more general compassion.]

Score 0: Answers which are insufficient or vague. For example:

- She acts in a compassionate way.

- She is kind.

OR: Answers which show inaccurate comprehension of the material or are implausible or irrelevant. For example:

- She thinks that the woman was a loving person. [Irrelevant: explains what the girl in the dialogue is saying, rather than referring to the story.] 
Question 31: GIFT (R119Q01)

Reading task: Interpreting texts

Text format: Continuous

Situation: Personal

What is the woman's situation at the beginning of the story?

A she is too weak to leave the house after days without food.

$B$ She is defending herself against a wild animal.

(C) Her house has been surrounded by flood waters.

D A flooded river has swept her house away.

\section{Scoring - Question 31}

Score 1: Answer $\mathrm{C}$ - her house has been surrounded by flood waters.

Score 0: Other answers.

\section{Question 32: GIFT (R119Q07)}

Reading task: Interpreting texts

Text format: Continuous

Situation: Personal

Here are some of the early references to the panther in the story.

"the cry awoke her, a sound so anguished..." (line 27)

"The answer was a repeated cry, but less shrill, tired sounding..." (line 36)

"She had... heard their cries, like suffering, in the distance." (lines 42-43)

Considering what happens in the rest of the story, why do you think the writer chooses to introduce the panther with these descriptions?

\section{Scoring - Question 32}

Score 2: Answers which recognise that the descriptions are intended to evoke pity. Reference to the writer's intention or effect on the reader may be stated or implied. Reference to what happens in the rest of the story may also be stated or implied. Answers may suggest that:

(1) the descriptions quoted link the panther with the woman (or humans generally) in suffering; OR

(2) the descriptions quoted prepare for the woman's later compassionate behaviour towards the panther; OR

(3) the panther is presented as an object of compassion.

For example:

- The panther sounds almost like a human, so it is like the woman, and you feel sorry for both of them. [Explicit reference to the link between the panther and the woman/humans. (1) Explicit reference to the effect on the reader.] 
- It makes you realise straight away that the panther is also a victim of the flood. [Implicit reference to the link between the panther and humans in "also" (1). Explicit reference to the effect on the reader.]

- The woman seems to feel sorry for it before she knows what it is. [Links the extracts with the woman's later compassionate behaviour (2), without explicit reference to intention or effect.]

- It makes you feel sorry for the panther. [Implied accurate understanding of the nuances of the descriptions (3). Explicit reference to effect on reader.]

- It sounds sad and distressed. [Implied understanding of nuances of the descriptions (3), with implicit reference to author's intention.]

Score 1: Answers which refer to possible intentions (or effects) of the quoted descriptions, other than that of evoking pity. Comment is consistent with comprehension of the text. Reference to the writer's intention or effect on the reader may be stated or implied. References to what happens in the rest of the story may also be stated or implied. Answers may refer to:

(1) the intention/effect of creating suspense or mystery (Note that such terms as "frightening" and "scary" are considered to show lack of comprehension of the quoted descriptions; and "interesting”, "easy to read" and "clear" are not sufficiently specific); OR

(2) the idea that the panther is presented from the woman's point of view.

For example:

- Because it creates suspense. You don't really know what was crying. (1)

- It introduces the panther slowly. (1)

- It's exciting. (1)

- You don't know what it is, just like the woman. [Combination of (1) and (2).]

- It describes the woman's feelings about the panther. (2)

OR: Answers which refer to the literal information given in the quoted descriptions. Comment is consistent with comprehension of the text. Reference to the writer's intention or effect on the reader may be stated or implied. References to what happens in the rest of the story may also be stated or implied. Answers may refer to:

(1) the realistic depiction of the panther; OR

(2) the way the descriptions fit with the literal setting and situation.

For example:

- The panther is a wild animal and wild animals cry. (1)

- The panther was hungry, and these animals make a noise when they are hungry. (1)

- She would notice the sounds it made because it was dark so she couldn't see it. (2)

- Hearing the panther now makes her remember when she has heard one before. (2)

Score 0: Answers which are insufficient or vague. For example:

- It makes it more interesting.

- It is strong descriptive language.

OR: Answers which show inaccurate comprehension of the material or are implausible or irrelevant. For example:

- The panther sounds vicious as though it is waiting to get her. [Implausible]

- These descriptions present the panther in such a way as to frighten the reader. [Inaccurate]

- She is telling the story from the panther's point of view. [Inaccurate] 
Question 33: GIFT (R119Q06)

Reading task: Retrieving information

Text format: Continuous

Situation: Personal

"Then creaking and groaning with effort the house struggled up..." (lines 20-21)

What happened to the house in this part of the story?

A it fell apart.

(B) It began to float.

C It crashed into the oak tree.

D It sank to the bottom of the river.

\section{Scoring - Question 33}

Score 1: Answer B - it began to float.

Score 0: Other answers.

Question 34: GIFT (R119Q08)

Reading task: Interpreting texts

Text format: Continuous

Situation: Personal

What does the story suggest was the woman's reason for feeding the panther?

\section{Scoring - Question 34}

Score 1: Answers which recognise the implication that the woman is motivated by pity or empathy towards the panther. They may also mention that the woman does not consciously understand her own motivation. For example:

- She felt sorry for it.

- Because she knew what it felt like to be hungry.

- Because she's a compassionate person.

- To help it live.

OR: Answers which recognise that the story does not explicitly explain the woman's motivation and/or that she does not consciously understand it. For example:

- She wasn't thinking what she was doing.

- Out of whim.

- Instinct.

- She didn't know.

- The story doesn't say.

OR: Answers which are in terms of the panther's physical need for food or help, without referring to the woman's motivation. For example: 
- Because it was hungry.

- Because it cried.

Score 0: Answers which are insufficient or vague.

OR: Answers which show inaccurate comprehension of the material or are implausible or irrelevant. They may describe the woman's motivation in terms of self-protection or fear. For example:

- She thought it would go away if she fed it.

- Because she was frightened of it.

- She wanted to make it her pet. [Implausible]

- To make friends with it. [Implausible]

- Because she loved it. [Implausible]

\section{Question 35: GIFT (R119Q04)}

Reading task: Interpreting texts

Text format: Continuous

Situation: Personal

When the woman says, "and then I'll see to you" (line 75) she means that she is

A sure that the cat won't hurt her.

B trying to frighten the cat.

(C) intending to shoot the cat.

D planning to feed the cat.

\section{Scoring - Question 35}

Score 1: Answer C - intending to shoot the cat.

Score 0: Other answers.

\section{Question 36: GIFT (R119Q05)}

Reading task: Reflection and evaluation

Text format: Continuous

Situation: Personal

Do you think that the last sentence of "The gift" is an appropriate ending?

Explain your answer, demonstrating your understanding of how the last sentence relates to the story's

meaning.

\section{Scoring - Question 36}

Score 2: Answers which go beyond a literal interpretation of the story but are consistent with accurate literal comprehension. They should evaluate the ending in terms of thematic completeness, by relating the last sentence to central relationships, issues or metaphors in the story. Answers may refer, for example, to the relationship between the panther and the woman; to survival; or to a gift or thanks. Opinion about appropriateness may be stated or implied. For example: 
- Yes. The story has brought the woman into contact with what is really essential in life, and the clean white bone is a symbol of that.

- Yes. I suppose that what was left of the ham by the panther was also a gift, the message being "live and let live".

- Yes. The bone is like a gift, and that is the theme of the story.

- Yes. The ham bone reminds us of what could have happened to the woman.

- It is appropriate because the animal sort of thanked her for the ham.

OR: Answers which go beyond a literal interpretation of the story but are consistent with accurate literal comprehension. They should evaluate the ending in terms of style or mood, by relating the last sentence to the general style or mood of the rest of the story. Opinion about appropriateness may be stated or implied. For example:

- Yes, it fits the matter-of-fact telling of the story.

- Yes, it continues the effect of something eerie.

- No, it is too abrupt when most of the story is given in great detail.

Score 1: Literal answers, which interpret the story in a way consistent with accurate literal comprehension. They evaluate the ending in terms of narrative sequence, by relating the last sentence to explicit events, (e.g. the cat having eaten the meat; the visit of the panther to the house; the subsiding of the flood). Opinion about appropriateness may be stated or implied. For example:

- Yes it gives you an answer to the question whether the cat ate the food.

- No. The part about the meat was already finished.

- It is finished because the meat is finished and so is the story.

- Yes. Now that the flood has subsided and it has eaten the meat, there is no reason for the cat to stay.

- I think it was a good ending because it proves that she had a panther on her porch. [Understanding at a literal level that the events in the story "really happened".]

- No, it is not a suitable end, it was not a gift, but it was very dangerous. [Indicates a wholly literal reading.]

- It is appropriate to describe that it was after the rain. [Reference to the end of the flood.]

Score 0: Answers which are insufficient or vague. For example:

- It is more than effective. It is really striking.

- No, the gift does not relate to the end.

- No. It would be better to finish with something more exciting. [Does not relate the ending to the rest of the story.]

- It ends by describing the bone.

OR: Answers which show inaccurate comprehension of the material or are implausible or irrelevant. For example:

- Yes, it showed that it was all just a dream. [Implausible]

- No, because the reader does not know why the cat has vanished. [Indicates lack of comprehension.] 


\section{READING UNIT 9}

\section{AMANDA ANDTHE DUCHESS}

Summary: Since Léocadia's death, the Prince, who was in love with her, has been inconsolable. At a shop called Réséda Soeurs, the Duchess, who is the Prince's aunt, has met a young shop assistant, Amanda, who looks amazingly like Léocadia. The Duchess wants Amanda to help her set the Prince free from the memories which haunt him.

A crossroads in the castle grounds, a circular bench around a small obelisk... evening is falling...

\section{AMANDA}

I still don't understand. What can I do for him, ma'am? I can't believe you could possibly have thought... And why me? I'm not particularly pretty. And even if someone were very pretty who could suddenly come between him and his memories like that?

\section{THE DUCHESS}

No-one but you.

$$
\text { AMANDA, sincerely surprised }
$$

$\mathrm{Me}$ ?

\section{THE DUCHESS}

The world is so foolish, my child. It sees only parades, gestures, badges of office... that must be why you have never been told. But my heart hasn't deceived me - I almost cried out at Réséda Soeurs the first time I saw you. To someone who knew more of her than just her public image, you are the living likeness of Léocadia.

A silence. The evening birds have now taken over from the afternoon birds. The grounds are filled with shadows and twittering.

$$
\text { AMANDA, very gently }
$$

I really don't think I can, ma' am. I have nothing, I am nothing, and those lovers... that was my fancy, don't you see?
She has got up. As if about to leave, she has picked up her small suitcase.

THE DUCHESS, gently also, and very wearily

Of course, my dear. I apologise.

She in turn gets up, with difficulty, like an old woman. $A$ bicycle bell is heard in the evening air; she gives a start.

Listen...it's him! Just show yourself to him, leaning against this little obelisk where he first met her. Let him see you, even if it's just this once, let him call out, take a sudden interest in this likeness, in this stratagem which I shall confess to him tomorrow and for which he will hate me - in anything but this dead girl who'll take him away from me one of these days, I'm sure... (She has taken her by the arm.) You will do that, won't you? I beg you most humbly, young lady. (She looks at her, beseechingly, and quickly adds:) And then, that way, you'll see him too. And... I can feel that I'm blushing again from saying this to you - life is just too mad! That's the third time I've blushed in sixty years, and the second time in ten minutes - you'll see him; and if he could ever (why not him, since he's handsome and charming and he wouldn't be the first?) if he could ever have the good fortune, for himself and for me, to take your fancy for one moment... The bell again in the shadows, but very close now.

$$
\text { AMANDA, in a whisper }
$$

What should I say to him? 
THE DUCHESS, gripping her arm

Simply say: "Excuse me, Sir, can you tell me the way to the sea?"

She has hurried into the deeper shadows of the trees. Just in time. There is a pale blur. It is the Prince on his bicycle. He passes very close to the pale blur of Amanda by the obelisk. She murmurs.

\section{AMANDA}

Excuse me, Sir...

He stops, dismounts from the bicycle, takes off his hat and looks at her.

\section{THE PRINCE}

Yes?

\section{AMANDA}

Can you tell me the way to the sea?

\section{THE PRINCE}

Take the second turning on your left.

He bows, sadly and courteously, gets back on the bicy-

THE CURTAIN FALLS much an old woman.

He didn't recognise me...

\section{THE DUCHESS} tonight? Yes, ma'am. in the huge trees of the grounds. cle and rides away. The bell is heard again in the

distance. The Duchess comes out of the shadows, very

$$
\text { AMANDA, gently, after a while }
$$

It was dark... And then, who knows what face he gives her now, in his dreams? (She asks timidly:) The last train has gone, young lady. In any case, wouldn't you like to stay at the castle

\section{AMANDA, in a strange voice}

It is completely dark. The two of them can no longer be seen in the shadows, and only the wind can be heard

Source: Jean ANOUILH, Léocadia (end of Scene II). Published by LA TABLE RONDE, 1984.

\section{TEXT 2}

\section{DEFINITIONS OF SOME THEATRICAL OCCUPATIONS}

Actor: plays a character on stage.

Director: controls and oversees all aspects of a play. He not only positions the actors, arranges their entrances and exits and directs their acting, but also suggests how the script is to be interpreted.

Wardrobe staff: produce the costumes from a model.

Set designer: designs models of the sets and costumes. These models are then transformed into their full size in the workshop.

Props manager: in charge of finding the required props. The word "props" is used to mean everything that can be moved: armchairs, letters, lamps, bunches of flowers, etc. The sets and costumes are not props.

Sound technician: in charge of all sound effects required for the production. He is at the controls during the show.

Lighting assistant or lighting technician: in charge of lighting. He is also at the controls during the show. Lighting is so sophisticated that a well-equipped theatre can employ up to ten lighting technicians. 
On the previous two pages there are two texts. Text 1 is an extract from the play Léocadia by Jean Anouilh and Text 2 gives definitions of theatrical occupations. Refer to the texts to answer the questions which follow.

\section{Question 37: AMANDA AND THE DUCHESS (R216Q01)}

Reading task: Interpreting texts

Text format: Continuous

Situation: Personal

What is this extract from the play about?

The Duchess thinks of a trick

A to get the Prince to come and see her more often.

$B$ to get the Prince to make up his mind finally to get married.

(C) to get Amanda to make the Prince forget his grief.

$D$ to get Amanda to come and live at the castle with her.

\section{Scoring - Question 37}

Score 1: Answer C - to get Amanda to make the Prince forget his grief.

Score 0: Other answers.

\section{Question 38: AMANDA AND THE DUCHESS (R216Q02)}

Reading task: Reflection and evaluation

Text format: Continuous

Situation: Personal

In the script of the play, in addition to the words to be spoken by the actors, there are directions for the actors and theatre technicians to follow.

How can these directions be recognised in the script?

\section{Scoring - Question 38}

Score 1: Answers which refer to italics. Allow non-technical descriptions. They may mention parentheses as well as italics. For example:

- (They are in) italics.

- Slanting writing.

- Like this: [Imitates italic style.]

- Handwriting.

- Writing in italics and also the use of brackets.

- They are in a skinny type of writing.

Score 0: Answers which are insufficient or vague. For example:

- Stage directions are in brackets. [Reference to brackets is correct for some stage directions, but the answer does not refer to italics.] 
Text format: Non-continuous

Situation: Personal

The table below lists theatre technicians involved in staging this extract from Léocadia. Complete the table by indicating one stage direction from TEXT 1 which would require the involvement of each technician.

The first one has been done for you.

\begin{tabular}{l|l} 
Theatre technicians & Stage direction \\
Set designer & A circular bench around a small obelisk \\
\hline Props manager & \\
\hline Sound technician & \\
\hline Lighting technician & \\
\hline
\end{tabular}

\section{Scoring - Question 39}

Score 1: (Props manager) Answers which indicate suitcase OR bicycle. They may quote a phrase from the stage directions. For example:

- Her small suitcase.

- Bicycle.

AND: (Sound technician) Answers which indicate bird song OR (evening) birds OR twittering OR bicycle bell OR wind OR silence. They may quote a phrase from the stage directions. For example:

- A bicycle bell is heard in the evening air.

- Only the wind can be heard.

- Evening birds.

- The evening birds have now taken over.

AND: (Lighting technician) Answers which indicate shadows OR pale blur OR [completely] dark OR evening. For example:

- The grounds are filled with shadows.

- The deeper shadows of the trees.

- Evening is falling.

- In the evening air.

Score 0: Other answers. 
Question 40: AMANDA AND THE DUCHESS (R216Q04)

Reading task: Retrieving information

Text format: Continuous

Situation: Personal

The director positions the actors on the stage. On a diagram, the director represents Amanda with the letter A and the Duchess with the letter D.

Put an A and a D on the following diagram of the set to show approximately where Amanda and the Duchess are when the Prince arrives.

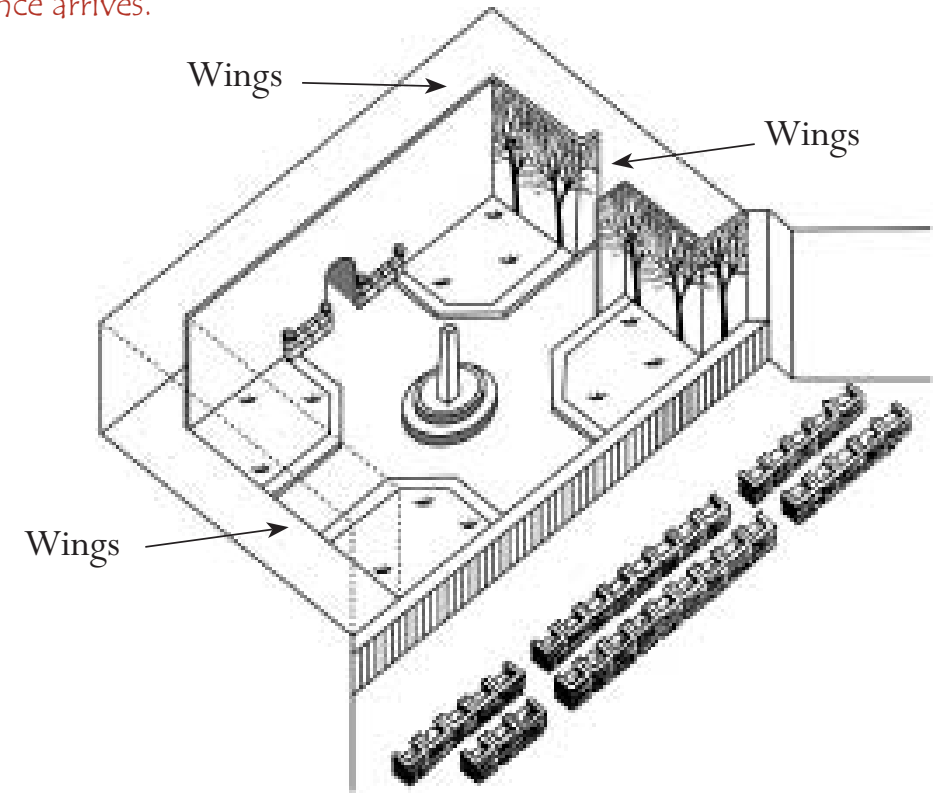

\section{Scoring - Question 40}

Score 1: Answers which mark A by the obelisk and D behind or near the trees. For example:
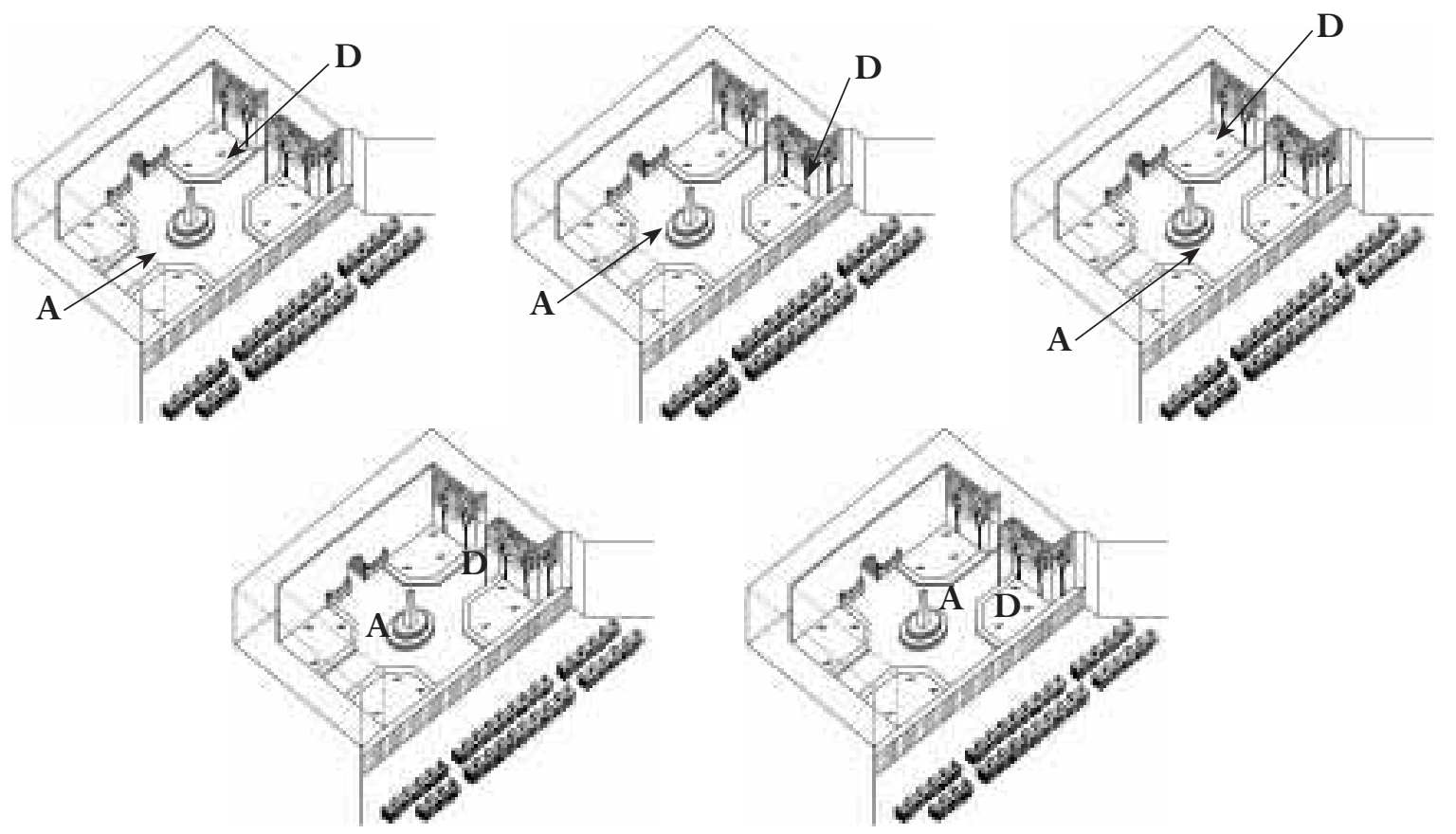
$\mathrm{R}$

Score 0: Other answers. For example:
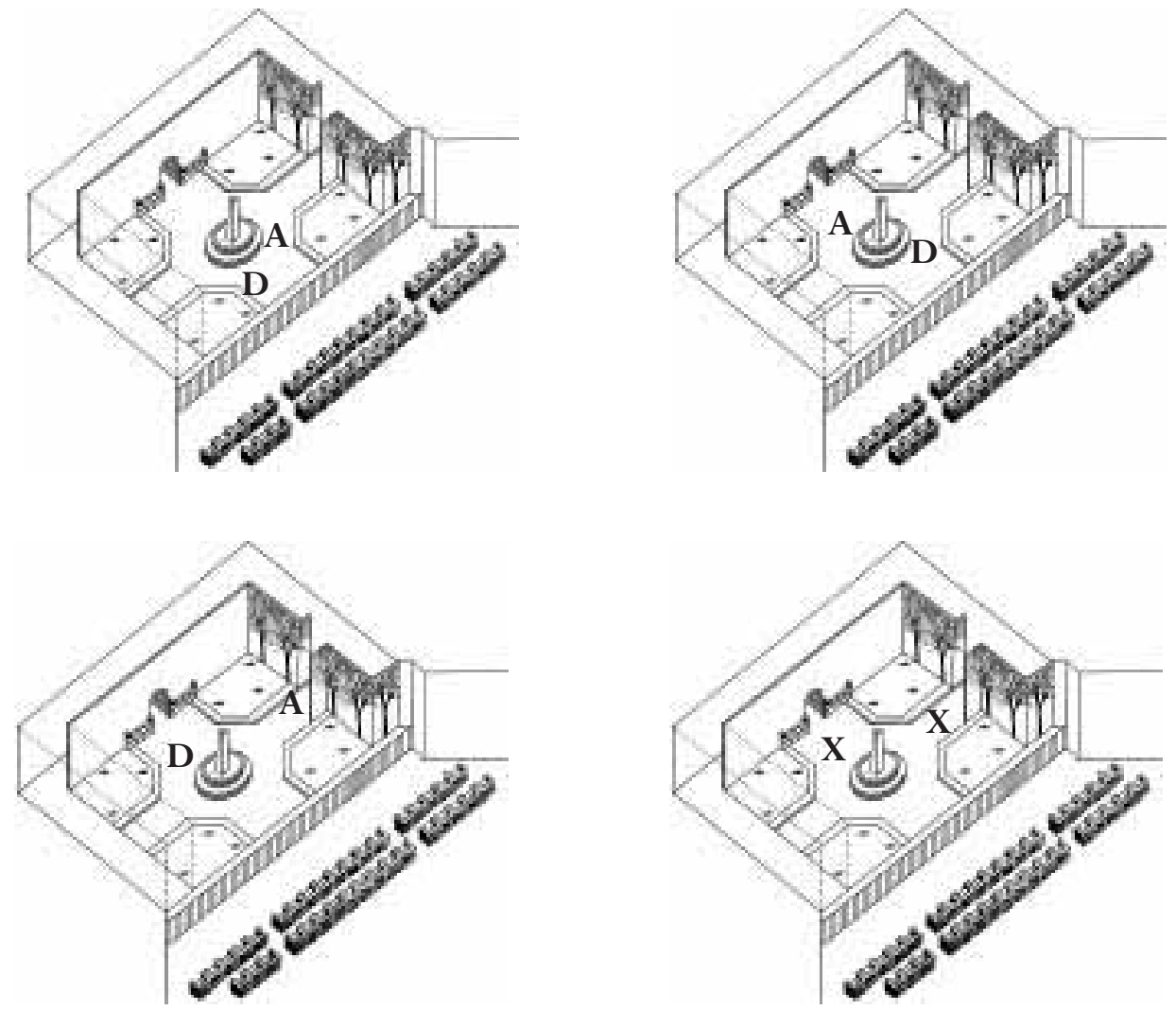

\section{Question 41: AMANDA AND THE DUCHESS (R216QO6)}

Reading task: Interpreting texts

Text format: Continuous

Situation: Personal

Towards the end of the extract from the play, Amanda says, "He didn't recognise me...".

What does she mean by that?

A That the Prince didn't look at Amanda.

B That the Prince didn't realise that Amanda was a shop assistant.

C That the Prince didn't realise that he'd already met Amanda.

(D) That the Prince didn't notice that Amanda looked like Léocadia.

\section{Scoring - Question 41}

Score 1: Answer D - that the Prince didn't notice that Amanda looked like Léocadia. Score 0: Other answers. 


\section{Centre on Internal and External Mobility}

\section{What is CIEM?}

CIEM stands for Centre on Internal and External Mobility, an initiative of the personnel department. A number of workers of this department work in CIEM, together with members from other departments and outside career consultants.

CIEM is available to help employees in their search for another job inside or outside the Canco Manufacturing Company.

\section{What does CIEM do?}

CIEM supports employees who are seriously considering other work through the following activities:

\section{- Job Data Bank}

After an interview with the employee, information is entered into a data bank that tracks job seekers and job openings at Canco and at other manufacturing companies.

\section{- Guidance}

The employee's potential is explored through career counselling discussions.

\section{- Courses}

Courses are being organized (in collaboration with the department for information and training) that will deal with job search and career planning.

\section{- Career Change Projects}

CIEM supports and coordinates projects to help employees prepare for new careers and new perspectives.

\section{- Mediation}

CIEM acts as a mediator for employees who are threatened with dismissal resulting from reorganisation, and assists with finding new positions when necessary.

\section{How much does CIEM cost?}

Payment is determined in consultation with the department where you work. A number of services of CIEM are free. You may also be asked to pay, either in money or in time.

\section{How does CIEM work?}

CIEM assists employees who are seriously considering another job within or outside the company.

That process begins by submitting an application. A discussion with a personnel counsellor can also be useful. It is obvious that you should talk with the counsellor first about your wishes and the internal possibilities regarding your career. The counsellor is familiar with your abilities and with developments within your unit.

Contact with CIEM in any case is made via the personnel counsellor. He or she handles the application for you, after which you are invited to a discussion with a CIEM representative.

\section{For more information}

The personnel department can give you more information. 
Use the announcement from a personnel department on the previous page to answer the questions below.

\section{Question 42: PERSONNEL (R234Q01)}

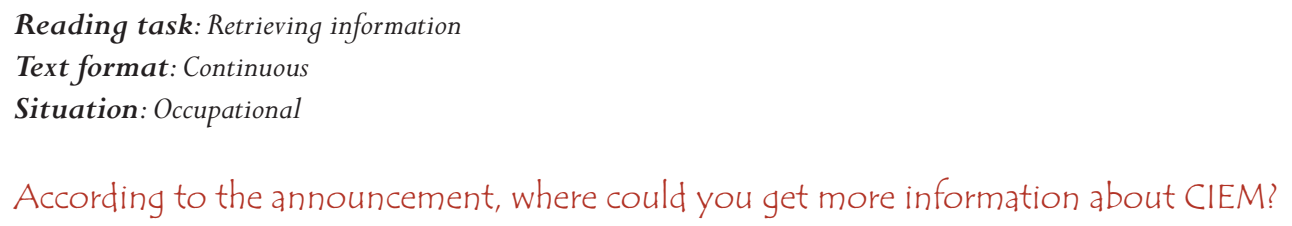

\section{Scoring - Question 42}

Score 1: Answers which mention at least ONE of the following:

(1) From the personnel department.

(2) From the personnel counsellor.

For example:

- Personnel department.

- The personnel counsellor can give you more information.

Score 0: Other answers. For example:

- CANCO Manufacturing Company.

\section{Question 43: PERSONNEL (R234Q02)}

Reading task: Retrieving information

Text format: Continuous

Situation: Occupational

List two ways in which CIEM helps people who will lose their jobs because of a departmental reorganisation.

\section{Scoring - Question 43}

Score 1: Answers which mention BOTH of the following:

(1) They act as a mediator for employees OR mediation.

(2) They assist with finding new positions. [Don't accept: "Job Data Bank”, “Guidance”, “Courses”, or "Career Change Projects".]

For example:

- Mediator.

Assists with finding new positions when necessary.

- Acts as a mediator.

Helps you to find a new job.

Score 0: Other answers. For example:

(a) Mediation, (b) Career change projects.

- Career change projects.

Courses. 
- Track/job seekers/job openings.

Mediation.

- Application or discussion with personnel counsellor. 
EDITORIAL

\section{Technology creates the need for new rules}

SCIENCE has a way of getting ahead of law and ethics. That happened dramatically in 1945 on the destructive side of life with the atomic bomb, and is now happening on life's creative side with techniques to overcome human infertility.

Most of us rejoiced with the Brown family in England when Louise, the first test-tube baby, was born. And we have marveled at other firsts - most recently the births of healthy babies that had once been embryos frozen to await the proper moment of implantation in the mother-to-be.

It is about two such frozen embryos in Australia that a storm of legal and ethical questions has arisen. The embryos were destined to be implanted in Elsa Rios, wife of Mario Rios. A previous embryo implant had been unsuccessful, and the Rioses wanted to have another chance at becoming parents. But before they had a second chance to try, the Rioses perished in an airplane crash.

What was the Australian hospital to do with the frozen embryos? Could they be implanted in someone else? There were numerous volunteers. Were the embryos somehow entitled to the Rioses' substantial estate? Or should the embryos be destroyed? The Rioses, understandably, had made no provision for the embryos' future.

The Australians set up a commission to study the matter. Last week, the commission made its report. The embryos should be thawed, the panel said, because donation of embryos to someone else would require the consent of the "producers," and no such consent had been given. The panel also held that the embryos in their present state had no life or rights and thus could be destroyed.

The commission members were conscious of treading on slippery legal and ethical grounds. Therefore, they urged that three months be allowed for public opinion to respond to the commission recommendation. Should there be an overwhelming outcry against destroying the embryos, the commission would reconsider.

Couples now enrolling in Sydney's Queen Victoria hospital for in vitro fertilization programs must specify what should be done with the embryos if something happens to them.

This assures that a situation similar to the Rioses won't recur. But what of other complex questions? In France, a woman recently had to go to court to be allowed to bear a child from her deceased husband's frozen sperm. How should such a request be handled? What should be done if a surrogate mother breaks her child-bearing contract and refuses to give up the infant she had promised to bear for someone else?

Our society has failed so far to come up with enforceable rules for curbing the destructive potential of atomic power. We are reaping the nightmarish harvest for that failure. The possibilities of misuse of scientists' ability to advance or retard procreation are manifold. Ethical and legal boundaries need to be set before we stray too far.

Use the newspaper editorial "Technology creates the need for new rules" on this page to answer the following questions. 


\section{Question 44: NEW RULES (R236QO1)}

Reading task: Interpreting texts

Text format: Continuous

Situation: Public

Underline the sentence that explains what the Australians did to help decide how to deal with the frozen embryos belonging to a couple killed in the plane crash.

\section{Scoring - Question 44}

Score 1: Answers which underline OR circle the sentence OR a part of the sentence that contains at least ONE of the following:

(1) "set up a commission”

(2) "three months be allowed for public opinion to respond to the commission recommendation....".

For example:

- [Underlining] ...The Australians set up a commission to study the matter... [Student has underlined one of the relevant sentences.]

- [Underlining] ...The Australians set up a commission to study the matter... and ... they urged that three months be allowed for public opinion to respond to the commission recommendation... [Student has underlined both of the relevant sections of the text.]

- [Underlining] ...The Australians set up a commission to study the matter. ... and ... In France, a woman recently had to go to court to be allowed to bear a child from her deceased husband's frozen sperm... [One section of the text is correctly underlined; the other underlining seems to be related to answering the next question, so accept.]

Score 0: Other answers. For example:

- [Underlining] ... The embryos should be thawed, the panel said, because donation of embryos to someone else would require the consent of the "producers," and no such consent had been given... [Student has underlined an irrelevant section of text.]

- [Underlining] ...The Australians set up a commission to study the matter... and ...The possibilities of misuse of scientists' ability to advance or retard procreation are manifold... [One section of the text is correctly underlined; the other underlining cannot be construed as an answer to the next question, so do not accept.]

\section{Question 45: NEW RULES (R236QO2)}

Reading task: Interpreting texts

Text format: Continuous

Situation: Public

List two examples from the editorial that illustrate how modern technology, such as that used for implanting frozen embryos, creates the need for new rules. 


\section{Scoring - Question 45}

Score 1: Answers which mention at least TWO of the following:

(1) When the Rioses died, there was a controversy over what was to be done with the embryos. [Don't accept the controversies in paragraph 4 (e.g., "What was the hospital to do with the frozen embryos?" "Were the embryos entitled to the estate?") unless the respondent explicitly links these controversies to the death of the embryo donors (the Rioses).]

(2) A woman in France had to go to court to be allowed to use her deceased husband's sperm.

(3) What should the rules be for a surrogate mother who refused to give up the infant she bore? For example:

- It showed a need for the producer to specify what should be done to the embryos if something happens to them, and for laws about what is to be done should a surrogate mother refuse to give up the child.

OR: $\quad$ Answers which mention ONE of the examples given above relating to bio-technology [(1), (2) or (3)] AND (the destructive potential of) atomic power.

Score 0: Other answers. For example:

- They have frozen the sperm and it should be kept frozen until used. [Irrelevant.]

- - are the embryos part of the estate

- could they be implanted in someone else [Unclear which part of the article these refer to. If

both are about the Rios case, the answer does not give TWO examples as instructed. If the French case is referred to in the second point, it is a misinterpretation since the wife is not "someone else".] 
A

$\mathbf{T}$

H

E

M

A

T

I

C

A

L

L

I

T

E

R

A

C

Y 
SAMPLE TASKS FOR THE ASSESSMENT

OF MATHEMATICAL LITERACY

IN PISA 2000

\section{The PISA definition of mathematical literacy and its context}

Mathematical literacy is defined in PISA as:

the capacity to identify, to understand, and to engage in mathematics and make well-founded judgements about the role that mathematics plays, as needed for an individual's current and future private life, occupational life, social life with peers and relatives, and life as a constructive, concerned, and reflective citizen.

Several aspects of this definition have specific meaning in the PISA context. As with reading, the definition revolves around wider uses in people's lives rather than simply carrying out mechanical operations. The term "literacy" is therefore used to indicate the ability to put mathematical knowledge and skill to functional use rather than just to master it within a school curriculum.

In the PISA definition, to "engage in" mathematics covers not simply physical or social actions (such as working out how much change to give someone in a shop) but also wider uses, including communicating, and relating to and appreciating things (such as having an opinion about the government's spending plans).

Mathematical literacy also implies the ability to pose and solve mathematical problems in a variety of contexts, as well as the inclination to do so, which often relies on personal traits such as selfconfidence and curiosity.

\section{Three dimensions of mathematical literacy}

To transform this definition into an assessment of mathematical literacy, three broad dimensions were identified. These are:
- Processes: Questions in PISA are structured around different types of skill needed for mathematics. Such skills are organised into three "competency clusters": the first cluster - reproduction - consists of simple computations or definitions of the type most familiar in conventional assessments of mathematics; the second - connections - requires the bringing together of mathematical ideas and procedures to solve straightforward and somewhat familiar problems; and the third cluster - reflection consists of mathematical thinking, generalisation and insight, and requires students to engage in analysis, to identify the mathematical elements in a situation, and to pose their own problems.

- Content: PISA organises content in relation to phenomena and the kinds of problems for which they were created, emphasising broad mathematical themes such as quantity, space and shape, change and relationships, and uncertainty.

- Context: An important aspect of mathematical literacy is doing and using mathematics in a variety of situations, including personal life, school life, work and leisure, the local community, and society.

\section{Mathematical processes}

PISA tasks are designed to encompass a set of general mathematical processes that are meant to be pertinent at all educational levels:

1. Mathematical thinking and reasoning, which includes:

- posing questions characteristic of mathematics ("Is there...?", "If so, how many?", "How do we find...?");

- knowing the kinds of answers that mathematics offers to such questions;

- distinguishing between different kinds of statements (definitions, theorems, conjectures, hypotheses, examples, conditioned assertions); and 
- understanding and handling the extent and limits of given mathematical concepts.

2. Mathematical argumentation, which includes:

- knowing what mathematical proofs are and how they differ from other kinds of mathematical reasoning;

- following and assessing chains of mathematical arguments of different types;

- possessing a feel for heuristics ("what can(not) happen, and why"); and

- creating mathematical arguments.

3. Mathematical communication, which includes:

- expressing oneself, in a variety of ways, on matters with a mathematical content, in oral as well as in written form; and

- understanding others' written or oral statements about such matters.

4. Modelling, which includes:

- structuring the field or situation to be modelled;

- translating "reality" into mathematical structures;

- interpreting mathematical models in terms of "reality";

- working with a mathematical model;

_ validating the model;

- reflecting, analysing, and offering a critique of a model and its results;

- communicating about the model and its results (including the limitations of such results); and

- monitoring and controlling the modelling process.

5. Problem posing and solving, which includes:

- posing, formulating and defining different kinds of mathematical problems (for example, pure, applied, open-ended and closed); and

- solving different kinds of mathematical problems, in a variety of ways.

6. Representation, which includes:

- decoding and encoding, translating, interpreting and distinguishing between different forms of representation of mathematical objects and situations, and the interrelationships between the various representations; and

- choosing and switching between different forms of representation, according to situation and purpose.

7. Using symbolic, formal and technical language and operations, which includes:

- decoding and interpreting symbolic and formal language, and understanding its relationship to natural language;

- translating from natural language to symbolic/formal language;

- handling statements and expressions containing symbols and formulae; and

- using variables, solving equations and undertaking calculations.

8. Use of aids and tools, which includes:

- knowing about, and being able to make use of, various aids and tools (including information technology tools) that may assist mathematical activity; and

- knowing about the limitations of such aids and tools.

PISA does not use tasks that assess the above competencies individually. When doing "real mathematics" it is necessary to draw simultaneously upon many of these skills.

In order to describe levels of mathematical competency, PISA organises processes into three classes, defining the type of thinking skill needed: i) reproduction, definitions and computations; ii) connections and integration for problem solving; and iii) mathematisation, mathematical thinking, generalisation and insight. In general, these processes are in ascending order of difficulty, but it does not follow that one must be mastered in order to progress to the other: it is possible for example to engage in mathematical thinking without being good at computations.

1. Competency Class 1: Reproduction, definitions and computations 
Class 1 covers processes assessed in many standardised tests, as well in comparative international studies, operationalised mainly in multiplechoice format. It deals with knowledge of facts, representing, recognising equivalents, recalling mathematical objects and properties, performing routine procedures, applying standard algorithms and developing technical skills.

2. Competency Class 2: Connections and integration for problem solving

Class 2 processes start making connections between the different strands and domains in mathematics, and integrate information in order to solve simple problems. Although the problems are supposedly non-routine, they require relatively minor degrees of mathematisation.

Within this competency class, students are also expected to handle different aspects of representation, according to situation and purpose. Connections also require students to be able to distinguish and relate different statements such as definitions, claims, examples, conditioned assertions and proofs. Decoding and interpreting symbolic and formal language, and understanding its relationship to natural language, form another aspect of this class. In this class, the problems are often placed within a context, and engage students in mathematical decision making.

3. Competency Class 3: Mathematisation, mathematical thinking, generalisation and insight

In this competency class, students are asked to mathematise situations: to recognise and extract the mathematics embedded in the situation and use mathematics to solve the problem, analyse, interpret, develop their own models and strategies, and make mathematical arguments, including proofs and generalisations.

These processes involve critical thinking, analysis and reflection. Students should not only be able to solve problems but also to pose prob- lems to communicate situations appropriately, and to have insight into the nature of mathematics as a science.

This level, which goes to the heart of mathematics and mathematical literacy, is difficult to test. The multiple-choice format for test items is usually inadequate. Questions with openended answers are more suitable, but both the design of such questions and the marking of answers are difficult.

\section{Mathematical content}

School mathematics curricula are usually organised in content strands. These strands compartmentalise mathematics and often over-emphasise computation and formulae. At the beginning of the $20^{\text {th }}$ century, mathematics could reasonably be regarded as consisting of some 12 distinct subjects: arithmetic, geometry, algebra, calculus, and so on. Today, however, between 60 and 70 distinct subjects would be a reasonable figure. Some subjects, such as algebra or topology, have split into various sub-fields; others, such as complexity theory or dynamic systems theory, are completely new areas of study. Rarely do problems arise in ways and contexts that allow their understanding and solution to be achieved through an application of knowledge from a single content strand. To be relevant, mathematics must reflect the complex patterns in the world around us.

For these and other reasons, PISA took a different approach and organised content around a phenomenological approach, describing content in relation to a phenomenon and the kinds of problems for which it was created, referred to as "overarching concepts". For the purpose of PISA, a selection of overarching concepts was made that would encompass sufficient variety and depth to reveal the essentials of mathematics and would at the same time represent or include the conventional mathematical curricular strands in an acceptable way. The following mathematical "overarching concepts" met this requirement: change and relationships, space and shape, quantity and uncertainty. 
PISA 2000 focused on the first two of these overarching concepts. They allowed a wide range of aspects of the curriculum to be represented, without giving undue weight to number skills.

\section{Change and relationships}

Every natural phenomenon is a manifestation of change. Examples of change include the growth of organisms, the cycle of seasons, the ebb and flow of tides, cycles of unemployment, weather changes, and stock exchange indices (e.g. the Dow-Jones index). Some of these change processes involve and can be described or modelled by straightforward mathematical functions: linear, exponential, periodic or logistic, either discrete or continuous. But many relationships fall into different categories and data analysis is quite often essential in order to determine the kind of relationship that is present. Mathematical relationships often take the shape of equations or inequalities, but relations of a more general nature (e.g. equivalence, divisibility, inclusion) may appear as well. Observing patterns of change in nature and in mathematics is therefore not confined to particular parts of the curriculum such as algebra.

PISA examined students' ability to represent changes in a comprehensible form, to understand the fundamental types of change, to recognise particular types of change when they occur, to apply these techniques to the outside world, and to control a changing world to our best advantage.

Functional thinking, i.e. thinking in terms of relationships, is one of the most fundamental disciplinary aims of the teaching of mathematics. Relationships may be given a variety of different representations, including symbolic, algebraic, graphical, tabular, and geometrical. Different representations may serve different purposes and have different properties. Hence translation between representations is often of key importance in dealing with situations and tasks.

\section{Space and shape}

Patterns are encountered everywhere around us: spoken words, music, video, traffic, buildings and art. Shapes can be regarded as patterns: houses, office blocks, bridges, starfish, snowflakes, town plans, cloverleaves, crystals and shadows. Geometric patterns can serve as relatively simple models of many kinds of phenomenon, and their study is possible and desirable at all levels.

In understanding space and constructions, students need to look for similarities and differences as they analyse the components of form and recognise shapes in different representations and different dimensions. The study of shapes is closely connected to the concept of 'grasping space'. This means learning to know, explore and conquer, in order to live, breathe and move with more understanding in the space in which we live.

Students should therefore be able to understand the properties of objects, and the relative position of objects. They must be aware of how they see things and why they see them as they do. They must learn to navigate through space and through construction and shapes. This means understanding the relationship between shapes and images or visual representations, such as that between a real city and photographs and maps of the same city. It includes also understanding how threedimensional objects can be represented in two dimensions, how shadows are formed and must be interpreted, what perspective is and how it functions.

In PISA 2000, testing time was evenly distributed between these two overarching concepts. In some tasks at least, marks were not only awarded for the "correct" answer but also for the different strategies used by students to solve the tasks.

\section{Mathematical situations and contexts}

An important aspect of the definition of mathematical literacy is using and doing mathematics in a variety of situations. Thus, students' mathematical insight and understanding need to be assessed in a variety of situations, partly to minimise the chance of students finding that tasks are not culturally relevant. 
One can think of a situation as being at a certain distance from the student. The closest is private life (daily life), next is school life, work and sports, followed by the local community and society as encountered in daily life, and furthest away are scientific contexts. In this way, one can define a more or less continuous scale of situations.

It is not always clear how the distance of the situation from the student affects performance. We cannot say that "closer" contexts are necessarily more attractive for students, or better suited than more scientific contexts. Indeed, some experts believe that familiarity with the context can be a hindrance, while research suggests that boys do better on experiential knowledge of numbers and measures from the daily world while girls perform better on tasks where a standard procedure is needed. Secondary school students appear to have less need for a personally relevant context than primary school children.

Whatever the distance from the students, PISA aims to ensure that tasks are based on "authentic" contexts which are likely to occur in a real-world setting. If mathematics education is to prepare students to be active and informed citizens it has to deal with "real" contexts such as pollution problems, traffic safety and population growth. This does not exclude, however, artificial fictional contexts based on the stylised representation of problems - such as a traffic situation in a nonexistent town.

\section{Format of test questions and marking}

PISA 2000 assessed mathematical literacy through a combination of question formats. Some tasks were assessed through multiple-choice questions, typically those associated with simpler mathematical processes.

Open-ended questions were preferred for assessing higher-order mathematical processes. Such questions often required students to show the steps taken or to explain how the answer was reached. They allowed students to demonstrate their level of ability by providing solutions of a range of mathematical complexity. Furthermore, since these responses could give valuable information about students' ideas and thinking, which could be fed back into curriculum planning, the marking guides for these questions included in the main study were designed to include a system of two-digit marking so that the frequency of various types of correct and incorrect responses could be recorded. The first digit was the actual score. The second digit, shown in parentheses, was used to categorise the different kinds of responses on the basis of the strategies used by the student to answer the question. There are two main advantages to using double-digit codes. Firstly, more information can be collected about students' misconceptions, common errors, and different approaches to solving problems. Secondly, double-digit coding allows a more structured way of presenting the codes, clearly indicating the hierarchical levels of groups of codes. It is important to note that markers were advised to ignore spelling and grammatical errors, unless they completely obscured the meaning, because this was not a test of written expression.

\section{The assessment of mathematical literacy in PISA 2000}

As with reading literacy, there were a number of units, each presenting a situation or problem on which students were set several questions or tasks. Different combinations of diagrams and written information introduced each unit. About twothirds of the tasks were in a form that could be marked unambiguously as correct or incorrect. Students demonstrated their proficiency by answering problems correctly and showing whether they understood the underlying mathematical principles involved in the task. For more complex tasks, students could gain full or partial credit.

Performance in mathematical literacy was marked in PISA 2000 on a single scale which, as in the 
case of reading literacy, was constructed with an OECD average score of 500 points and a standard deviation of 100 points, and with about two-thirds of students across OECD countries scoring between 400 and 600 points. The scale measured students' ability to recognise and interpret mathematical problems encountered in their world, to translate these problems into a mathematical context, to use mathematical knowledge and procedures to solve the problems within their mathematical context, to interpret the results in terms of the original problem, to reflect upon the methods applied, and to formulate and communicate the outcomes.

Since the assessment of mathematical and scientific literacy was more limited than that of reading literacy in PISA 2000, no attempt was made to define levels of proficiency, as was done in reading. It is nonetheless possible to provide a broad description of performance in mathematics and science in terms of the knowledge and skills that students need to demonstrate at various points on the relevant scales.

In the case of the mathematical literacy scale, this description is as follows.

- Towards the top end, around 750 points, students typically take a creative and active role in their approach to mathematical problems. They interpret and formulate problems in terms of mathematics, can handle more complex information, and can negotiate a number of processing steps. Students at this level identify and apply relevant tools and knowledge (frequently in an unfamiliar problem context), use insight to identify a suitable way of finding a solution, and display other higher-order cognitive processes such as generalisation, reasoning and argumentation to explain and communicate results.

- At around 570 points on the scale, students are typically able to interpret, link and integrate different representations of a problem or different pieces of information; and/or to use and manipulate a given model, often involving algebra or other symbolic representations; and/or to verify or check given propositions or models. Students typically work with given strategies, models or propositions (e.g., by recognising and extrapolating from a pattern), and they select and apply relevant mathematical knowledge in order to solve a problem that may involve a small number of processing steps.

- At the lower end of the scale, around 380 points, students are usually able to complete only a single processing step consisting of reproducing basic mathematical facts or processes, or applying simple computational skills. Students typically recognise information from diagrammatic or text material that is familiar and straightforward and in which a mathematical formulation is provided or readily apparent. Any interpretation or reasoning typically involves recognition of a single familiar element of a problem. The solution calls for application of a routine procedure in a single processing step. 
723 (Question 3) This task requires students to show insight into mathematical functions by comparing the growth of a linear function with that of a quadratic function. Students are required to construct a verbal description of a generalised pattern, and to create an argument using algebra. Students need to understand both the algebraic expressions used to describe the pattern and the underlying functional relationships, in such a way that they can see and explain the generalisation of these relationships in an unfamiliar context. A chain of reasoning is required, and communication of this in a written explanation. (M136003)

712 (Question 4) This task requires students to identify an appropriate strategy and method for estimating the area of an irregular and unfamiliar shape, and to select and apply the appropriate mathematical toods in an unfamiliar context. Students need to choose a suitable shape or shapes with which to model the irregular area [for example, approximating parts of the map with rectangle(s), circle(s), triangle(s)]. Students need to know and apply the appropriate formulae for the shapes they use; to work with scale; to estimate length; and to carry out a computation involving a few steps. (M148Q02)

655 (Question 8) This task requires students to understand and interpret a graphical representation of a physical relationship (speed and distance of a car) and relate it to the physical world. Students need to link and integrate two very different visual representations of the progress of a car around a racetrack. Students have to identify and select the correct option from among given challenging alternatives. (M159005)

655 (Question 2) This task requires students to interpret expressions containing words and symbols, and to link different representations (pictorial, verbal and algebraic) of two relationships (one quadratic and one linear). Students have to find a strategy for determining when the two functions will have the same solution (for example, by trial and error, or by algebraic means), and to communicate the result by explaining the reasoning and calculation steps involved. (M136002)

548 (Question 1) Students are given a hypothetical scenario involving planting an orchard of apple trees in a square pattern, with a row of protective conifer trees around the square. They are asked to complete a table of values generated by the functions that describe the number of trees as the size or orchard is inceased. This task requires students to interpret a written description of a problem situation, to link this to a tabular representation of some of the information, to recognise a pattern and then to extend this pattern. Students need to work with given models and to relate two different representations (pictorial and tabular) of two relationships (one quadratic and one linear) in order to extend the pattern. (M136001)

\section{Figure 2}

\section{TASK DIFFICULTY}

537 (Question 9) Students are given a written mathematical description of geometric objects, and are asked to select from given options a diagram that fits the description. This is an intramathematical task that requires students to link several pieces of information in text containing mathematical terms to standard geometric representations. Students need to link elements of one representation in words and symbols with corresponding elements of a representation in diagram form, selecting the appropriate matching representation from a number of options. (M161001)

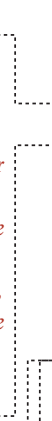

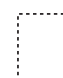

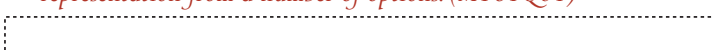

524 (Question 11) Students are given a mathematical model (in the form of a diagram) and a written mathematical description of a real-world object (a pyramid-shaped roof) and asked to calculate one of the lengths in the diagram. This task requires students to work with a familiar geometric model and to link information in verbal and symbolic form to a diagram. Students need to visually "disembed" a triangle from a 2-dimensional representation of a 3-dimensional object; to select the appropriate information about side length relationships; and to use knowledge of similar triangles in order to solve the problem. (M037Q02)

492 (Question 10) Students are given a mathematical model (in the form of a diagram) and a written mathematical description of a real-world object (a pyramid-shaped roof) and asked to calculate the area of the base. This task requires students to link a verbal description with an element of a diagram; to recall the area formula for a square with given sides; and to identify the required information in the diagram. Students then need to carry out a simple calculation in order to compute the required area. (M037Q01)
492 (Question 5) This task requires students to interpret a graphical representation of a physical relationship (distance and speed of a car travelling on a track of unknown shape). Students need to interpret the graph by linking a verbal description with two particular features of the graph (one simple and straightforward, and one requiring a deeper understanding of several elements of the graph and what it represents), and then to identify and read the required information from the graph, selecting the best option from given alternatives. (M159001)

413 (Question 7) This task requires students to read information from a graph representing a physical relationship (speed and distance of a car). Students need to identify the place in the graph referred to in a verbal description in order to recognise what is happening to the speed of the vehicle at that point, and then to select the best matching option from among given alternatives. (M159Q03)

403 (Question 6) This task requires students to read information from a graph representing a physical relationship (speed and distance of a car). Students need to identify one specified feature of the graph (the display of speed); to read directly from the graph a value that minimises the feature; and then to select the best match from among given alternatives. (M159002) 


\section{MATHEMATICS UNIT 1}

\section{Apples}

A farmer plants apple trees in a square pattern. In order to protect the trees against the wind he plants conifers all around the orchard.

Here you see a diagram of this situation where you can see the pattern of apple trees and conifers for any number (n) of rows of apple trees:

$$
\begin{aligned}
& \mathbf{X}=\text { conifer } \\
& \mathbf{0}=\text { apple tree }
\end{aligned}
$$

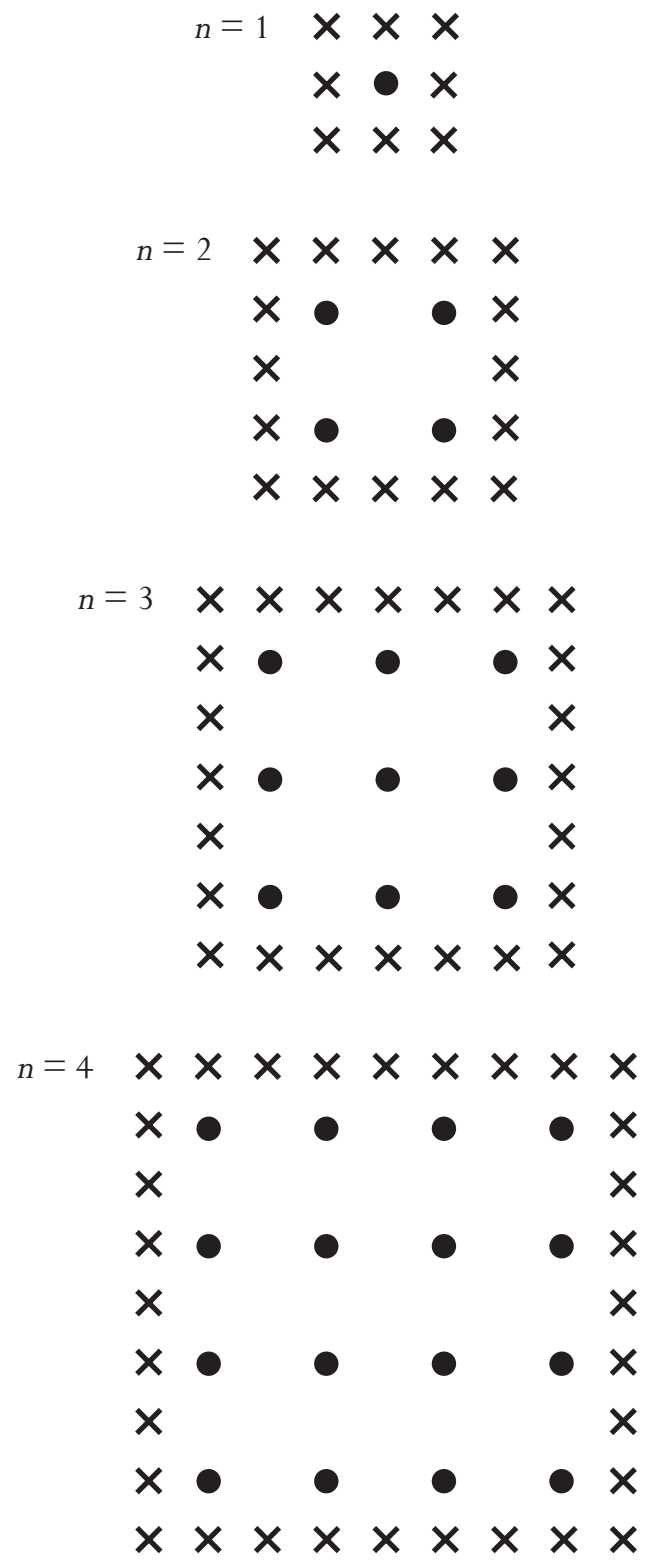




\section{Question 1:APPLES (M136Q01)}

Process: Competency class 2 (Connections and integration for problem solving)

Content: Change and relationships

Situation: Educational

Complete the table:

\section{Scoring - Question 1}

\begin{tabular}{c|cc}
$n$ & Number of apple trees & Number of conifers \\
\hline 1 & 1 & 8 \\
\hline 2 & 4 & 16 \\
\hline 3 & 9 & 24 \\
\hline 4 & 16 & 32 \\
\hline 5 & 25 & 40 \\
\hline
\end{tabular}

Score 1: Answers which show all 7 entries correct.

Score 0: Other answers.

\section{Question 2: APPLES (M136Q02)}

Process: Competency class 2 (Connections and integration for problem solving)

Content: Change and relationships

Situation: Educational

There are two formulae you can use to calculate the number of apple trees and the number of conifers for the pattern described above:

Number of apple trees $=n^{2}$

Number of conifers $=8 n$

where $n$ is the number of rows of apple trees.

There is a value of $n$ for which the number of apple trees equals the number of conifers. Find the value of $n$ and show your method of calculating this.

\section{Scoring - Question 2}

[These scores are for the correct answer, $n=8$, using different approaches]

Score 1(1): Answers which give $\mathrm{n}=8$, with the algebraic method explicitly shown. For example:

- $\mathrm{n}^{2}=8 \mathrm{n}, \mathrm{n}^{2}-8 \mathrm{n}=0, \mathrm{n}(\mathrm{n}-8)=0, \mathrm{n}=0 \& \mathrm{n}=8$, so $\mathrm{n}=8$ 
Score 1(2): Answers which give $n=8$, but no clear algebra is presented, or no work shown. For example:

$\cdot \mathrm{n}^{2}=8^{2}=64,8 \mathrm{n}=8: 8=64$

- $\mathrm{n}^{2}=8 \mathrm{n}$. This gives $\mathrm{n}=8$.

- $8 \times 8=64, \mathrm{n}=8$

- $\mathrm{n}=8$

- $8 \times 8=8^{2}$

Score 1(3): Answers which give $\mathrm{n}=8$ using other methods, e.g., using pattern expansion or drawing.

[These scores are for the correct answer, $n=8$, PLUS the answer $n=0$, with different approaches.]

Score 1(4): Answers which are similar to those given under score 1(1) (clear algebra), but give both answer $\mathrm{n}=8$ AND $\mathrm{n}=0$. For example:

- $\mathrm{n}^{2}=8 \mathrm{n}, \mathrm{n}^{2}-8 \mathrm{n}=0, \mathrm{n}(\mathrm{n}-8)=0, \mathrm{n}=0 \& \mathrm{n}=8$

Score 1(5): Answers which are similar to those given under score 1(2) (no clear algebra), but give both answer $\mathrm{n}=8$ AND $\mathrm{n}=0$.

Score 0(0): Other answers, including the answer $n=0$. For example:

- $\mathrm{n}^{2}=8 \mathrm{n}$ (a repeat of the statement from the question)

$\cdot \mathrm{n}^{2}=8$

- $\mathrm{n}=0$. You can't have the same number, because for every apple tree, there are 8 conifers.

\section{Question 3: APPLES (M136003)}

Process: Competency class 3 (Mathematisation, mathematical thinking, generalisation and insight)

Content: Change and relationships

Situation: Educational

Suppose the farmer wants to make a much larger orchard with many rows of trees. As the farmer makes the orchard bigger, which will increase more quickly: the number of apple trees or the number of conifers? Explain how you found your answer.

\section{Scoring - Question 3}

Score 2(1): Answers which are correct (apple trees) AND which give some algebraic explanations based on the formulae $\mathrm{n}^{2}$ and $8 \mathrm{n}$. For example:

- Apple trees $=\mathrm{n} \times \mathrm{n}$ and conifers $=8 \times \mathrm{n}$. Both formulas have a factor $\mathrm{n}$, but apple trees have another $\mathrm{n}$, which will get larger while factor 8 stays the same. The number of apple trees increases more quickly.

- The number of apple trees increases faster because that number is being squared instead of multiplied by 8 .

- Number of apple trees is quadratic. Number of conifers is linear. So apple trees will increase faster.

- Answer uses graph to demonstrate that $\mathrm{n}^{2}$ exceeds $8 \mathrm{n}$ after $\mathrm{n}=8$.

Score 1(1): Answers which are correct (apple trees) AND are based on specific examples or on extending the table. For example: 
- The number of apple trees will increase more quickly because, if we use the table (previous page), we find that the no. of apple trees increases faster than the no. of conifers. This happens especially after the no. of apple trees and the number of conifers are the same.

OR

- The table shows that the number of apple trees increases faster.

Answers which are correct (apple trees) and show SOME evidence that the relationship between $\mathrm{n}^{2}$ and $8 \mathrm{n}$ is understood, but not so clearly expressed as in Score 2(1). For example:

- Apple trees after $\mathrm{n}>8$.

- After 8 rows, the number of apple trees will increase more quickly than conifers.

- Conifers until you get to 8 rows, then there will be more apple trees.

Score 0(1): Answers which are correct (apple trees) but give an insufficient or wrong explanation, or no explanation. For example:

- Apple trees.

- Apple trees because they are populating the inside which is bigger than just the perimeter.

- Apples trees because they are surrounded by conifers.

Score 0(2): Incorrect answers. For example:

- Conifers.

- Conifers because for every additional row of apple trees, you need lots of conifers.

- Conifers. Because for every apple tree there are 8 conifers.

- I don't know. 


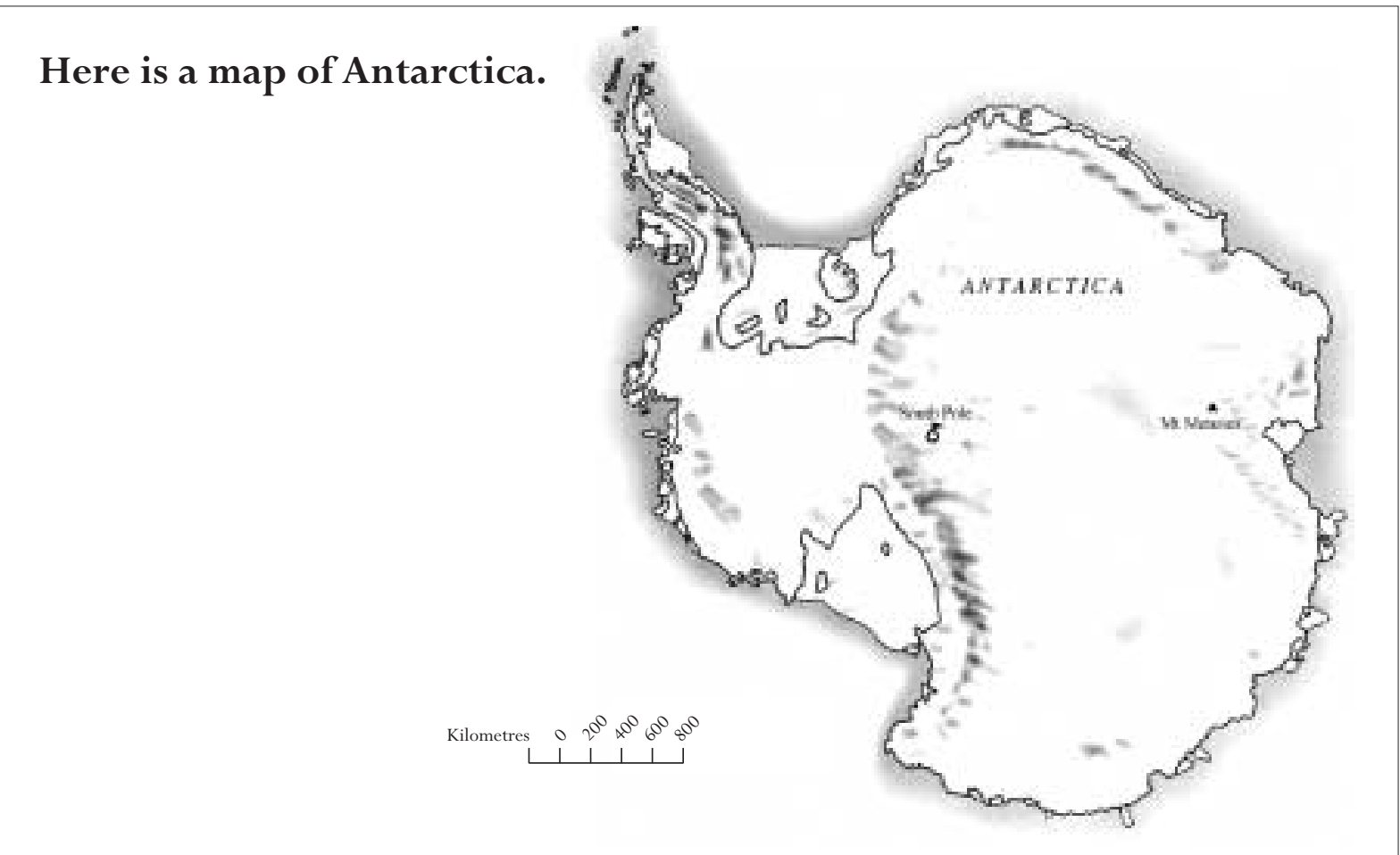

\section{Question 4: CONTINENT AREA (M148QO2)}

Process: Competency class 2 (Connections and integration for problem solving)

Content: Space and shape

Situation: Personal

Estimate the area of Antarctica using the map scale.

Show your working out and explain how you made your estimate. (You can draw over the map if it helps you with your estimation)

\section{Scoring - Question 4}

[These scores are for answers that use the correct method AND give the correct result. The second digit indicates the different approaches.]

Score 2(1): Answers which are estimated by drawing a square or rectangle - between 12000000 sq kms and $18000000 \mathrm{sq}$ kms (units not required).

Score 2(2): Answers which are estimated by drawing a circle - between 12000000 sq kms and 18000000 sq kms.

Score 2(3): Answers which are estimated by adding areas of several regular geometric figures - between 12000000 and 18000000 sq kms.

Score 2(4): Answers which are estimated by other correct methods - between 12000000 sq kms and $18000000 \mathrm{sq} \mathrm{kms}$.

Score 2(5): Answers which are correct (between 12000000 sq kms and 18000000 sq kms ) but no working out is shown. 
[These scores are for answers that use the correct method BUT give an incorrect or incomplete result. The second digit in parentheses indicates the different approaches, matching the second digit in parentheses of the Full credit Scores.]

Score 1(1): Answers which are estimated by drawing a square or rectangle - correct method but incorrect or incomplete answer. For example:

- Draws a rectangle and multiplies width by length, but the answer is an overestimate or an underestimate (e.g., 18200 000).

- Draws a rectangle and multiplies width by length, but the number of zeros is incorrect (e.g., $4000 \times 3500=140000)$.

- Draws a rectangle and multiplies width by length, but forgets to use the scale to convert to square kilometres (e.g., $12 \mathrm{~cm} \mathrm{x} 15 \mathrm{~cm}=180$ ).

- Draws a rectangle and states the area is $4000 \mathrm{~km}$ x $3500 \mathrm{~km}$. No further working out.

Score 1(2): Answers which are estimated by drawing a circle - correct method but incorrect or incomplete result.

Score 1(3): Answers which are estimated by adding areas of several regular geometric figures - correct method but incorrect or incomplete result.

Score 1(4): Answers which are estimated by other correct methods - but incorrect or incomplete result.

Score 0(1): Answers which show the perimeter instead of area. For example:

- $16000 \mathrm{~km}$ as the scale of $1000 \mathrm{~km}$ would go around the map 16 times.

Score 0(2): Incorrect answers. For example:

- $16000 \mathrm{~km}$ (no working out is shown, and the result is incorrect).

\section{Summary table}

A summary table below shows the relationship between the scores:

\begin{tabular}{l|ccc} 
Estimation method & \multicolumn{3}{|c}{ Score } \\
\hline & $\begin{array}{c}\text { Full credit }- \text { Answers which are } \\
\text { correct: between } 12000000 \\
\text { and } 18000000 \mathrm{sq} \mathrm{kms}\end{array}$ & $\begin{array}{c}\text { Partial credit - Answers using } \\
\text { the correct method but giving an } \\
\text { incorrect }\end{array}$ & No incomplete result. \\
Drawing a rectangle & $2(1)$ & $1(1)$ & - \\
\hline Drawing a circle & $2(2)$ & $1(2)$ & - \\
\hline Adding regular shapes & $2(3)$ & $1(3)$ & - \\
\hline Other correct methods & $2(4)$ & $1(4)$ & $0(1)$ \\
\hline No working shown & $\mathbf{2 ( 5 )}$ & - & $0(2)$ \\
\hline Perimeter & - & - & - \\
\hline Other incorrect answers & - & & -
\end{tabular}

Note: When coding this question, apart from reading what the student has written in words in the space provided, make sure that you look also at the map itself to see what drawings or marks the student has made there. Very often, students find it difficult to explain in words exactly what they have done, but clues can be found from looking at the markings on the map itself. The aim is not to see whether students can express themselves well in words. The aim is to try to work out how they arrived at their answers. Therefore, even if no written explanation is given, but you can tell what the student has done from sketches on the map or from the formulae used, the answer should be regarded as containing an adequate explanation. 


\section{MATHEMATICS UNIT 3 \\ Speed of a racing car}

This graph shows how the speed of a racing car varies along a flat 3 kilometre track during its second lap.

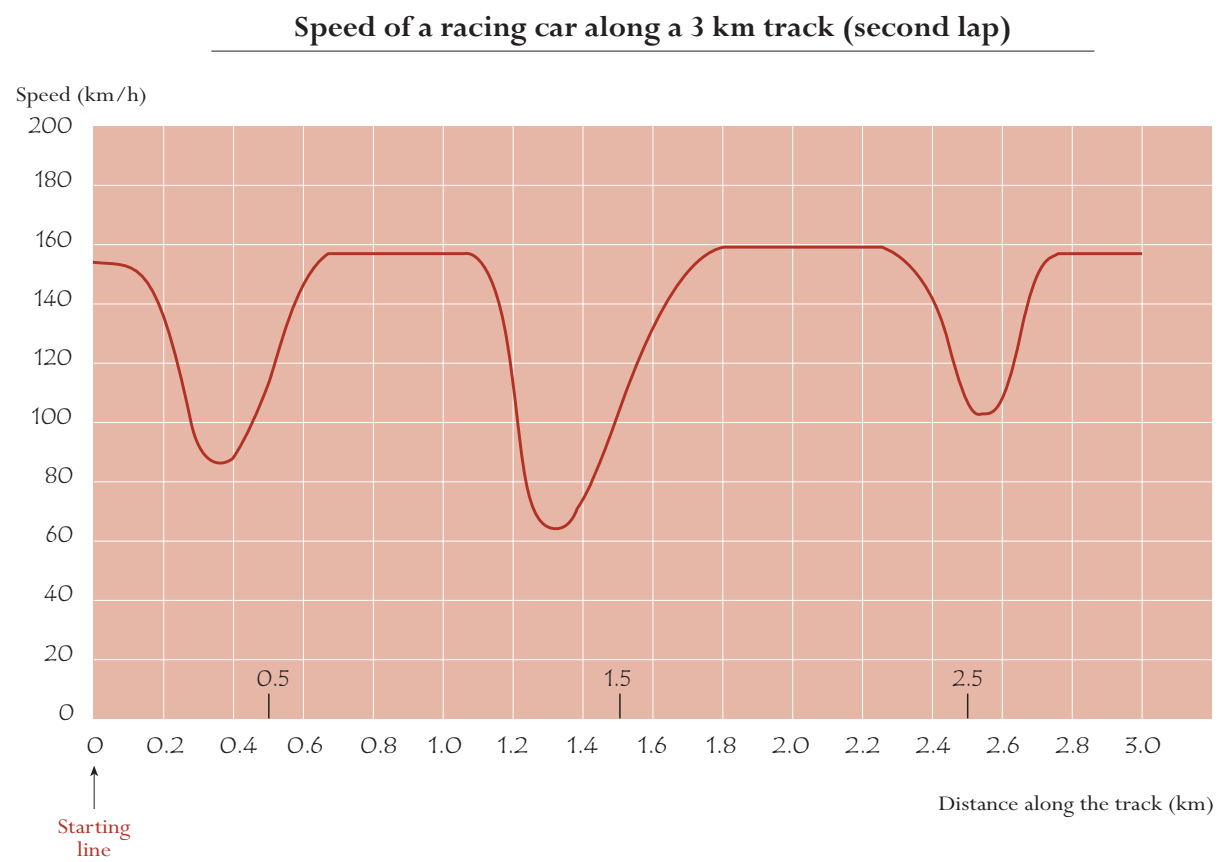

Source: In memory of Claude Janvier, who died in June 1998. Modified task after his ideas in Janvier, C. (1978): The interpretation of complex graphs - studies and teaching experiments. Accompanying brochure to the Dissertation. Univrsity of Nottingham, Shell Centre for Mathematical Education, Item C-2.

The pictures of the tracks are taken from Fischer, R \& Malle, G. (1985): Mensch und Mathematik. Bibliographisches Institut: Mannheim-Wien-Zurich, 234-238.

\section{Question 5: SPEED OF RACING CAR (M159Q01)}

Process: Competency class 2 (Connections and integration for problem solving)

Content: Change and relationships

Situation: Scientific

What is the approximate distance from the starting line to the beginning of the longest straight section

of the track?
A $0.5 \mathrm{~km}$.
(B) $1.5 \mathrm{~km}$.
C $2.3 \mathrm{~km}$.
D $2.6 \mathrm{~km}$.

\section{Scoring - Question 5}

Score 1: Answer B-1.5 km.

Score 0: Other answers. 


\section{Question 6: SPEED OF RACING CAR (M159Q02)}

Process: Competency class 1 (Reproduction, definitions and computations)

Content: Change and relationships

Situation: Scientific

Where was the lowest speed recorded during the second lap?

A At the starting line.

B At about $0.8 \mathrm{~km}$.

(C) At about $1.3 \mathrm{~km}$.

D Halfway around the track.

\section{Scoring - Question 6}

Score 1: Answer C - at about $1.3 \mathrm{~km}$.

Score 0: Other answers.

\section{Question 7: SPEED OF RACING CAR (M159Q03)}

Process: Competency class 1 (Reproduction, definitions and computations)

Content: Change and relationships

Situation: Scientific

What can you say about the speed of the car between the $2.6 \mathrm{~km}$ and $2.8 \mathrm{~km}$ marks?

A The speed of the car remains constant.

(B) The speed of the car is increasing.

C The speed of the car is decreasing.

D The speed of the car cannot be determined from the graph.

\section{Scoring - Question 7}

Score 1: Answer B - the speed of the car is increasing.

Score 0: Other answers.

\section{Question 8: SPEED OF RACING CAR (M159Q05)}

Process: Competency class 2 (Connections and integration for problem solving)

Content: Change and relationships

Situation: Scientific

Here are pictures of five tracks:

Along which one of these tracks was the car driven to produce the speed graph shown earlier?

\section{Scoring - Question 8}
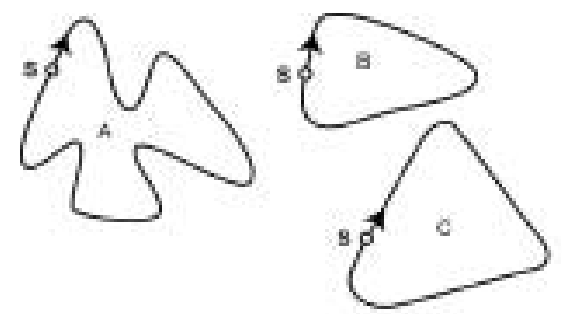

S: Starting point
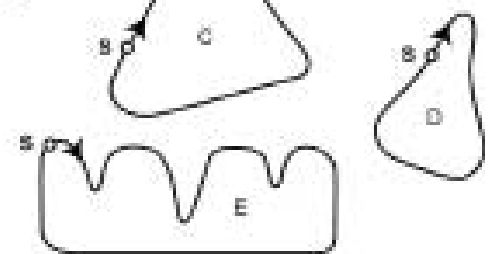

Score 1: Answer B.

Score 0: Other answers. 


\section{MATHEMATICS UNIT 4}

\section{Triangles}

Circle the one figure below that fits the following description.

Triangle $P Q R$ is a right triangle with right angle at $R$. The line $R Q$ is less than the line PR. M is the midpoint of the line $P Q$ and $N$ is the midpoint of the line $Q R$. $S$ is a point inside the triangle. The line $M N$ is greater than the line MS.

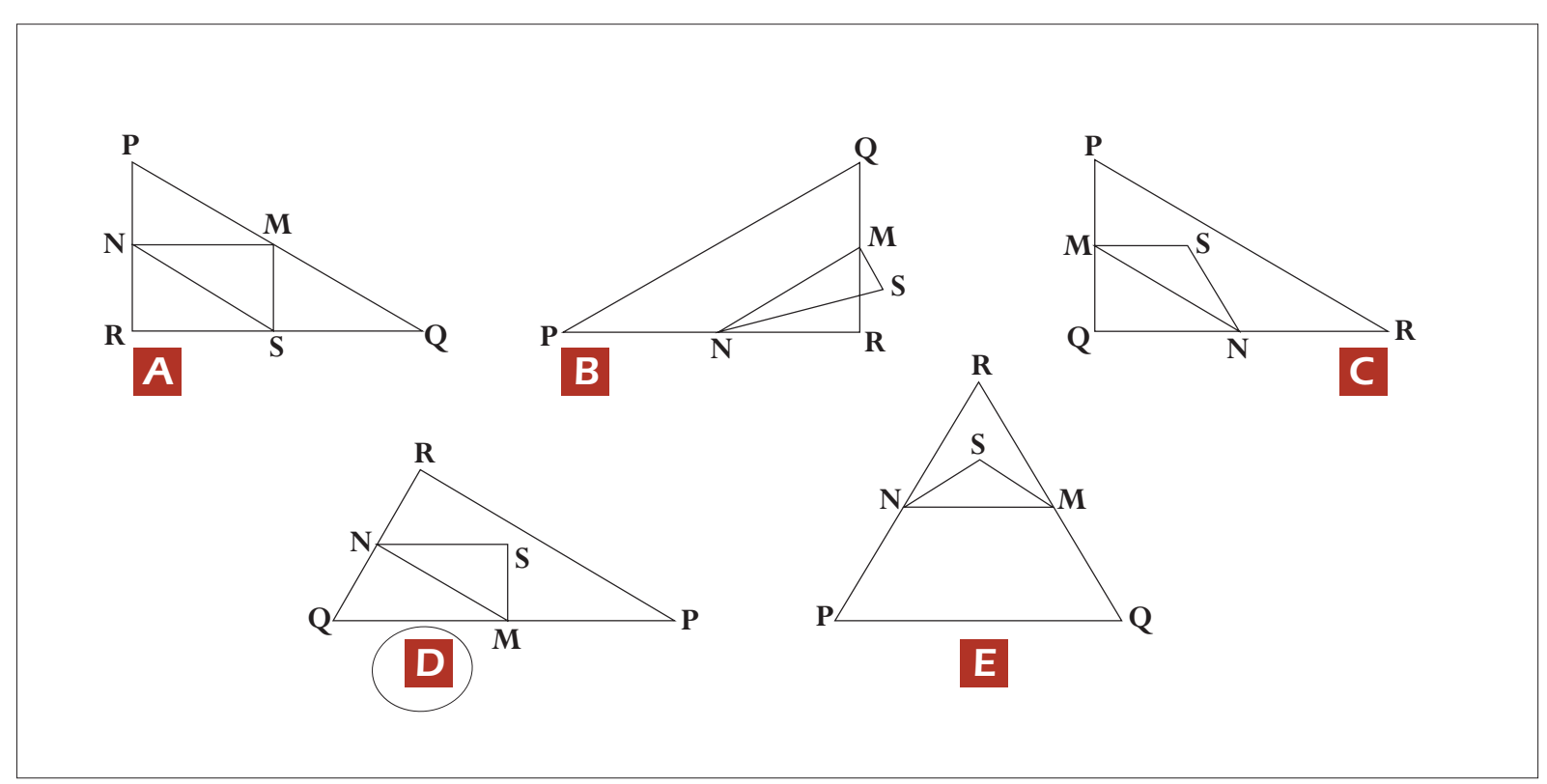

Question 9:TRIANGLES (M161Q01)

Process: Competency class 1 (Reproduction, definitions and computations)

Content: Space and shape

Situation: Scientific

\section{Scoring - Question 9}

Score 1: Answer D.

Score 0: Other answers. 


\section{MATHEMATICS UNIT 5}

Farms

Here you see a photograph of a farmhouse with a roof in the shape of a pyramid.

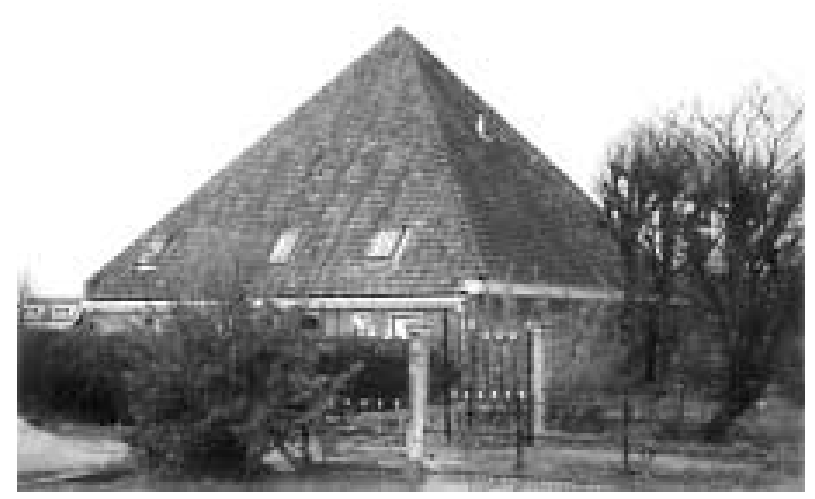

Below is a student's mathematical model of the farmhouse roof with measurements added.

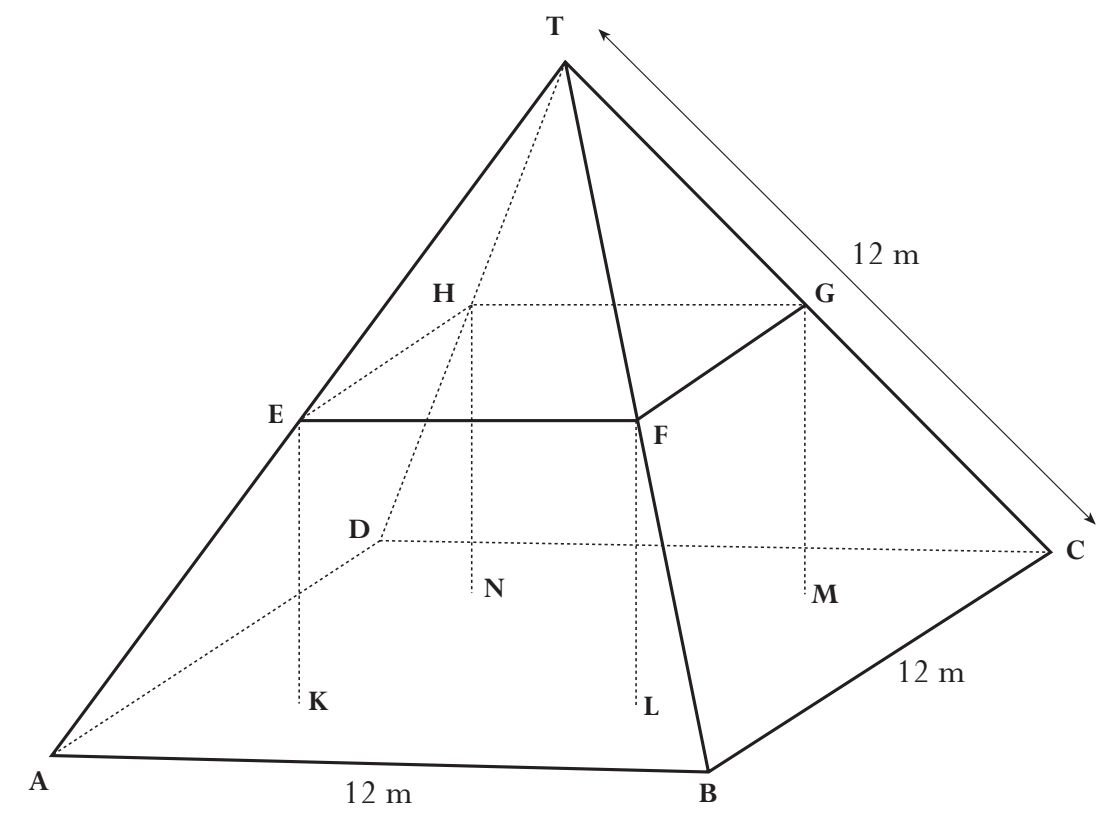

The attic floor, ABCD in the model, is a square. The beams that support the roof are the edges of a block (rectangular prism) EFGHKLMN. E is the middle of AT, F is the middle of BT, G is the middle of CT and $\mathrm{H}$ is the middle of DT. All the edges of the pyramid in the model have length $12 \mathrm{~m}$. 
Question 10: FARMS (M037Q01)

Process: Competency class 1 (Reproduction, definitions and computations)

Content: Space and shape

Situation: Occupational

Calculate the area of the attic floor $A B C D$.

The area of the attic floor $A B C D=$ $m^{2}$

\section{Scoring - Question 10}

Score 1: 144 (unit already given).

Score 0: Other answers.

\section{Question 11: FARMS (M037Q02)}

Process: Competency class 2 (Connections and integration for problem solving)

Content: Space and shape

Situation: Occupational

Calculate the length of EF, one of the horizontal edges of the block.

The length of $\mathrm{EF}=$ m

\section{Scoring - Question 11}

Score 1: 6 (unit already given).

Score 0: Other answers. 

5

C

I

E

N

T

F

I

C

L

I

T

E

R

A

C

Y 
SAMPLE TASKS FOR THE ASSESSMENT

OF SCIENTIFIC LITERACY IN PISA 2000

\section{The PISA definition of scientific literacy and its context}

Scientific literacy is defined in PISA as:

the capacity to use scientific knowledge, to identify questions and to draw evidence-based conclusions in order to understand and help make decisions about the natural world and the changes made to it through human activity.

An important aspect of scientific literacy is that it is considered a key outcome of education by age 15 for all students, whether or not they continue to learn science thereafter. Scientific thinking is required by citizens, not just scientists. It has been widely accepted in the past that reading and mathematical skills are important for all adults, in many life contexts. The inclusion of scientific literacy as a general competency for life reflects the growing centrality of scientific and technological questions to $21^{\text {st }}$ century life. The definition does not imply that tomorrow's adults need large reservoirs of scientific knowledge, but that the key is to be able to think scientifically about the evidence that they encounter.

\section{Three dimensions of scientific literacy}

To transform this definition into an assessment of scientific literacy, three broad dimensions have been identified. These are:

- Processes: The mental processes that are involved in addressing a question or issue (such as identifying evidence or explaining conclusions);

- Content: The scientific knowledge and conceptual understanding that are required in using these processes; and
- Context: Situations in which the processes and understanding are applied - such as the personal context of health and nutrition or the global context of climate.

Within each dimension, decisions have been made about which components need to be included for example, what kinds of scientific process are the most important to master. The intention has been to focus on literacy as a broad competence rather than on the mastery of curriculum content only. The arguments and decisions about these components are now briefly outlined below.

\section{Scientific processes}

PISA emphasises the ability to use scientific knowledge and to know about science. The assessment of such abilities helps us to understand how well science education is preparing future citizens to participate in societies ever more affected by scientific and technological advances. Students should be equipped with understanding of the nature of science, of its procedures, of its strengths and limitations and of the kinds of question that it can, and cannot, answer. Students should also be able to recognise the type of evidence required in a scientific investigation and the extent to which reliable conclusions can be drawn from evidence. It is considered important for students to be able to communicate their understanding and arguments effectively to particular audiences, for they will otherwise have no voice in the matters that are debated in society.

It should be possible for all these abilities to be derived from experiencing science at first hand and from investigations and experiments in school. However, the concern in PISA is not to find out whether students can undertake scientific investigations for themselves, but rather whether their school experiences have culminated in an understanding of scientific processes and the ability to apply scientific concepts that enable them "to make decisions about the natural world and the changes made to it through human activity".

These arguments have led to the identification of the following scientific processes for assessment in PISA: 


\section{Recognising scientifically investigable questions}

This means being able to identify the kinds of question that science can attempt to answer, or the specific question that is, or might be, tested in a particular situation.

It can be assessed, for example, by presenting a situation in which questions could be answered scientifically and requiring these to be identified, or by presenting several questions and asking which can be answered by scientific investigation.

2. Identifying evidence needed in a scientific investigation

This process involves identifying or proposing the evidence required to answer the questions posed in a scientific investigation, or the procedures needed to gather that evidence.

It can be assessed, for example, by presenting an investigation and asking students to identify the evidence needed or the action to be taken to obtain valid evidence.

\section{Drawing or evaluating conclusions}

This process involves relating conclusions to the evidence on which they are based, or should be based.

It can be assessed, for example, by providing students with an account of an investigation and the conclusions drawn from it and asking for an evaluation of these conclusions, or by asking for a conclusion or alternative conclusions to be drawn that are consistent with given evidence.

\section{Communicating valid conclusions}

The process involved here is that of expressing, in a way that is appropriate to a given audience, the conclusions that can be drawn from available evidence.

It can be assessed, for example, by presenting students with a situation which requires information or evidence from different sources to be brought together to support a given course of action or conclusion. The emphasis here is on the clarity of communication rather than the particular conclusion being communicated, provided that this is consistent with scientific understanding.

\section{Demonstrating understanding of scientific concepts}

This is the process of showing understanding by being able to apply concepts in situations different from those in which they were learned. It involves not only recalling knowledge but also showing the relevance of that knowledge or using it to make predictions or to provide explanations.

It can be assessed, for example, by asking for explanations or predictions about a given situation, phenomenon or event.

It is acknowledged and indeed emphasised that in using all of these processes some scientific knowledge is required. This is most obvious in Process 5, but it applies to Processes 1 to 4 equally, for these can be described as "scientific processes" when they are applied to scientific content.

\section{Scientific concepts}

The scientific concepts selected for PISA are expressed in terms of broad integrating ideas that help to explain aspects of our material environment. The PISA framework does not attempt to identify all concepts that would meet this criterion; assessing them comprehensively would be impossible within the constraints of limited test "space". Instead, concepts will be sampled from the following main themes:

1. Structure and properties of matter

2. Atmospheric change

3. Chemical and physical changes

4. Energy transformations

5. Forces and movement

6. Form and function

7. Human biology

8. Physiological change

9. Biodiversity 
10. Genetic control

11. Ecosystems

12. The Earth and its place in the universe

13. Geological change

\section{Scientific situations}

The PISA definition of scientific literacy emphasises the application of processes and concepts in relation to problems and issues in the real world. Students who have acquired some measure of scientific literacy will be able to apply what they have learned in school and non-school situations. A scientific situation is taken here to mean a real-world phenomenon in which science can be applied. Note the distinction between a scientific concept (such as atmospheric change) and an aspect of our world in which it is applied (such as weather or climate).
The areas of application of science have been grouped under three broad headings:

1. Science in life and health;

2. Science in Earth and environment; and

3. Science in technology.

Problems and issues under these headings can affect us as individuals, as members of a local community or as world citizens; often as all three. Moreover, some areas in which science is applied have a long history, illustrating changes in scientific understanding over time and providing opportunities for recognising the application of science in contexts that are no longer familiar today.

The situations that can be used for assessing scientific literacy can thus be characterised both by the broad area of application and by the aspects of our lives in which they are relevant:

\begin{tabular}{l|l|l|l} 
Relevance & \multicolumn{3}{|c}{ Areas of application } \\
\hline Personal, & $\begin{array}{l}\text { Science in life } \\
\text { and health }\end{array}$ & $\begin{array}{l}\text { Science in Earth } \\
\text { and environment }\end{array}$ & $\begin{array}{l}\text { Science in } \\
\text { technology }\end{array}$ \\
\cline { 2 - 4 } $\begin{array}{l}\text { Community, } \\
\text { Global, }\end{array}$ & $\begin{array}{l}\text { Health, disease and } \\
\text { nutrition; maintenance } \\
\text { and sustainable use of } \\
\text { species; interdependence } \\
\text { of physical and biological } \\
\text { systems }\end{array}$ & $\begin{array}{l}\text { Pollution; production } \\
\text { and loss of soil; } \\
\text { weather and climate }\end{array}$ & $\begin{array}{l}\text { Biotechnology; use of } \\
\text { materials and waste } \\
\text { disposal; use of energy; } \\
\text { transportation }\end{array}$ \\
\hline
\end{tabular}

\section{Format of test questions and marking}

Assessment units presented students with a reallife situation, taken from an authentic source, and a series of questions about it. Each question required the use of one or more of the process skills and some scientific knowledge. The presentation of the stimulus material (problem or issue) required the reading of some text, together with a table or diagrammatic representation. However, since several questions were linked to the same stimulus material in each unit, the overall time spent reading, rather than answering a question, was no greater than in a series of stand-alone questions in a conventional test.
PISA 2000 assessed scientific literacy through a combination of question formats. Some tasks were assessed through multiple-choice questions, typically those associated with simpler scientific processes. Open-ended questions were preferred for assessing higher-order scientific processes. The marking scheme for these open-ended questions provided not only general guidelines but examples of answers for each response category. Furthermore, since these responses could give valuable information about students' ideas and thinking, which could be fed back into curriculum planning, the marking guides for these questions included in the main study were designed to include a system of two-digit marking so that the frequency of various types of 
correct and incorrect responses could be recorded. The first digit was the actual score. The second digit, shown in parentheses, is used to categorise the different kinds of responses on the basis of the strategies used by the student to answer the question. There are two main advantages to using double-digit codes. Firstly, more information can be collected about students' misconceptions, common errors, and different approaches to solving problems. Secondly, double-digit coding allows a more structured way of presenting the codes, clearly indicating the hierarchical levels of groups of codes. It is important to note that markers were advised to ignore spelling and grammar errors, unless they completely obscured the meaning, because this was not a test of written expression.

\section{The assessment of scientific literacy in PISA 2000}

Scientific literacy was assessed in a manner similar to that of mathematical literacy, using a series of units, each of which presented a real scientific situation, followed by questions about it. Some two-thirds of the tasks were in a form that could be marked unambiguously as correct or incorrect. For more complex tasks, students could gain full or partial credit.

Like performance in mathematical literacy, performance in scientific literacy was marked in PISA 2000 on a single scale with an OECD average score of 500 points and a standard deviation of 100 points, and with about two-thirds of students across OECD countries scoring between 400 and 600 points. The scale used measures students' ability to use scientific knowledge (understanding of scientific concepts); to recognise scientific questions and to identify what is involved in scientific investigations (understanding of the nature of scientific investigation); to relate scientific data to claims and conclusions (use of scientific evidence); and to communicate these aspects of science.

The criteria defining the increasing difficulty of tasks along the scale involve: the complexity of the concepts used, the amount of data given, the chain of reasoning required, and the precision required in communication. In addition, the level of difficulty is influenced by the context of the information, the format, and the presentation of the question. The tasks in PISA require scientific knowledge involving (in ascending order of difficulty) recall of simple scientific knowledge or common scientific knowledge or data; the application of scientific concepts or questions and a basic knowledge of investigation; the use of more highly developed scientific concepts or a chain of reasoning; and knowledge of simple conceptual models or analysis of evidence in order to try out alternative approaches.

- Towards the top end of the scientific literacy scale (around 690 points) students are generally able to create or use conceptual models to make predictions or give explanations; to analyse scientific investigations in order to grasp, for example, the design of an experiment or to identify an idea being tested; to compare data in order to evaluate alternative viewpoints or differing perspectives; and to communicate scientific arguments and/or descriptions in detail and with precision.

- At around 550 points, students are typically able to use scientific concepts to make predictions or provide explanations; to recognise questions that can be answered by scientific investigation and/or to identify details of what is involved in a scientific investigation; and to select relevant information from competing data or chains of reasoning in drawing or evaluating conclusions.

- Towards the lower end of the scale (around 400 points), students are able to recall simple factual scientific knowledge (e.g. names, facts, terminology, simple rules); and to use common scientific knowledge in drawing or evaluating conclusions. 


\section{Figure 3}

Short description of selected scientific literacy tasks and their associated scores

682 (Question 5) Students are shown a comic strip showing three stages as oxygen molecules are split under the influence of the sun and recombine into ozone molecules. This task requires students to interpret the comic strip and communicate it to a person with limited scientific knowledge. To gain full credit, students need to describe what is happening in at least two of the three stages of the comic strip with a fair level of precision and detail. (S253Q01, score 3)

\section{TASK DIFFICULTY}

666 (Question 1) This task requires students to relate the data given as evidence in order to evaluate different perspectives. (S195Q02, score 2)

642 (Question 6) This task requires students to link part of the text to their own experience of weather conditions (thunderstorms occuring relatively close to Earth), to draw a conclusion about the nature of the ozone produced ('good' or 'bad'). The task requires student to draw an inference, going beyond information stated. (S253Q02)

638 (Question 1) This task requires students to use scientific evidence to relate data systematically to possible conclusions using a chain of reasoning that is not given to the students. (S195QO2, score 1)

628 (Question 5) Students are shown a comic strip showing three stages as oxygen molecules are split under the influence of the sun and recombine into ozone molecules. This task requires students to interpret the comic strip and communicate it to a person with limited scientific knowledge. To gain partial credit, students need to communicate a simple scientific description. (S253Q01, score 1 or score 2)

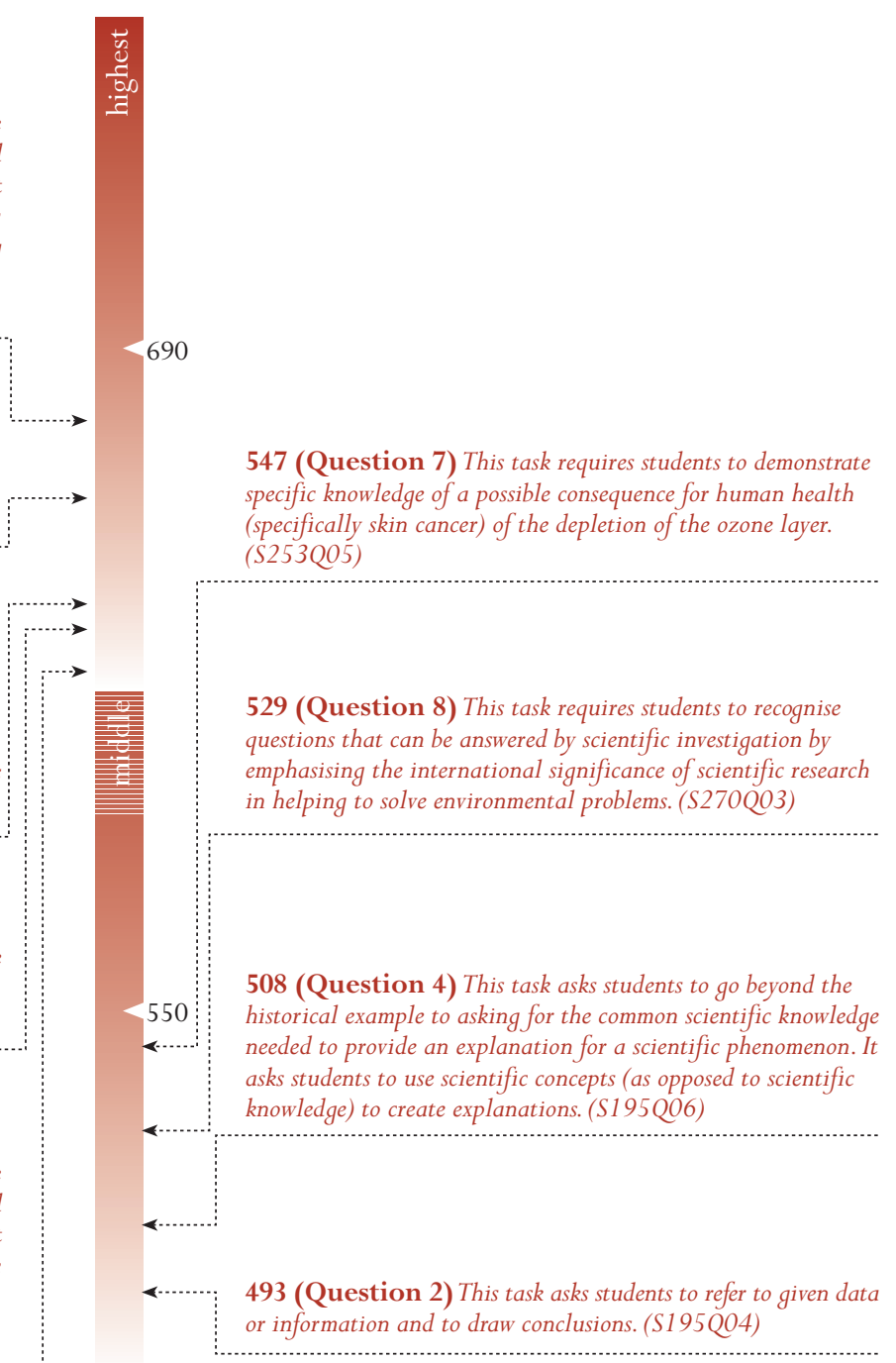

Source: OECD PISA, 2001. 


\section{SCIENCE UNIT 1}

Semmelweis

\section{Semmelweis' diary text 1}

'July 1846. Next week I will take up a position as "Herr Doktor" at the FirstWard of the maternity clinic of the Vienna General Hospital. I was frightened when I heard about the percentage of patients who die in this clinic. This month not less than 36 of the 208 mothers died there, all from puerperal fever. Giving birth to a child is as dangerous as first-degree pneumonia.'

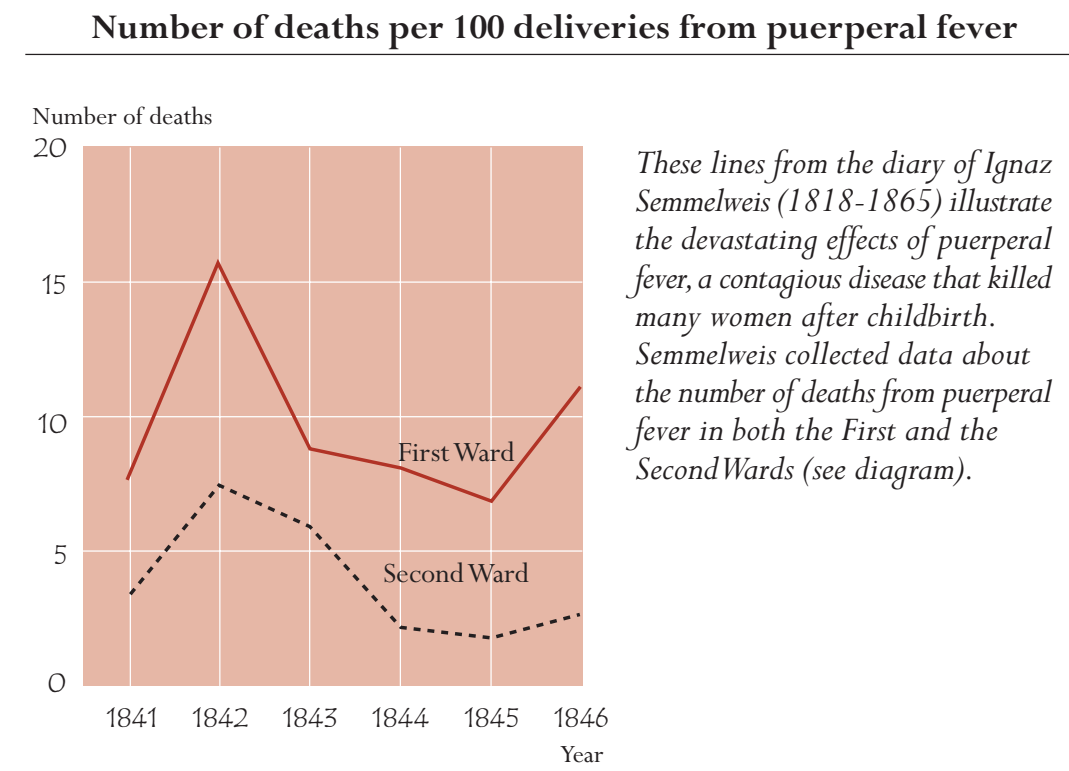

Physicians, among them Semmelweis, were completely in the dark about the cause of puerperal fever. Semmelweis' diary again:

'December 1846. Why do so many women die from this fever after giving birth without any problems? For centuries science has told us that it is an invisible epidemic that kills mothers. Causes may be changes in the air or some extraterrestrial influence or a movement of the earth itself, an earthquake.'

Nowadays not many people would consider extraterrestrial influence or an earthquake as possible causes of fever. We now know it has to do with hygienic conditions. But in the time Semmelweis lived, many people, even scientists, did! However, Semmelweis knew that it was unlikely that fever could be caused by extraterrestrial influence or an earthquake. He pointed at the data he collected (see diagram) and used this to try to persuade his colleagues. 


\section{Question 1: SEMMELWEIS'DIARY (S195Q02)}

Process: Critically evaluating scientific evidence/data

Concept: Science in life and health (Human biology)

Situation: Historical

Suppose you were Semmelweis. Give a reason (based on the data Semmelweis collected) why puerperal fever is unlikely to be caused by earthquakes.

\section{Scoring - Question 1}

Score 2(1): Answers which refer to the difference between the number of deaths (per 100 deliveries) in both wards. For example:

- The fact that the first ward had a high rate of women dying compared to women in the second ward, obviously shows that it had nothing to do with earthquakes.

- Not as many people died in ward 2 so an earthquake couldn't have occurred without causing the same number of deaths in each ward.

- Because the second ward isn't as high, maybe it had something to do with ward 1.

- It is unlikely that earthquakes cause the fever since death rates are so different for the two wards.

Score 1(1): Answers which refer to the fact that earthquakes don't occur frequently. For example:

- It would be unlikely to be caused by earthquakes because earthquakes wouldn't happen all the time.

Score 1(2): Answers which refer to the fact that earthquakes also influence people outside the wards. For example:

- If there were an earthquake, women from outside the hospital would have got puerperal fever as well.

- If an earthquake were the reason, the whole world would get puerperal fever each time an earthquake occurs (not only wards 1 and 2).

Score 1(3): Answers which refer to the thought that when earthquakes occur, men don't get puerperal fever. For example:

- If a man were in the hospital and an earthquake came, he wouldn't get puerperal fever, so earthquakes cannot be the cause.

- Because girls get it and not men

Score 0(1): Answers which state (only) that earthquakes cannot cause the fever. For example:

- An earthquake cannot influence a person or make him sick.

- A little shaking cannot be dangerous.

Score 0(2): Answers which state (only) that the fever must have another cause (right or wrong). For example:

- Earthquakes do not let out poison gases. They are caused by the plates of the Earth folding and faulting into each other.

- Because they have nothing to do with each other and it is just superstition.

- An earthquake doesn't have any influence on pregnancy. The reason was that the doctors were not specialised enough. 
Score 0(3): Answers which are combinations of scores 0(1) and 0(2). For example:

- Puerperal fever is unlikely to be caused by earthquakes as many women die after giving birth without any problems. Science has told us that it is an invisible epidemic that kills mothers.

- The death is caused by bacteria and the earthquakes cannot influence them.

Score 0(4): Other incorrect answers. For example:

- I think it was a big earthquake that shook a lot.

- In 1843 the deaths decreased in Ward 1 and less so in Ward 2.

- Because there weren't any earthquakes in the wards and they still got it. [Note: the assumption that there were no earthquakes at that time is not correct.]

\section{Semmelweis' diary text 2}

Part of the research in the hospital was dissection. The body of a deceased person was cut open to find a cause of death. Semmelweis recorded that the students working on the First Ward usually took part in dissections on women who died the previous day, before they examined women who had just given birth. They did not pay much attention to cleaning themselves after the dissections. Some were even proud of the fact that you could tell by their smell that they had been working in the mortuary, as this showed how industrious they were!

One of Semmelweis' friends died after having cut himself during such a dissection. Dissection of his body showed he had the same symptoms as mothers who died from puerperal fever. This gave Semmelweis a new idea.

\section{Question 2: SEMMELWEIS' DIARY (S195Q04)}

Process: Recognising questions

Concept: Science in life and health (Human biology)

Situation: Historical

Semmelweis' new idea had to do with the high percentage of women dying in the maternity wards and the students' behaviour.

What was this idea?

(A) Having students clean themselves after dissections should lead to a decrease of puerperal fever.

B Students should not take part in dissections because they may cut themselves.

C Students smell because they do not clean themselves after a dissection.

D Students want to show that they are industrious, which makes them careless when they examine the women. 


\section{Scoring - Question 2}

Score 1: Answer A - having students clean themselves after dissections should lead to a decrease of puerperal fever.

Score 0: Other answers.

\section{Question 3: SEMMELWEIS' DIARY (S195Q05)}

Process: Apply scientific knowledge in situation presented

Concept: Science in life and health (Human biology)

Situation: Historical

Semmelweis succeeded in his attempts to reduce the number of deaths due to puerperal fever. But puerperal fever even today remains a disease that is difficult to eliminate.

Fevers that are difficult to cure are still a problem in hospitals. Many routine measures serve to control this problem. Among those measures are washing sheets at high temperatures.

Explain why high temperature (while washing sheets) helps to reduce the risk that patients will contract a fever.

\section{Scoring - Question 3}

Score 1(1): Answers which refer to killing of bacteria. For example:

- Because with the heat many bacteria will die.

- Bacteria will not stand the high temperature.

- Bacteria will be burnt by the high temperature.

- Bacteria will be cooked. [Note:Although "burnt" and "cooked" are not scientifically correct, each of the last two answers as a whole can be regarded as correct.]

Score 1(2): Answers which refer to killing of micro-organisms, germs or viruses. For example:

- Because high heat kills small organisms which cause disease.

- It's too hot for germs to live.

Score 1(3): Answers which refer to the removal (not killing) of bacteria. For example:

- The bacteria will be gone.

- The number of bacteria will decrease.

- You wash the bacteria away at high temperatures.

Score 1(4): Answers which refer to the removal (not killing) of micro-organisms, germs or viruses. For example:

- Because you won't have the germ on your body.

Score 1(5): Answers which refer to sterilisation of the sheets. For example:

- The sheets will be sterilised.

Score 0(1): Answers which refer to killing of disease. For example:

- Because the hot water temperature kills any disease on the sheets.

- The high temperature kills most of the fever on the sheets, leaving less chance of contamination. 
Score 0(2): Other incorrect answers. For example:

- So they don't get sick from the cold.

- Well when you wash something it washes away the germs.

\section{Question 4: SEMMELWEIS' DIARY (S195Q06)}

Process: Apply scientific knowledge to situation presented

Concept: Science in life and health (Biodiversity)

Situation: Historical

Many diseases may be cured by using antibiotics. However, the success of some antibiotics against puerperal fever has diminished in recent years.

What is the reason for this?

A Once produced, antibiotics gradually lose their activity.

(B) Bacteria become resistant to antibiotics.

C These antibiotics only help against puerperal fever, but not against other diseases.

D The need for these antibiotics has been reduced because public health conditions have improved considerably in recent years.

\section{Scoring - Question 4}

Score 1: Answer B - bacteria become resistant to antibiotics.

Score 0: Other answers. 


\section{SCIENCE UNIT 2}

\section{Ozone}

Read the following section of an article about the ozone layer.

The atmosphere is an ocean of air and a precious natural resource for sustaining life on the Earth. Unfortunately, human activities based on national/personal interests are causing harm to this common resource, notably by depleting the fragile ozone layer, which acts as a protective shield for life on the Earth.

5 Ozone molecules consist of three oxygen atoms, as opposed to oxygen molecules which consist of two oxygen atoms. Ozone molecules are exceedingly rare: fewer than ten in every million molecules of air. However, for nearly a billion years, their presence in the atmosphere has played a vital role in safeguarding life on Earth. Depending on where it is located, ozone can either protect or harm life on Earth. The ozone in the troposphere (up to 10 kilometres above the

10 Earth's surface) is "bad" ozone which can damage lung tissues and plants. But about 90 percent of ozone found in the stratosphere (between 10 and 40 kilometres above the Earth's surface) is "good" ozone which plays a beneficial role by absorbing dangerous ultraviolet (UV-B) radiation from the Sun.

Without this beneficial ozone layer, humans would be more susceptible to certain diseases due 15 to the increased incidence of ultra-violet rays from the Sun. In the last decades the amount of ozone has decreased. In 1974 it was hypothesised that chlorofluorocarbons (CFCs) could be a cause for this. Until 1987, scientific assessment of the cause-effect relationship was not convincing enough to implicate CFCs. However, in September 1987, diplomats from around the world met in Montreal (Canada) and agreed to set sharp limits to the use of CFCs.

Source: Connect, UNESCO International Science, Technology \& Environmental Education Newsletter, section from an article entitled "The Chemistry of Atmospheric policy”, Vol., XXII No. 2, 1997 (spelling adapted).

\section{Question 5: OZONE (S253Q01)}

Process: Communicating to others valid conclusions from evidence/data

Concept: Science in Earth and environment (chemical and physical changes)

Situation: Global

In the text above nothing is mentioned about the way ozone is formed in the atmosphere. In fact each day some ozone is formed and some other ozone disappears. The way ozone is formed is illustrated in the following comic strip.
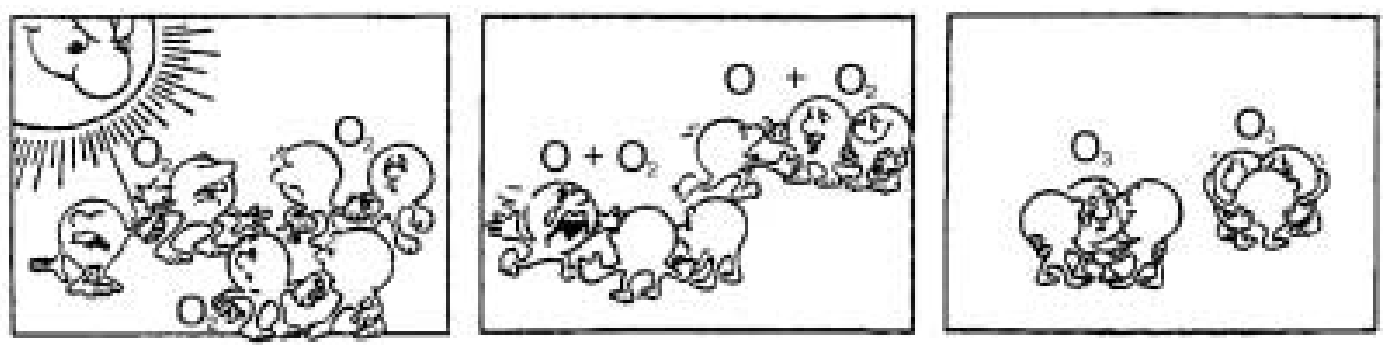

Source: Deilig er den Himme, Temahefte 1, Institute for Physics, University of Oslo, August 1997. 
Suppose you have an uncle who tries to understand the meaning of this strip. However, he did not get any science education at school and he doesn't understand what the author of the strip is explaining. He knows that there are no little fellows in the atmosphere but he wonders what those little fellows in the strip stand for, what those strange notations $\mathrm{O}_{2} \mathrm{O}_{2}$ and $\mathrm{O}_{3}$ mean and which processes the strip represents. He asks you to explain the strip. Assume that your uncle knows:

- that $O$ is the symbol for oxygen;

- what atoms and molecules are.

Write an explanation of the comic strip for your uncle.

In your explanation, use the words atoms and molecules in the way they are used in lines 5 and 6 .

\section{Scoring - Question 5}

Score 3(1): Answers which mention the following three aspects:

- First aspect: an oxygen molecule or some oxygen molecules (each consisting of two oxygen atoms) are split into oxygen atoms (picture 1).

- Second aspect: the splitting (of oxygen molecules) takes place under the influence of sunlight (picture 1).

- Third aspect: the oxygen atoms combine with other oxygen molecules to form ozone molecules (pictures 2 and 3).

\section{Remarks on each of the three aspects}

\section{First aspect:}

- The splitting should be described using the correct words (see lines 5 and 6) for $\mathrm{O}$ (atom or atoms) and $\mathrm{O}_{2}$ (molecule or molecules).

- If $\mathrm{O}$ and/or $\mathrm{O}_{2}$ have been described only as "particles" or "small parts" no credit should be given for this aspect.

\section{Second aspect:}

- The sun's influence should be related to the splitting of $\mathrm{O}_{2}$ (an oxygen molecule or oxygen molecules).

- If the sun's influence is related to the forming of an ozone molecule from an oxygen atom and an oxygen molecule (pictures 2 and 3) no credit should be given for this second aspect.

- Note: Aspects 1 and 2 may typically be given in the one sentence.

\section{Third aspect:}

- Credit (one point) should be given for this aspect if the answer contains any description of an $\mathrm{O}$ combining with an $\mathrm{O}_{2}$. If the formation of $\mathrm{O}_{3}$ is described as the combining of (three, separate) $\mathrm{O}$ atoms, credit should not be given for this third aspect.

- If $\mathrm{O}_{3}$ is not described as a molecule or molecules but for example as "a group of atoms" this can be tolerated for the third aspect.

Examples of Score 3(1):

- When the sun shines on the $\mathrm{O}_{2}$ molecule the two atoms separate. The two $\mathrm{O}$ atoms look for other $\mathrm{O}_{2}$ molecules to join with. When the $\mathrm{O}_{1}$ and $\mathrm{O}_{2}$ join they form $\mathrm{O}_{3}$, which is ozone.

- The strip illustrates the formation of ozone. If an oxygen molecule is affected by the sun, it breaks into two separate atoms. These separate atoms, $\mathrm{O}$, float around looking for a molecule to link up to; they link up to existing $\mathrm{O}_{2}$ molecules and form an $\mathrm{O}_{3}$ molecule, as three atoms are now joined together; $\mathrm{O}_{3}$ forms ozone. 
- The little guys are $\mathrm{O}$, or oxygen atoms. When two are joined they make $\mathrm{O}_{2}$ or oxygen molecules. The sun causes these to decompose into oxygen again. The $\mathrm{O}_{2}$ atoms then bond with $\mathrm{O}_{2}$ molecules creating $\mathrm{O}_{3}$, which is ozone . [Note: this answer can be regarded as correct. There is only one slip of the pen ("O $\mathrm{O}_{2}$ atoms" after having mentioned "oxygen atoms" previously).]

Score 2(1): Answers which correctly mention only the first and second aspects. For example:

- The sun decomposes the oxygen molecules into single atoms. The atoms fuse into groups. The atoms form groups of 3 atoms together.

Score 2(2): Answers which correctly mention only the first and third aspects. For example:

- Each of the little fellows stand for one atom of oxygen. $\mathrm{O}$ is one oxygen atom, $\mathrm{O}_{2}$ is an oxygen molecule and $\mathrm{O}_{3}$ is a group of atoms all joined together. The processes shown are one pair of oxygen atoms $\left(\mathrm{O}_{2}\right)$ getting split and then each joining with 2 other pairs forming two groups of $3\left(\mathrm{O}_{3}\right)$.

- The little fellows are oxygen atoms. $\mathrm{O}_{2}$ means one oxygen molecule (like a pair of little fellows holding hands) and $\mathrm{O}_{3}$ means three oxygen atoms. The two oxygen atoms of one pair break apart and one joins each of the other pairs and out of the three pairs, two sets of three oxygen molecules $\left(\mathrm{O}_{3}\right)$ are formed.

Score 2(3): Answers which correctly mention only the second and third aspects. For example:

- The oxygen is broken up by the sun's radiation. It splits in half. The two sides go and join other oxygen "particles" forming ozone.

- Most of the time in pure oxygen $\left(\mathrm{O}_{2}\right)$ environments oxygen comes in pairs of 2 so there are 3 pairs of 2. 1 pair is getting too hot and they fly apart going into another pair making $\mathrm{O}_{3}$ instead of $\mathrm{O}_{2}$. [Note: Although "one pair is getting too hot" is not a very good description for the sun's influence, credit should be given for the second aspect; the third aspect can also be regarded as correct.]

Score 1(1): Answers which correctly mention only the first aspect. For example:

- Oxygen molecules are breaking down. They form O atoms. And sometimes there are ozone molecules. The ozone layer remains the same because new molecules are formed and others die.

Score 1(2): Answers which correctly mention only the second aspect. For example:

- $\mathrm{O}$ represents an oxygen molecule, $\mathrm{O}_{2}=$ oxygen, $\mathrm{O}_{3}=$ ozone. Sometimes both oxygen molecules, joining each other, are separated by the sun. The single molecules join another pair and form ozone $\left(\mathrm{O}_{3}\right)$.

Score 1(3): Answers which correctly mention only the third aspect. For example:

- The 'O' (oxygen) molecules are forced to bond with $\mathrm{O}_{2}\left(2\right.$ x oxygen molecules) to form $\mathrm{O}_{3}$ (3 x oxygen molecules), by the heat of the sun. [Note: the underlined part of the answer shows the third aspect. No credit can be given for the second aspect, because the sun is not involved in the formation of ozone from $\mathrm{O}+\mathrm{O}_{2}$ but only in breaking down bonds in $\mathrm{O}_{2}$.]

Score 0(1): Answers which do not correctly mention any of the three aspects. For example:

- The sun (ultraviolet rays) burns the ozone layer and at the same time is destroying it as well. Those little men are the ozone layers and they run away from the sun because it is so hot. [Note: no point can be awarded, not even for mentioning something about the sun's influence.]

- The sun is burning the ozone in the first box. In the second box they are running away with tears in their eyes and in the third box they are cuddling each other with tears in their eyes.

- Well uncle Herb it's simple. ' $O$ ' is one oxygen particle, the numbers next to ' $O$ ' increase the amounts of particles in the group. 
Question 6: OZONE(S253QO2)

Process: Critically evaluating scientific evidence/data

Concept: Science in Earth and environment (Earth/Space)

Situation: Global

Ozone is also formed during thunderstorms. It causes the typical smell after such a storm. In lines 10-12 the author of the text distinguishes between "bad ozone" and "good ozone".

In terms of the article, is the ozone that is formed during thunderstorms "bad ozone" or "good ozone"? Choose the answer and the explanation that is supported by the text.

\begin{tabular}{l|ll} 
& Bad ozone or good ozone? & Explanation \\
\hline A & Bad & It is formed during bad weather. \\
\hline B & Bad & It is formed in the troposphere. \\
\hline C & Good & It is formed in the stratosphere. \\
\hline D & Good & It smells good. \\
\hline
\end{tabular}

\section{Scoring - Question 6}

Score 1: Answer B - bad. It is formed in the troposphere.

Score 0: Other answers.

\section{Question 7: OZONE(S253Q05)}

Process: Applying scientific knowledge in situation presented

Concept: Science in life and health (physiological change)

Situation: Global

Lines 14 and 15 state: "Without this beneficial ozone layer, humans would be more susceptible to certain diseases due to the increased incidence of ultra-violet rays from the Sun."

Name one of these specific diseases.

\section{Scoring - Question 7}

Score 1: Answers which refer to skin cancer. For example:

- Skin cancer.

- Melonoma. [Note: this answer can be regarded as correct, despite the fact that it has a spelling mistake.]

Score 0: Answers which refer to other specific types of cancer. For example:

- Lung cancer.

OR

Answers which only refer to cancer. For example:

- Cancer.

OR

Other incorrect answers. 


\section{Question 8: OZONE (S270Q03)}

Process: Recognising questions

Concept: Science in Earth and environment (Earth/Space)

Situation: Global

At the end of the text, an international meeting in Montreal is mentioned. At that meeting lots of questions in relation to the possible depletion of the ozone layer were discussed. Two of those questions are given in the table below.

Which of the questions below can be answered by scientific research?

Circle Yes or No for each.

\begin{tabular}{l|c} 
Question: & Answerable by scientific research? \\
\hline $\begin{array}{l}\text { Should the scientific uncertainties about the influence of } \\
\text { CFCs on the ozone layer be a reason for governments to take no action? }\end{array}$ & Yes / No \\
\hline $\begin{array}{l}\text { What would the concentration of CFCs be in the atmosphere in the year 2002 if the } \\
\text { release of CFCs into the atmosphere takes place at the same rate as it does now? }\end{array}$ & Yes / No \\
\hline
\end{tabular}

\section{Scoring - Question 8}

Score 1: Answers which indicate No and Yes, in that order.

Score 0: Other responses. 


\section{References}

OECD (1999), Measuring Student Knowledge and Skills - A New Framework for Assessment, Paris.

OECD (2000), Measuring Student Knowledge and Skills - The PISA Assessment of Reading, Mathematical and Scientific Literacy, Paris.

OECD (2001), Knowledge and Skills for Life - First Results from PISA 2000, Paris. 